Florida International University FIU Digital Commons

$11-9-2012$

\title{
Goma Curriculum, A Character Education Paradigm: Composing a Text for Shaping Classroom Character Culture
}

\author{
Alicia D. Ritchey \\ Florida International University, aritchenterprise@aol.com
}

DOI: $10.25148 /$ etd.FI12120516

Follow this and additional works at: https://digitalcommons.fiu.edu/etd

\section{Recommended Citation}

Ritchey, Alicia D., "Goma Curriculum, A Character Education Paradigm: Composing a Text for Shaping Classroom Character Culture" (2012). FIU Electronic Theses and Dissertations. 789.

https://digitalcommons.fiu.edu/etd/789 


\section{FLORIDA INTERNATIONAL UNIVERSITY}

Miami, Florida

GOMA CURRICULUM, A CHARACTER EDUCATION PARADIGM:

COMPOSING A TEXT FOR SHAPING CLASSROOM CHARACTER CULTURE

A dissertation submitted in partial fulfillment

of the requirements for the degree of

DOCTOR OF EDUCATION

in

CURRICULUM AND INSTRUCTION

by

Alicia D. Ritchey

2012 
To: Dean Delia C. Garcia

College of Education

This dissertation, written by Alicia D. Ritchey, and entitled Goma Curriculum, A Character Education Paradigm: Composing a Text for Shaping Classroom Character Culture, having been approved in respect to style and intellectual content, is referred to you for judgment.

We have read this dissertation and recommend that it be approved.

Delia C. Garcia

Joan Wynne

Kyle Perkins

Linda Spears-Bunton, Major Professor

Date of Defense: November 9, 2012

The dissertation of Alicia D. Ritchey is approved.

Dean Delia C. Garcia

College of Education

Dean Lakshmi N. Reddi

University Graduate School

Florida International University, 2012 
(C) Copyright 2012 by Alicia D. Ritchey

All rights reserved 


\section{DEDICATION}

This dissertation is dedicated to the memory of my Dad, the late Mr. David Ritchey, Sr., who assured me he would be here with me at the end of this journey. I see you, Daddy! God is merciful. 


\section{ACKNOWLEDGMENTS}

I am honored to have had the support of an esteemed panel of academicians who represent my dissertation committee in the persons of Dr. Linda Spears-Bunton, Dr. Delia Garcia, Dr. Joan Wynne, and Dr. Kyle Perkins, each of whom I regard highly. I am thankful for you, Dr. Linda Spears-Bunton, my major professor, a phenomenal educator and scholar, who has been with me for the duration of this journey insisting that no hardship or seeming setback is a legitimate excuse for "throwing in the towel"; moreover that teaching is one of the greatest opportunities to right our communities through a literacy of promise. Dean Dr. Delia Garcia, former program leader of my Master's degree program in Urban Education, I consider it divine providence that you would be right here to help usher me across this academic threshold. I have been comforted by your presence. I am grateful for Dr. Kyle Perkins for acknowledging my work, not only as a worthy research project, but also as ground-breaking. I share as much gratitude for Dr. Joan Wynne, who expressed genuine interest in my research and did not hesitate to join the team of those directly responsible for seeing this project through to completion. Thank you, Dr. Patricia Barbetta for encouraging me with your persistent, "Get it done, Alicia!" Dr. Linda Bliss, I have been enriched by your expertise in research methods; more importantly, your gentle and kind spirit as an educator servant is a gift to every student who encounters you. I am appreciative of those eminent scholars, Dr. Lisa Delpit, Dr. Ira Blake, and Dr. Rebecca Powell, who helped to bring clarity to my research ideas.

To my beloved husband and friend, Marion Kenneth Brown, you have played an incredible role in my evolution as a character-centered educator. I am humbled and truly blessed by your many years of support as you stood with me to see the fulfillment of this 
vision. I will always love you! To my parents, Ozzie K. Ritchey-Palmer and Mr. James Palmer, who encompass me about with prayer and wise counsel, I love you both beyond words. To my beloved siblings: Angeler, William, Wanda, David, Jr., Robin, Dwight, Nick, Tonya, Elliott, Stacey, Alfonso, Tamyra, and Marianne (Frankie, Kay (mts), Ginou, Samara, John \& Crystal, Adrian, Lawrence, Neek, and Lisa Beverly), thanks always for your love, laughter, and support both during and outside this project. To Deryl, Jr., Linda Barnes, Dr. Helen Ellison, Dr. Alicia Gwynn, Sarah Johnson, Yonna Daniels, Dr. DaVina Hoyt, Dr. Sharon Samuels, and Barbara King, thank you guys for listening to me talk through the ideas that comprise this work. I am thankful for the administrative team, who represent the organization that provided the primary data of this research: Dexter, Eneka, Linda, Tom E., Dawn W., Karen, and Genevieve. A special tribute is due to the memory of Charles "Love" Owens and Maxine Phelps, friends and supporters. Thanks to Cathy Riggins, Esquire, sent to remind me of MY 'Jubilee and The Year of the Lord's Release.' To my church family, I appreciate your caring, sharing, loving spirit toward me; and for your financial sustenance that has helped me to complete my research. Indeed, I am thankful to God for my spiritual leader, Pastor Dudley Carter, a constant covering, who prays for me and encouraged me through the transition. I am especially grateful to have met and been mentored by a man deserving of great honor, Dr. Deryl G. Hunt; one who epitomizes Goma, and whose work has unequivocal merit, not only for purposes of teaching and learning, but also for initiating social change as inclusive communities are pursued, built, and sustained. To my God, through Christ, thy Servant, He who has kept me from falling, He who is the author and finisher of my faith, the Love of my life, and the Center of my Joy, in You, I live, and move, and have my being. 


\begin{abstract}
OF THE DISSERTATION
GOMA CURRICULUM, A CHARACTER EDUCATION PARADIGM:

COMPOSING A TEXT FOR SHAPING CLASSROOM CHARACTER CULTURE
\end{abstract}

by

Alicia D. Ritchey

Florida International University, 2012

Miami, Florida

Professor Linda Spears-Bunton, Major Professor

The written text, and approaches to reading it, serves well as an analogy for the classroom space as a "text" that teachers are able to compose; and students are able to read, interpret meaning(s) of, and make responses to and about (Rosenblatt, 1988). Researchers point to ways in which the classroom can be conceptualized as a text to be evoked, experienced, and read (Freire \& Macedo, 1987; Powell, 2009; Rosenblatt, 1988).

The present study analyzed secondary data including: 10 transcripts of teacher talks and six self-reports retrieved from the program evaluation archives of DOR Foundation. The data described six teachers' classroom experiences subsequent to professional development centered on Goma character education curriculum that was used during a summer youth program located in South Georgia. Goma, an acronym that stands for Goal, Objective, Method, and Attitude, is a character education paradigm derived from The Inclusive Community Building Ellison Model, the theoretical framework used for this study. The Model identifies conflict resolution as one of its five foci (Hunt, Howard, \& Rice, 1998). Hunt (2006) conceived Goma as part of a 7-Step unitary process, also named the 7-Step pathway, to demonstrate how conflict resolution is accomplished within a variety of contexts. 
Analysis of the data involved: (a) a priori coding of teacher talks transcripts using the components of the Goma 7-Step pathway as coding categories, (b) emergent coding of teacher talks transcripts for the types of experiences teachers evidenced, and (c) emergent coding of teachers' self-reports for categories of teachers' instructional activities. Results of the study showed positive influence of Goma curriculum on participating teachers and their instructional practices. Teachers were shown to have had cognitive, instructional, emotional, and social experiences that were most evident when they reported changes in their attitudes toward their students, themselves, and their instructional practices. The present study provided implications for classroom teachers wherein all aspects of teachers' instructional practices can be guided by principles of positive character; and can be used to help compose kinds of "texts" that may likely contribute to a classroom character culture. 


\section{TABLE OF CONTENTS}

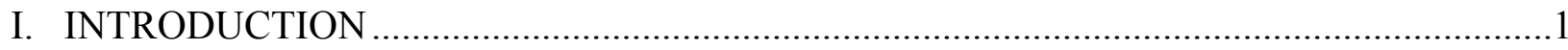

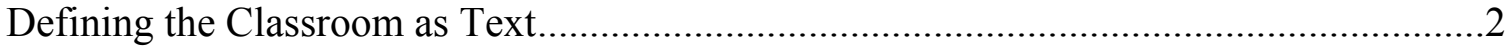

From Text to Poem: Character Education in Progress.......................................................5

Reader Response: Approaches to the Text ………….................................................

Teachers as Facilitators of Student Readings of Classroom Text.......................................

Texts, Contexts, and Curriculum-Teachers as Character Educators .................................10

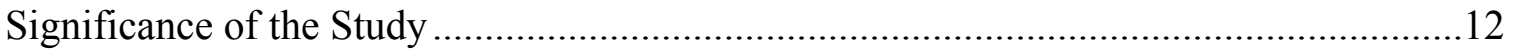

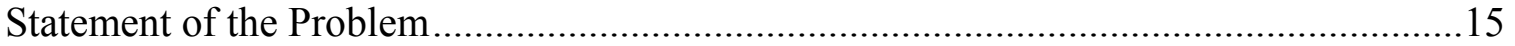

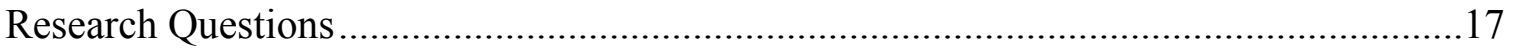

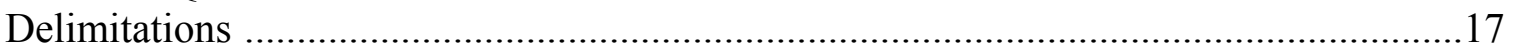

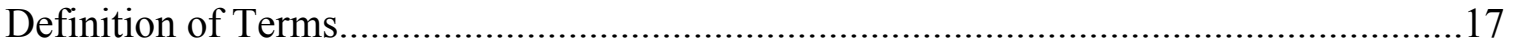

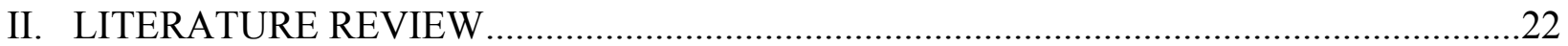

Knowledge-Skills-Disposition: Nuances of Instructional Practices

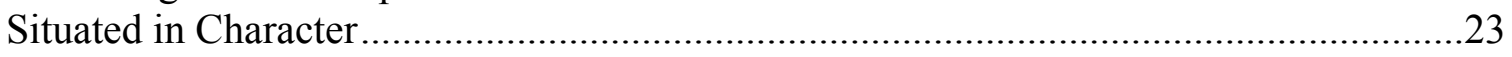

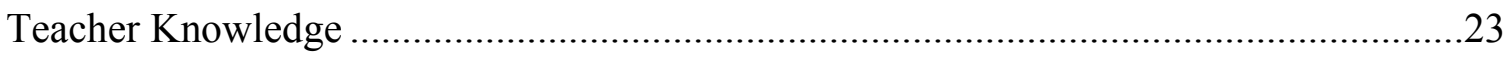

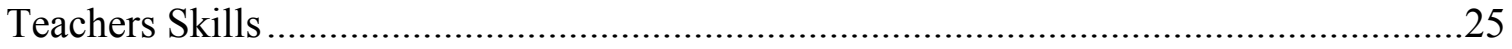

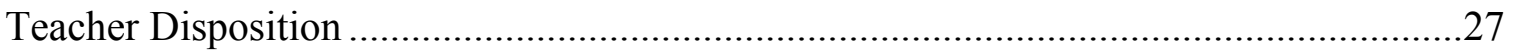

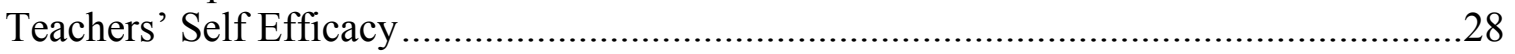

Cultural Relevance: A Classroom Character Culture Catalyst............................................30

Goma Curriculum: A Character Education Paradigm ........................................................33

Theoretical Underpinnings of Goma: The Inclusive Community Building

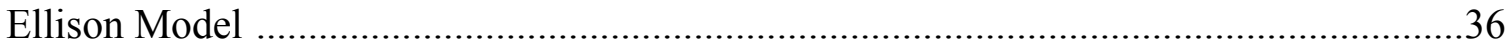

The Ellison Model Techniques ...................................................................................38

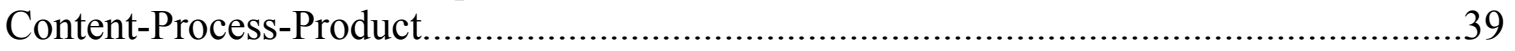

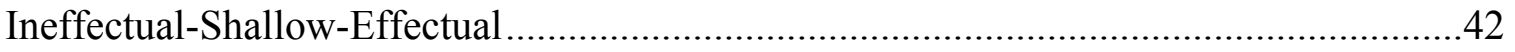

Diversity-Unity-Community …………………………................................................

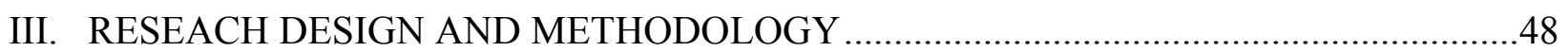

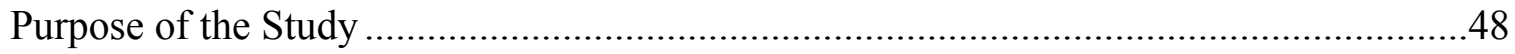

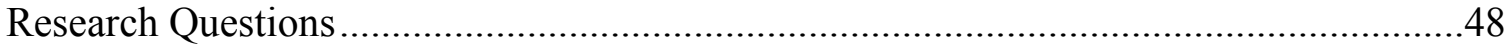

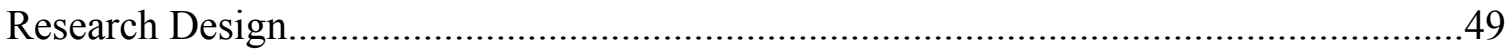

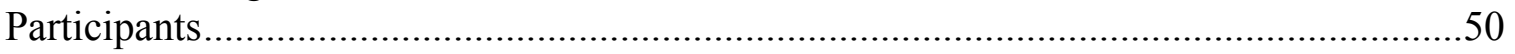

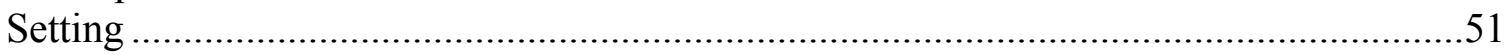

Community Profile

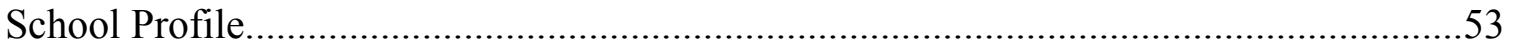

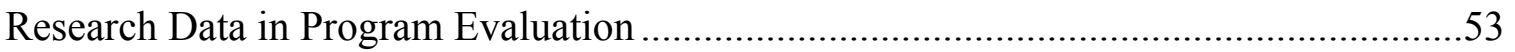

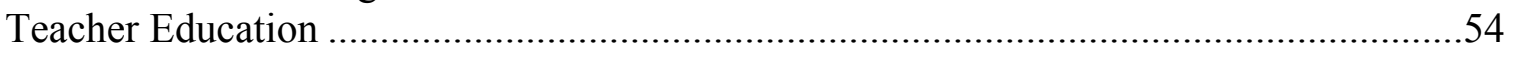

Teacher Talks and Self-reports: Data Collection........................................................55

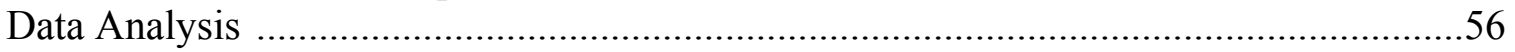




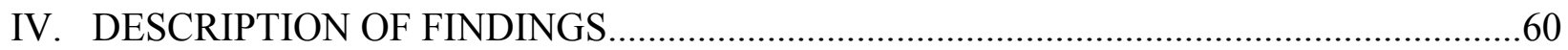

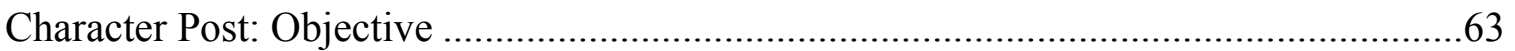

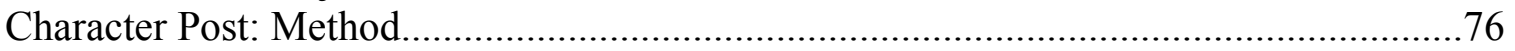

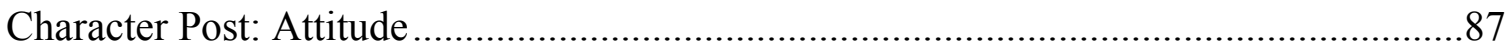

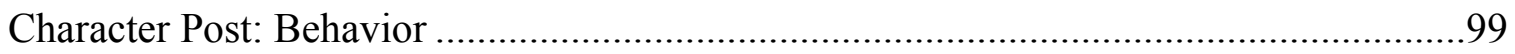

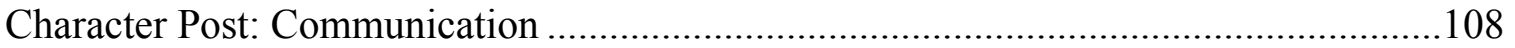

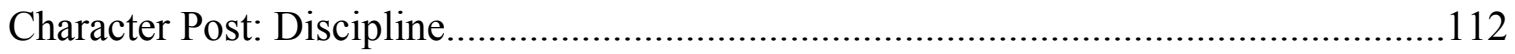

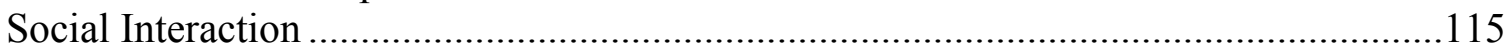

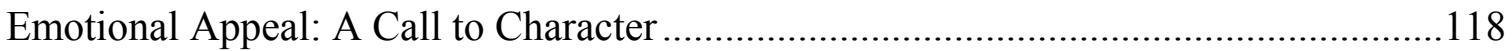

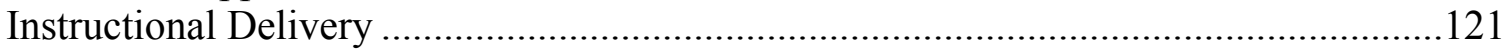

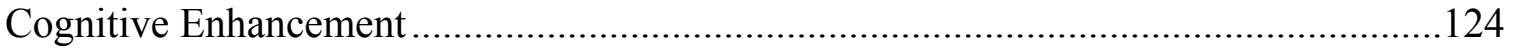

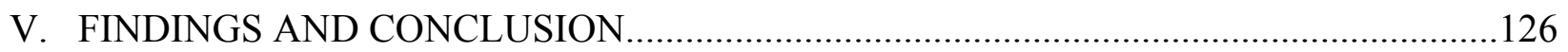

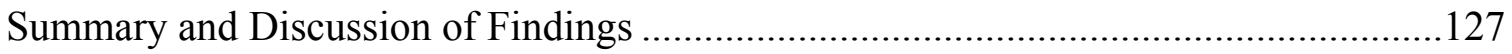

Summary of the Impact of Goma Curriculum on Participating Teachers ......................140

Summary of Instructional Practices as Opportunities for

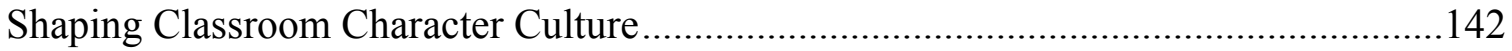

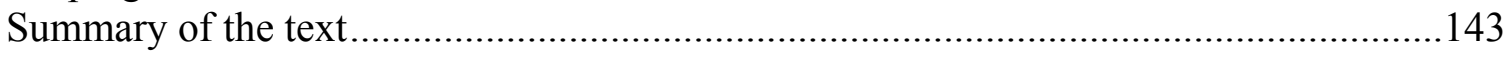

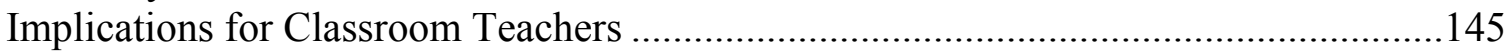

Teachers' Attitudes ............................................................................. 145

Teacher Education and Professional Development for

In-Service \& Pre-Service Teachers................................................................... 147

Recommendations for Further Research............................................................ 148

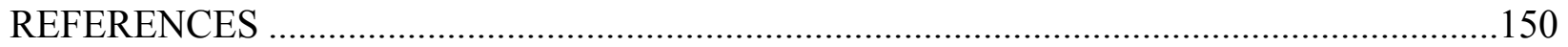

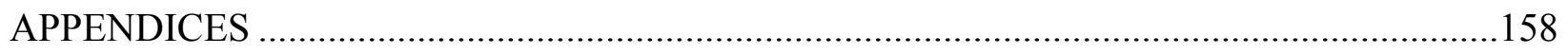

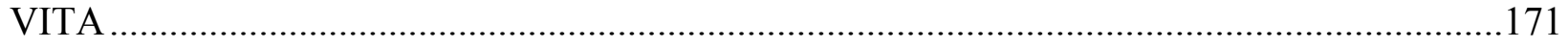




\section{LIST OF FIGURES}

TABLE

PAGE

1. Conceptualizing the classroom: A text to be evoked, experienced, and read.........................4

2. Goma 7-Step Process with definitions from Goma curriculum.......................................13

3. Goma 7-Step process reflecting a character focus at each character station .........................14

4. Goma alignment with Knowledge/Skills/Disposition .................................................22

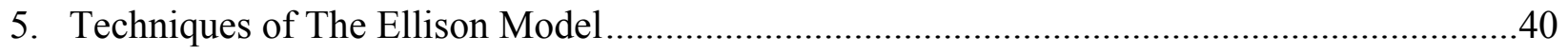

6. Three column-chart used for coding teacher responses ................................................58

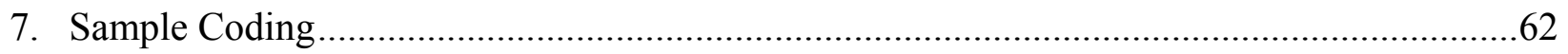

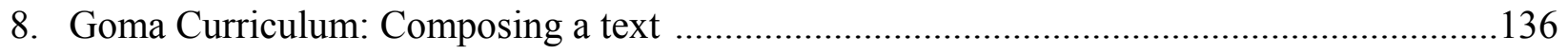




\section{CHAPTER I}

\section{INTRODUCTION}

Prior to students' encounter with the printed word, they often confront an unwritten, though sometimes transparent "text" that impacts learning and teaching in significant ways. The text, and approaches to reading it, serves well as an analogy for the classroom space as a text that teachers are able to construct in ways that students are able to read, interpret meaning(s) of, and make responses to and about. Within the context of reading, Louise Rosenblatt acknowledged several characteristics of how text may be viewed: "it designates a set or series of signs interpretable as linguistic symbols; ... the text is not simply the inked marks on the page or the uttered vibrations in the air; ... [and the text] may be thought of as the printed signs in their capacity to serve as symbols" $(1998 ;$ p.12). Taken together, these traits provide an understanding of text as both literal and experiential in ways that can be presented in many forms of communication beyond the written and oral. For instance, an arrangement of desks in the classroom may pose a text that students might read in terms of how teachers value certain modes of student interaction. While this value may not be communicated in verbal or written form, it is yet an intelligible symbol bearing traits of text as Rosenblatt described.

This chapter establishes the context for understanding the classroom community as an emerging text and explores how it might be read and interpreted for its character building capacity. The chapter also discusses students' engagement with this classroom text as it is composed and managed by their teachers' instructional practices that help to create particular classroom environments. The background of the problem of the study, and specific issues surrounding character education are examined, as well. The significance and rationale for the study are explicated in this chapter. 


\section{Defining the Classroom as Text}

Non-verbal symbols are replete throughout the classroom space. They represent such texts that are born of or engendered by the classroom community, described herein as classroom community or social text. Out of this text emerges a classroom culture - a culture identifiable by particular characteristics which are often determined by academic and social experiences and relationships forged within the classroom space. Shaped within the classroom space is a learning community comprised of teachers, curricular resources (including literary texts and other curricular arrangements), and student learners. Together, they form a triad with each element interacting with and influencing the other (Schubert, 1997), and contributing to the development of a classroom climate, as well. Understood in this way, the classroom then becomes like any other text - filled with both characters and events. This classroom text elicits responses from its readers such as making predictions, questioning, visualizing, clarifying, and evaluating literary and lived experiences within this space.

Drawing from the work of Paulo Freire, one might better understand how the classroom can be conceptualized as a "text" to be evoked, experienced, and read. Freire illustrated this point using his own personal literacy development experiences, where he presents the notion of "the word" in the same vein that Rosenblatt used text. He described his learning to read as a process which began long before he could read printed text. He recalled the experiences of his childhood as learning to read the world first. His knowledge of literacy evolved naturally from what he had experienced (Freire \& Macedo, 1987). In other words, learning to read the world provided understanding or points of reference useful in his literacy development (reading the word).

By a consideration of other forms of texts, namely popular texts (i.e., media texts [music videos and film]; as well as cultural icons [children's toys and games]), the work of Rebecca 
Powell (2009) on literacy development converged with Rosenblatt and Freire's usage of concept of text. In referencing the act of reading beyond that of a literary process, Powell argued that reading of texts (literacy) must not be limited to the reading of "words on the page; reading rather acknowledges a variety of signifiers [that] can be read and deconstructed for their inherent ideological messages" (p. 185). Simply stated, messages found within a given text can be presented within a variety of formats without invalidating the inherent meaning of the text. Textbooks, oral discourse, bulletin boards, arrangement of classroom space, even feedback/praise/recognition might serve as classroom media used to present particular messages, whether deliberately or unbeknownst to the teacher. Powell further explained reading as a sustained process of engagement with particular experiences - experiences with people, environment, and artifacts (see Figure 1 on p. 4). To illustrate this point, she described a young child's experience with African American panhandlers while walking with his mother down a particular street. Before he and his mother would get to the point of approaching the panhandlers, his mom and he would cross the street. Subsequently, the lad developed a notion of African American males as people he should avoid. For the youngster, the messages embedded within his experiences provided a social text, which he internalized and used to develop an identity for himself and African American males. Thus, it can be understood then that through experiences with reading the world, individuals not only develop a self-identity, but they also learn to organize themselves in relation to others within categories of "us" and "them" (Spears-Bunton \& Powell, 2009).

In the classroom, signifiers would then represent daily interactions among students, teachers, and elements of the curriculum both the environment and the artifacts. Consequently, classroom texts may yield opportunities to cultivate relationships, enhance personal character, 
and develop a "classroom character culture." We can assume Freire's posture and argue that the literacy of one's world and word is developed through the ebb and flow between students, teachers, and curriculum, wherein a classroom community text is shaped. Such exchanges reinforce-the literacy of the participant readers toward ultimately adopting the text as part of their own narrative - part of the story of their lives. The composition of this narrative, influenced by students' experiences with the classroom community text can be couched within a character education framework (Shubert, 1997). This idea is often overlooked by teachers especially when the moral and performance character seen in the behaviors of students are different from that which teachers would desire.

Figure 1: Conceptualizing the classroom: A text to be evoked, experienced, and read

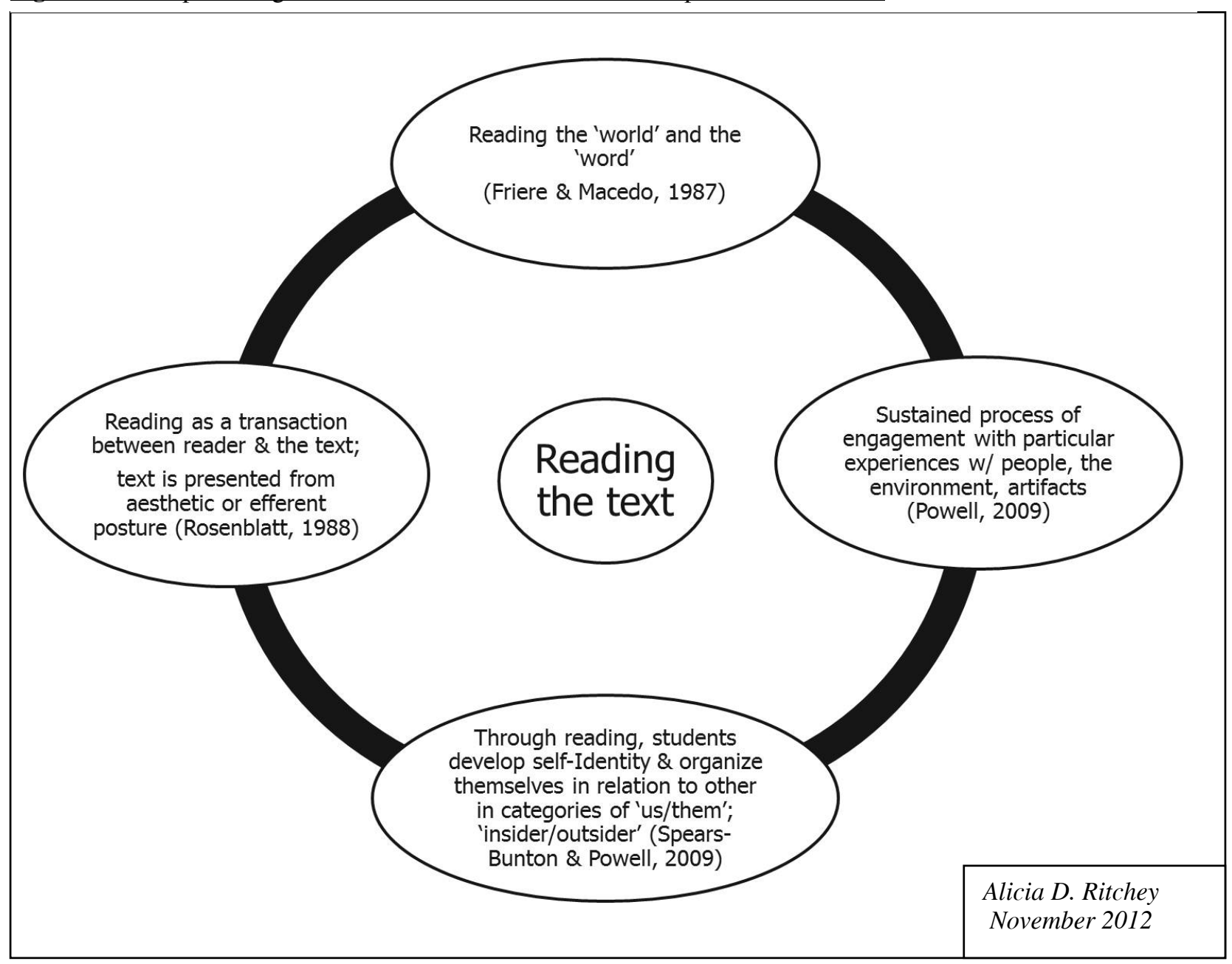




\section{From Text to Poem: Character Education in Progress}

With the current aims of school improvement initiatives, what happens in the classroom as part of a character education discourse often takes a back seat given the wide misconception that character cannot be measured (Milson, 2003). Even still, if there were agreement that character could be measured, it is yet not certain that schools would direct their overall focus toward character education. Instead, the preponderance of school-wide attention is more focused toward schools making Adequate Yearly Progress, increasing the number of students taking advanced courses, learning gains of the lowest $25 \%$ percent, graduation rates, and student performance on state and national standardized exams. While many schools have not examined the relation between character education and student, classroom environment and students' orientation to academic performance does not seem like a far stretch.

Nel Noddings (1997) argued that individuals are as rational as the environment of which they are a product. This idea points to a relationship between individuals and their environment. From her viewpoint, it can be reasoned that the traditions of the environment often relate to the development of the individual's character. Noddings wrote, "We are not first disengaged, rational mechanisms and then participants in a society; rather, whatever rationality we exhibit is itself a product of the tradition in which we are raised and educated" (p. 131). Understood within the context of the classroom, students' engagement in curricular traditions that are affirming, inclusive, and empowering are more likely to produce a particular classroom culture - a character culture where students are able to make appropriate academic and social responses that evidence themselves as products of good character. Arguably then, what students learn about themselves and others through their classroom experiences is a compelling indication of a character education process. 
Traditionally, character education is defined as "a national movement creating schools that foster ethically, responsible, and caring young people by modeling and teaching good character" (Berkowitz \& Bier, 2005, p. 2). This definition signifies that good character must first be modeled by teachers and other adults at school sites in order for students to attain it themselves. The present study views character education, at least within the classroom space, as the process by which one's character is shaped through schooling and classroom experiences involving teaching/learning and social practices that are guided by principles of respect, trust, and honor. Such experiences would likely help to establish a culture that is based on a classroom community text that presents an affirming narrative of student learners as social and academic achievers (Purpel, 1997).

Interestingly, the ways in which students respond to literary text is much like the possible ways they are able to read the classroom community text and respond to it (Freire \& Macedo, 1987; Powell, 2009). The quality of their responses is largely dependent on teachers' instructional practices that may foster a classroom culture which may be regarded as a "character culture." Specifically, as it relates to the present study, a classroom character culture is the type environment that is initiated by teachers' inclusive management and presentation of the curriculum in ways that maximize relationship-building opportunities within the classroom space. Evident in this environment are teaching/learning and social practices that are guided by principles of respect, trust, and honor. The process by which this culture is created would then be referred to as character education. In this case, teachers' instructional practices would involve the nature of instructional delivery of subject area content, classroom management, the integration of social interaction, and a deliberate and overt emphasis toward character building. 


\section{Reader Response: Approaches to the Text}

Rosenblatt's seminal work, Literature as Exploration (1995) outlines two positions the reader may take as he or she approaches the text: efferent or aesthetic. In efferent posture, the reader merely extracts information from the text to be used for other purposes such as "the mathematician reading his equations or the physicist pondering his formulae" (p. 24). In these examples, the focus of the reader's attention is on what concepts or solutions are to be "carried away from their reading" (p. 24). Within the efferent approach, the relationship between the text and the reader is not acknowledged. In this case, learning is not measured by the students' ability to provide an intimately personal response in an analytical and articulate fashion, rather the students' ability to "paraphrase, define, and apply proper rubrics" (p. 56). The efferent approach to reading maintains that the reader keeps intellectually silent. In other words, within the efferent framework, the experiences, the perspective, and critical analysis of the reader do not contribute to the reading process. The philosophy of this approach defines reading as an act of deconstruction, where reading involves one (the text) acting upon the other (the reader) on a linear plane, in a single direction. The aesthetic approach to reading, on the other hand, argues that the literary experience is transactional, involving an exchange between the reader and the text to create meaning. Aesthetic reading acknowledges the reader as a valuable contributor in the transaction. In the aesthetic posture, the reader is expected to give life to the words on the page and construct meaning from the text (Rosenblatt, 1995). Moreover, aesthetic reading can be viewed as an effective building block to awaken readers' interests in the text enabling students to consider the text more critically and in a more scholarly way (Spears-Bunton, 2009).

Drawing from Rosenblatt's description of aesthetic versus efferent, classrooms would have marked differences as an efferent versus an aesthetic text. For example, the expectation of 
the reader as a silent member of the reading transaction would have particular characteristics in a classroom created as an efferent text. In this case, the teacher, the presenter of the text who facilitates the reading process of the classroom text, is likely to make limited considerations of the student learner, in terms of their experiences, their perspectives and ways of knowing, and understandings of the world. Conversely, as an aesthetic text, the classroom would provide the student learners opportunities to contribute to the development of the text as a space for meaningful learning. Within the aesthetic domain, students might be regarded as curriculum makers alongside their teachers. In this case, students would be allowed to help set curriculum goals, determine suitable methods for achieving the goals, have occasions to evaluate their teachers, as well as the process by which this occurs, and modify instruction as needed. Because the aesthetic paradigm is set to acknowledge the reader as a valuable contributor in the transaction, teachers who subscribe to the aesthetic approach make considerations of students in ways that facilitate a character culture within the classroom space.

\section{Teachers as Facilitators of Student Readings of Classroom Texts}

Teachers, instructional leaders of the classroom, design and organize aspects of the classroom by allocating space, time, materials, and structure for diverse kinds of learning activities. As classroom teachers, they help mediate between students and the classroom community text allowing students to make connections and construct meaning of their classroom experiences. In every aspect of their instructional practices, teachers are able to manipulate elements of the curriculum, which coupled with teachers' knowledge, skills, and dispositions, are all used to help create a story line within the classroom space.

As curriculum decision makers, teachers have enormous power within the confines of the classroom to not only shape the character of their student learners, but also the larger society in 
which their students will ultimately become participants. Schubert (1986) posits that teachers bring a particular interpretation to curriculum that is reflected in the resulting classroom environment they create - an environment which is informed by their own knowledge, skills, and dispositions towards students. Within this environment, students experience the formal curriculum. Here the teacher serves as a liaison or gatekeeper between the curriculum and the student. Moreover, through manipulation of the curricula elements, the teacher is able to determine the character that students experience, even when it is not the character intended by the social forces of the curriculum or those who control the curriculum. Otherwise, a classroom character culture that supports equitable and affirming student opportunities would seldom be present within classrooms. Consequently, it is the character of the curriculum that engenders, or in some cases favors, certain academic and social responses from the learner toward him or herself and others. Given this, character education can be viewed within broad terms to include students' social and academic experiences with the classroom curriculum. Understood in this light, character education involves the impact of these classroom experiences on student learners. Further, the role of the teachers as classroom character agents or simply character educators is greatly considered. Character education might then be centered on the goal of creating inclusive learning environments that value teachers and students as reciprocal teaching and learning partners. In so doing, teachers' instructional practices (i.e., planning, instructional delivery assessment, and behavior management) would reflect a character-centered pedagogy that would ultimately lead toward a classroom character culture. Expected outcomes might include enhanced self-images, conflict resolution skills, and relationship and community building competencies. 


\section{Texts, Contexts \& Curriculum-Teachers as Character Educators}

Much of the scholarly emphasis of character education is directed toward the student learner with less research on the character development of the teacher. Although teacher education reform acknowledges the preparation of teachers as character educators as an important endeavor, teacher education programs spend little time toward this end (Milson, 2003). While some subject areas deal specifically with issues of morality, behavior, judgment, good versus evil, etc. (i.e., teachers of English, language arts, and social studies), not all content area teachers are knowledgeable as to how to use the subject area as a segue to character development. In an expansive report on the effects of K-12 character education programs, researchers generated a conceptual model that has as one of its assumptions that character education targets a particular stage of child development, with no emphasis on the development of the teacher (Berkowitz \& Bier, 2005). Even in the case of studies that examine teachers relating to character education, usually it relates to teachers imposing good character upon the student learner (Berkowitz \& Bier, 2005; Milson \& Melig, 2002).

While some studies have examined the role of the teacher and their involvement with character education initiatives, fewer researchers have studied ways in which character education opportunities emerge within the wide scope of teachers' instructional practices. As stated earlier, instructional practices may fit within the following categories: (a) instructional delivery of subject area content, (b) classroom management, and (c) integration of social interaction, as well as (d) the deliberate overt emphasis toward character building. These categories may be viewed as a network of support through which the curriculum functions. Ironically, the content of the curriculum has long been used to compose a classroom text and ultimately shape students' character. Curriculum scholar, Klein (1991), defines curriculum as a controlling document 
providing an outline for what is to be administered or taught. Of itself, it is an expression of a set of social values, the bridge between philosophy and operations.

According to Klein (1991), there are a number of elements that comprise a curricular framework. These include goals, objectives, purposes, content, materials, resources, activities, teaching strategies, evaluation, grouping, time, and space. The ways in which teachers manipulate these curricular elements might be viewed as pathways to a particular classroom environment that relate to specific character-based outcomes among their student learners. In other words, students through continuous engagement with these curricular elements, as the teacher manipulates them, are exposed to texts that help shape or mis-shape their perceptions of their moral character, as well as orient the student learners toward particular academic performance. It becomes important for teachers to make curricular choices that are inclusive of the representations of all their student learners, including those whose learning systems, modes of communication, value systems and other aspects of culture and identity may be different from the mainstream. To dismiss this reality would communicate teachers' values regarding those whom they teach. Instructional practices such as these may further disconnect many student learners from the classroom curriculum, leading many students straightway into alternative and remedial programs. This cycle becomes a classic classroom text where some student learners are portrayed as inferior, deficient, and incapable of academic and social success.

For the purpose of this study, the curricular choices of teachers are all regarded as part of the development of the classroom text and the character education process of their students, as well. The present study highlights discussions of six teachers who, in an attempt to create a culture of character in their classrooms, shared their classroom experiences subsequent to their participation in professional development based on a character education framework known as 
Goma character education curriculum (Goma curriculum). Goma, an acronym that stands for Goal, Objective, Method, and Attitude, is part of a 7-step process that also includes Behavior, Communication, and Discipline. Goma is derived from The Inclusive Community Building Ellison Model (The Ellison Model), later discussed in the review of the literature as the theoretical framework of the present study. The Ellison Model identifies conflict resolution as one of its five foci (Hunt, Howard, \& Rice, 1998). Hunt (2006) conceived Goma as part of a 7Step unitary process, also named the 7-Step pathway, in order to demonstrate how conflict resolution is accomplished within a variety of contexts. Goma curriculum takes into account vectors of conflict that shape the multiple perspectives represented within classroom communities. In Goma curriculum, each phase of the process is considered a character post or character station. Each post or station is defined within a teaching/learning context (see Figure 2 on p.13). As well, each station supports a specific emphasis toward character building, thus the reference to the curricular framework as a character education paradigm (see Figure 3 on p. 14).

Simply stated, Goma curriculum is a curricular framework of concepts, teaching strategies, as well as character-building lessons designed to build self-efficacy, resolve conflict, and orient learners toward improved social and academic performance. Goma curriculum represents a set of values that emerge in the planning, implementation, assessment, and management of classroom relationships.

\section{Significance of the Study}

The present study focused specifically on six teachers. These teachers shared their memories and perceptions of the impact of Goma curriculum on their instructional practices, on themselves, their student learners, and their overall classroom environments. The present study is significant for several reasons. First, it focuses on teachers as the population of interest. With 
Figure 2: Goma 7-Step Process with definitions from Goma curriculum

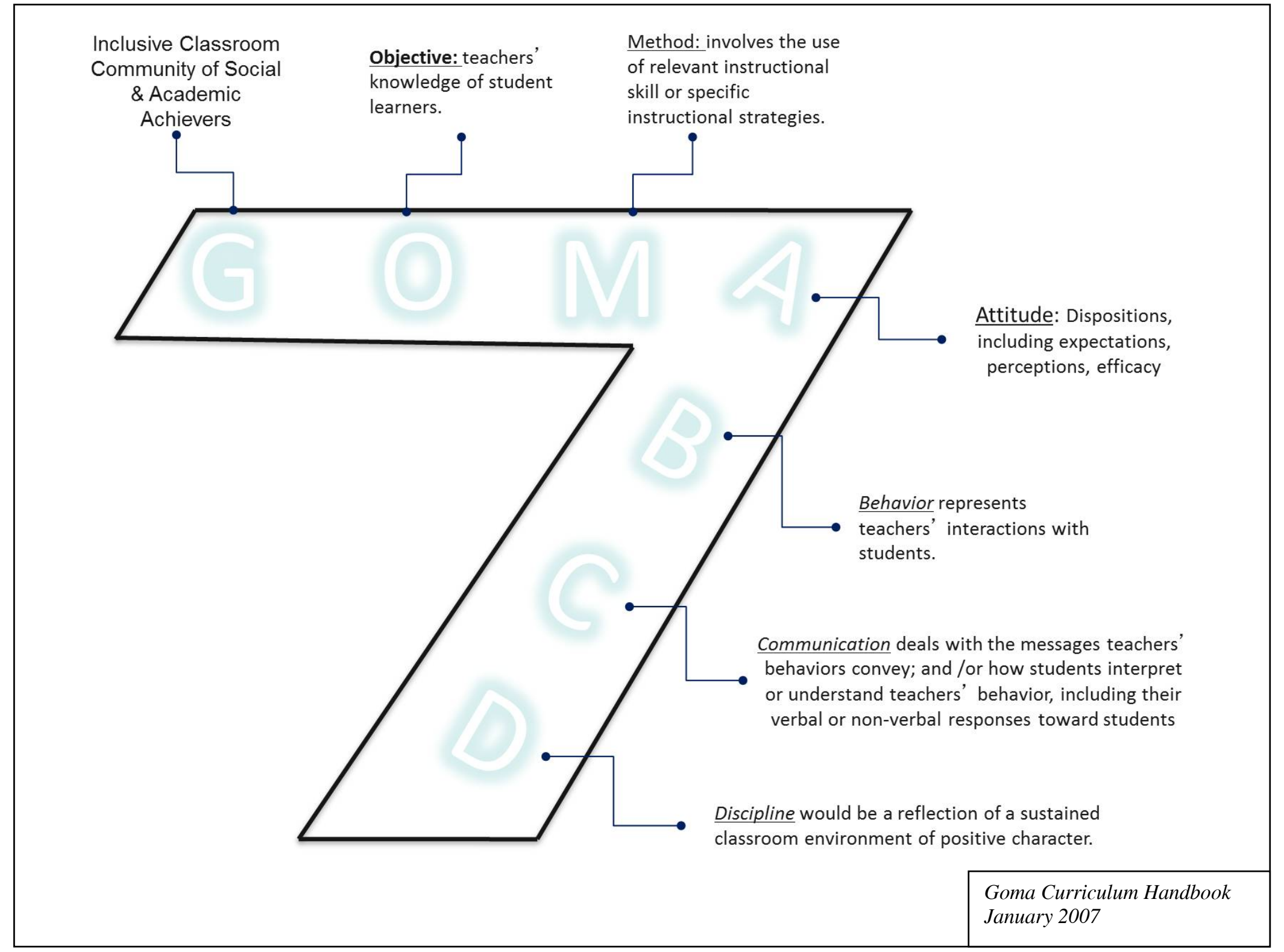


Figure 3: Goma 7-Step process reflecting a character focus at each character station.

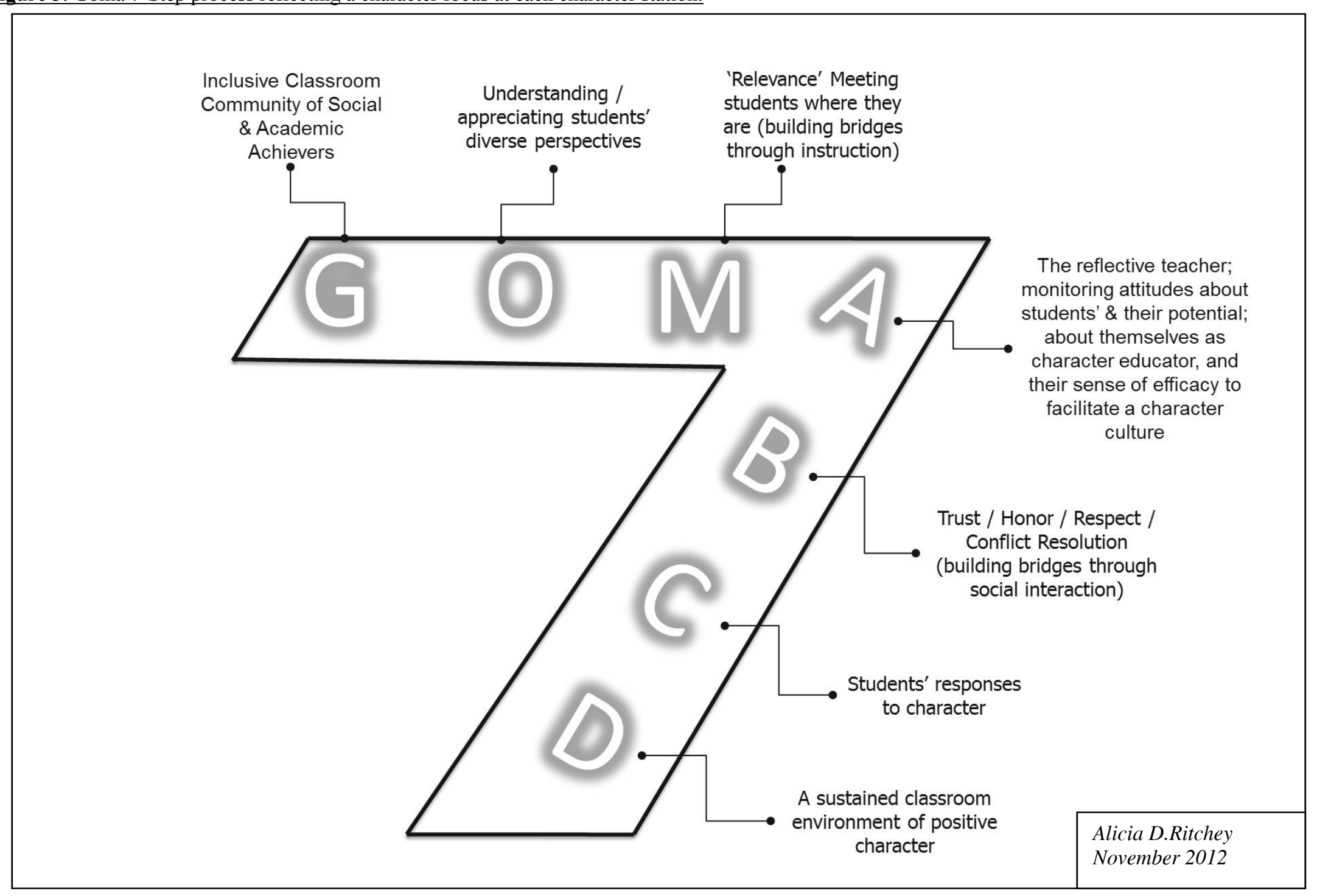


most character education efforts directed toward student learners, much of the research centers around student learners as well, in particular how they are impacted by character education initiatives. This study, however, expands current literature on the impact of character education given its focus on the character education of teachers. Though from a secondary lens, the study offers opportunities to glimpse what may be challenges, as well as best practices for implementing character education programs (Milson, 2003).

Another important feature of the present study is the nature of its design. The overwhelming research on character education programs employs quantitative approaches. For example, the report on what works in character education, presented by researchers with the Character Education Partnership (Berkowitz and Bier, 2005), identified 33 character education programs for their instructional practices. These programs were said to be scientifically sound. The report, however, lacked any qualitative review of the programs. Other research on the same topic seems to follow the quantitative trend (Reiman, 2004). The present study, having employed qualitative methods, furthers character education discourse as participants' voices are included as data for understanding how this subject matter might be expanded.

The present study is unique not only in that it engages qualitative methods, but also in its use of secondary data drawn from qualitative resources (i.e., interviews and self-reports). Hence, this study helps to provide understanding for ways in which secondary data extracted from qualitative studies might be used to answer new questions as is common among quantitative research.

\section{Statement of the Problem}

The present study follows attempts to examine ways teachers might provide students a classroom environment enriched with character-based experiences. The study uses the metaphor 
of a text to describe this environment as a space where students are able to read, analyze, and interpret meaning. The study draws from program evaluation data of a character education framework (Goma curriculum) used during a youth summer institute in South Georgia.

The youth summer institute, from whence the data of this study was drawn, focused on character education of students, but it also had a component for developing teachers as character educators. The teacher education component comprised professional development, where teachers received 30 contact hours of coursework in Goma curriculum and The Ellison Model. Additionally, teachers were involved in direct classroom experiences with students. Teachers also participated in teacher-talks and self-reports, a platform for teachers to share their classroom experiences following their training in Goma curriculum. In particular, the program evaluation sought to determine to what extent the teacher training and implementation of Goma curriculum influenced teachers' instructional practices. The present study re-examined the data to explore the nature of the experiences teachers had as they employed Goma curriculum strategies. Additionally, in re-examining the data, the present study was undertaken to understand what character building opportunities may exist over the span of teachers' instructional practices toward creating a character culture within the classroom. It becomes critical to investigate these opportunities for approaches that support and demonstrate (a) a working knowledge of students as learners, (b) curricular strategies appropriate for character building, and (c) high expectations and perceptions that encourage positive self-concepts among students about their abilities to be successful independent learners. These elements might well be built into a structured character education model appropriate for student learners of all ages and backgrounds. 


\section{Research Questions}

The present study was guided by the following questions:

1) What kinds of experiences were teachers having as they progressed along the character education pathway of Goma curriculum?

2) What opportunities do teachers' instructional practices provide for creating a character culture in their classrooms?

\section{Delimitations}

The present study examined the impact of a specific character education program, Goma curriculum, on the attitudes and instructional/social classroom practices of six teachers who participated in a summer youth program in South Georgia. Since teachers have great influence in determining the kind of classroom experiences that comprise the classroom text to which their student learners are exposed, the present study focused on the character education of teachers and not students.

\section{Definition of Terms}

The following terms and concepts are used throughout the study. To benefit the reader, these concepts and terms are hereby defined operationally, as they are presented in Goma curriculum Handbook: A Character Education Guide for Teachers (2007) referred to as Goma curriculum Handbook for the duration of this manuscript.

Antagonistic approach to character development. An antagonistic approach to character education is an exclusive mono-cultural approach to teaching and learning that is designed to create broad academic and social gaps.

Attitude. Attitude is a character post on the 7-Step pathway of Goma curriculum that relates to teachers' disposition, including perceptions, expectations, and efficacy. 
Behavior. Behavior is a character post on the 7-Step pathway of Goma curriculum that represents teachers' interactions with students.

Classroom Character culture. Classroom character culture is the type environment that is initiated by teachers' inclusive management and presentation of the curriculum in ways that maximize relationship building opportunities within the classroom space. Evident in this environment are relevant teaching/learning practices, and social practices that are guided by principles of respect, trust, and honor.

Character Post. A character post is a station or marker along the 7-Step pathway of Goma curriculum. Each marker is unique in terms of what it represents as an instructional and social practice, as well as the likely experiences one may have while at the station. However, they are referred to as character posts because at each marker, some aspect of character is emphasized and evident.

Communication. Communication is a character post on the 7-Step pathway of Goma curriculum that deals with the messages teachers' behaviors convey and /or how students interpret or understand teachers' behaviors, including their verbal or non-verbal responses toward students.

Discipline. Discipline is a character post on the 7-Step pathway of Goma curriculum that reflects a sustained classroom environment of positive character.

DOR Foundation. The pseudonym for the organization that presented the summer Institute/ character education program discussed in the study. 
Environment. Environment is the desired outcome of teachers' bringing together specific motivational standards that empower students and affirm their potential as social and academic achievers. Environment is also a product of teachers' deliberate use of classroom artifacts, space, and other resources to ensure a sense of comfort, safety, and conduciveness for student learning.

Goal. The goal of Goma curriculum is viewed as the development of students' character, particularly their self-esteem as learners, their view of themselves as educational helpers, and their personal acknowledgement as competent academic and social achievers. The overall goal is the construction of an inclusive community, comprised of members who share a character-centered philosophy.

Goma Curriculum. Goma curriculum is a curricular framework of concepts, teaching strategies, as well as character-building lessons designed to build self-efficacy, resolve conflict, and orient learners toward improved social and academic performance. Goma curriculum represents a set of values that emerge in the planning, implementation, assessment, and management of classroom relationships.

Honor. Honor is the act of teachers esteeming students as co-curriculum makers who help to: (a) create meaning, (b) construct new knowledge, (c) set curricular goals for learning, (d) make decisions regarding content and instructional delivery, and (e) evaluate teachers' abilities to disseminate information in a manner that is comprehensible by students and relevant to their lives.

Inclusion. Inclusion refers to teachers' acknowledgement and use of student diversities to create an environment where all students feel empowered and respected. 
Movement. Movement is teachers' engagement of students in dialogue and performance-based activities that help to inspire (or move) students to share, reflect, and expand their perspectives, sense of knowing, and ultimately their vast repertoire of responses to different social and academic stimuli.

Method. Method is a character post on the 7-Step pathway of Goma curriculum that involves the use of relevant instructional skills or specific instructional strategies.

Objective. Objective is a character post on the 7-Step pathway of Goma curriculum that is defined as teachers' knowledge of student learners.

Protagonist approach to character education. A protagonist approach to character education is an inclusive unifying framework that involves ways of teaching and learning that equally affirms the academic and social potential of all learners.

Relevance. Relevance is a key feature found in teachers' instructional strategies that enables students to make connections between the curriculum and their own lives.

Respect. Respect is the act of teachers' integrating students' voices and communities into the classroom lessons in meaningful ways, as well as acknowledging and valuing their lived and historical cultural experiences.

Seven -Step Pathway (7-Step Pathway). Formally known as the Goma 7-Step process, this is a character and community building framework that was originally designed to assist individuals through a conflict resolution unitary process. Hunt (2006) conceived the Goma 7-step process, also named the 7-Step pathway, to demonstrate the process by which conflict resolution is accomplished within a variety of contexts. 
Trust. Trust is the act of teachers demonstrating a level of confidence in students' ability to make sound and logical judgments and appropriately use information, manipulatives, and other resources.

Unity. Unity relates to teachers' skillful management of curricular elements (space, time, content, etc.), as well as other strategies teachers used to: (a) engage students in activities that take into account of who the students are as learners, their needs, and their interests and (b) bring together all classroom members into a community of successful learners. 


\section{CHAPTER II}

\section{LITERATURE REVIEW}

This review of literature presents a discussion of teachers' knowledge, skills, and dispositions since these are often presented when considering what teachers bring to the classroom (Garcia, 2002). Moreover, teachers' knowledge, skills, and dispositions are said to help shape classroom environments (Schubert, 1986). Finally, knowledge, skills, and dispositions align suitably, and may even be viewed synonymously, with the Objective, Method, and Attitude character posts of Goma curriculum framework (see Figure 4 on p. 22). The review of literature presents a view of disposition both in terms of self-efficacy, as well as perceptions and expectations. These aspects of teaching are couched within character education discourse, as well as cultural relevance domain. Further, the chapter discusses Goma curriculum as a culturally responsive pedagogy, which is described in its relationship to teaching and learning in ways that support classroom character culture. Finally, the chapter provides an in-depth discussion of The Inclusive Community Building Ellison Model, the theoretical perspective upon which the present study rests.

Figure 4: Goma alignment with Knowledge/Skills/Disposition

\begin{tabular}{|c|c|}
\hline Goal & ned) \\
\hline Objective & Knowledge \\
\hline Method & Skills \\
\hline Attitude & Disposition \\
\hline
\end{tabular}




\section{Knowledge-Skills-Disposition: Nuances of Instructional Practices Situated in Character}

\section{Teacher Knowledge}

Traditional practices in curriculum development require little effort on the part of teachers to understand their students as classroom clients. Student needs, benchmarks or gradelevel expectations, subject matter content, and in most cases, daily classroom lessons are all predetermined before the learner steps into the classroom. As a case in point, researchers affirm that American schools have historically remained inclined toward the creation of a public education system which moves in the direction of the dominant culture with hardly any consideration of the minority learner (Artiles \& Trent, 1994; Brophy \& Good, 1974; Proctor, 1984). If the preceding research holds true in the contemporary classroom, then expectedly, frequently used textbooks, the process of testing construction, and even classroom environments would be presented in ways that might counter the realities of many learners. Hence, it would seem that there is a direct relationship between teachers' knowledge of students and the classroom culture. Current research on teachers' knowledge and students' outcomes confirm this relationship (Carpenter, Fennema, Peterson, \& Carey, 1998; Hill, Rowan, \& Ball, 2005).

Teachers' knowledge of students would seem almost necessary in order to assist students to expand their knowledge base. Moreover, without some grounded knowledge of students' backgrounds and past experiences, it would seem that teachers would be unable to make appropriate curricular choices to which students feel connected. Sitton (1980) suggests that teachers, in order to provide appropriate and effective instruction for the students, must recognize the gulf that divides the school culture and that of certain students. He further suggested that with knowledge of students' culture, teachers are better prepared to operate across ethnic, linguistic, and social class boundaries. His discussion is driven by the pivotal question: 
“How much are teachers aware of their students' cultural definition of things, and how (if at all) do teachers adjust their teaching to this aspect of children's culture?" (p. 541).

Research provides significant consideration of teacher knowledge. However the preponderance of research related to teacher knowledge emphasizes more of their knowledge of the content rather than their student learners (Carpenter, Fennema, Peterson, \& Carey, 1998; Croninger, Rice, Rathbun, \& Nishio, 2007; Hill, Rowan, \& Ball, 2005). Still there are some character-based assumptions in the research, even in cases where teacher knowledge is content specific. For example, Carpenter et al. (1998) considered pedagogical content knowledge and its relationship to student outcomes. Their study revealed insight extending beyond teachers' knowledge of content to include teachers' knowledge of students. According to the results of their study, none of the teachers' variables (general knowledge of problems, problem difficulty, or knowledge of strategies used) correlated with student achievement; however, the teachers' ability to predict their students' success in solving different problems showed significant relations in student outcomes. This suggests that teachers' knowledge of their students impacted achievement because teachers were more likely to gear classroom instruction based on their knowledge of what the students were able to successfully complete, not necessarily based on the strategies students used to solve problems. What can be derived from their study is an understanding that teachers' knowledge of content alone does not produce desired outcomes of academic achievement. Instead, this might well produce a conflict-ridden environment where students are disconnected from the academic concepts of the curriculum and disconnected from the approaches teachers use to deliver the content.

On the other hand, teachers' knowledge of their students and, in this case, the strategies they are likely to employ during problem solving might become a basis for teaching the 
necessary content as prescribed by the mandated curriculum, including standards and benchmarks. In this way, students interpret the environment as relevant and conducive to their success. Consequently, students are likely to more become comfortable with learning, and their literacy development is enhanced (Dunn, Beach, \& Kontos, 1994). Certainly, teachers' content knowledge is essential, but when teacher knowledge is inclusive of both the content and the students, the probability of a classroom character culture is more likely.

Griffin (1998) argued that teaching is, in fact, an intellectual activity. He summarized the complexities of good teaching suggesting that this is more than taking a set of material, and following directions. Griffin's notion of good teaching also involved higher order thinking where teachers synthesize their intellectual resources, analyze student responses, and make evaluations about what might be appropriate for diverse populations of students. Toward this end, students are likely to engage in reading a character-based narrative that affirms their potential and orients them toward making advanced social and academic responses.

\section{Teacher Skill}

Another aspect of teaching that influences classroom character culture is teacher skill (Cirino, Pollard-Durodola, \& Foorman, 2007; Shulman \& Armitage, 2005). Shulman and Aritage's (2005) study of a middle school located in a high poverty community measured student achievement taking into account: (a) attendance, (b) report card grades, and (c) standardized test scores. The research was based on a program model that focused on professional development in attempts to encourage engaging, thought-provoking student-centered pedagogy among middle school teachers. Participating teachers experienced an increased sense of self-efficacy, and a transformed view of their teaching skills. After their involvement with the program model, teachers felt personally responsible for the students' academic success. The results showed that 
their style of teaching changed to become more reflective and they were more willing to explore different methods of instructional practices. Moreover, teachers felt an increase in their ability to help reluctant students with their coursework. In addition, teachers felt that they could reverse the negative effects of an adverse home environment. This was different from the traditional responses of many teachers, who did not feel capable of changing difficult behaviors of their classroom students (Milson \& Mehlig, 2003).

Clearly, academic achievement of students taught by teachers trained in this project demonstrated significant academic responses. The results showed a $104.4 \%$ increase on standardized mathematics and English/language arts compared to other middle schools within the district, $63 \%$ more students met or exceeded state standards, and there was a $21.4 \%$ decrease in students who failed to meet state standards. Conversely, the percentage of students who failed to meet state standards from comparable middle schools remained virtually unchanged. Student participants also earned higher grades in their classes and evidenced a decline in the number of students who were absent from school. These changes in students' academic responses resulted from changes in teachers' instructional skills, wherein students were allowed to exert control over their own learning. Additionally, student needs were acknowledged when curriculum was planned. When examined critically, teacher skill is then yet another contributor to classroom character culture as demonstrated in the previous study.

What can students understand regarding when teachers release some of their control and give students more classroom autonomy? Assumedly, the empowerment of students as a teaching skill relays character values of respect and trust to students. As shown in the previous study, this may result in character -based outcomes of responsibility, leadership, and success by student learners. Researchers such as Davidson, Lickona, and Khmelkov (2007) have recently 
begun to connect character with student performance. Their report on smart and good schools provides a fresh perspective of character to include both performance character and moral character. Students attending the 24 schools identified as high performing schools overwhelmingly reported that teachers who care about their students teach well and treat students well. Within the context of teaching, performance character might be synonymously viewed as teacher skill, the ability to manipulate the elements of curriculum in a way that communicates moral character toward student learners. In this regard, the teacher, or character educator, is an embodiment and a model of both performance and moral character, prompting students to behave and perform in like manner.

\section{Teacher Disposition}

Johnson and Reiman (2007) define teacher disposition as characteristics of the teacher that predispose them to behave in certain ways within a context where there is arguably more than appropriate ways to respond to a certain situation. Their study of teachers' moral values, judgments, and actions used a case study methodology to observe beginning teachers' instructional practices in classroom settings. The study revealed that measures of teacher judgment were congruent with teacher action, and that teachers' dispositions, in fact, had an impact on the student's academic responses.

Researchers posit a significant relationship between teachers' dispositions, including teacher perceptions and expectations, and student response /performance (Brophy, Cooper, and Good, 1983). Both teacher perceptions and expectations, as classroom stimuli, impact the learning environment beginning with instruction (Gay, 1997), and could adversely affect students' social and academic progress. Researchers (Ladson-Billings, 1994; Weiner, 1993) argue that empathy and enthusiasm, motivation to learn and teach students from diverse 
backgrounds, as well as high expectations for all student learners are key attributes of effective teachers. Seemingly, teacher expectations spark students' performance, which in turn reinforces teacher perceptions and expectations. This cyclical process, if positive, would likely enhance student-teacher relationships.

Earlier accounts of the evaluation of student progress focused on problems which pointed toward the student (Coleman, 1966; Jencks, et al., 1972). Subsequently, the focus shifted to examine the role of teachers and schools, particularly among minority student learners. Findings support low teacher expectations for many minority students causing negative impact of these learners outside the classroom (Good, 1981; Taylor, 2000). Clearly all students need committed teachers who maintain instructional practices that are affirming and beneficial for diverse learners, and who set a standard of excellence to which the students are expected to attain. Unfortunately, certain students are confronted with teachers who lack positive dispositions toward particular student groups based on a number of factors, including: race, socio-economic status, and even students' heights (Smith \& Neimi, 2007). As indicated in their research, one of the primary challenges of teachers is the development of an ethical or moral self that allows them to interact effectively with their students. Moreover, studies have indicated that as teachers develop dispositions and actions that promote classroom equity, fairness, and respect, students become more engaged.

\section{Teacher Self Efficacy}

Self-efficacy is the belief that one can successfully accomplish a particular task. Albert Bandura (1997), a social learning theorist, conceptualized this concept many years ago. Bandura's key contentions regarding the role of self-efficacy beliefs in human functioning is that people act and are motivated beyond what they consider to be factual and true. Other researchers 
(Pajares, 2002) argue that people are not just creatures who are at the whim of environmental factors. Instead they possess cognitive mechanisms that enable them to process their experiences, either negatively or positively, toward the end of affecting the outcome. How the individual responds to his/her environment is based on particular attributes of the individual (Barkley, 2006). This response produces an end-product which is itself the reciprocal nature of the person interacting with his/her environment and vice versa. This interaction is what is termed Triadic Reciprocal Causation (Henson, 2002).

The concept of teacher efficacy derives quite naturally from Bandura's notions of selfefficacy. Puchner and Taylor (2006) describe teacher self-efficacy as having a strong impact on the performance of students. They further argue that teachers who have a high sense of selfefficacy are more likely to expect their students to perform well, to view low performing students in a positive light, to have a close relationship with their students, and to persist longer when students are encountering barriers to the learning process. Conversely, teachers with a low sense of self-efficacy are more likely to be overly critical of their students' performance, to use embarrassment and punishment when students do not perform well, and to use control in their relationships with their students. Researchers, Knoblauch \& Hoy (2007), also discussed the selfefficacy beliefs of teachers impacted by teacher training. While they discovered that teachers' self-efficacy beliefs may change based on the school setting, other research has found that these beliefs may also be moderated by student populations (Paneque and Barbetta, 2006). The work of Paneque and Barbetta focused on the self-efficacy beliefs of special education teachers who teach students with learning disabilities and whose native language is not English. This adds significantly to the body of literature because research in this area is scant. Their research, in 
particular, examined the relationship between certain dependent variables and teachers' efficacy beliefs relative to this student population.

Two hundred and two elementary special education teachers representing 31 elementary schools participated in the survey study. Results of this study emphasized the importance of language proficiency of special education teachers, who teach ELL students with learning disabilities. This study has implication for regular education, as well as ESE and ELL teachers. With the inclusion model, both ELL and ESE are increasingly being mainstreamed into regular education classes. Therefore, teachers who possess knowledge of how language proficiency impacts student learning in ELL and ESE programs, can use appropriate skills to help their students assess prior knowledge and support the learning of new content knowledge, as well.

Taken together, the application of knowledge, skill, and disposition toward enhancing students' academic and social responses would seemingly culminate into a culturally relevant paradigm, wherein teachers would become sensitive to the needs of their students. This sensitivity has the potential to foster an environment where students of diverse cultural, academic, and socio-economic backgrounds believe they can achieve. It is highly probable to find within such a classroom environ a text filled with positively affirming experiences that provides a high level of comfort for students. As this culture is created, and persists over time, teachers can expect a classroom norm of student achievement.

\section{Cultural Relevance: a Classroom Character Culture Catalyst}

In practice, cultural relevance helps to establish a trustworthy relationship between teachers and students as students acknowledge a sense value from teachers who tailor instructional practices with consideration of students' learning processes and cultural identity. This supports teachers' attempts to provide culturally responsive instruction that acknowledges 
different cultures and learning styles. The work of Jennifer Turner (2003) supports a focus on culturally relevant teaching. Turner's study presented the professional narratives of three European teachers whose classrooms were comprised primarily of African American students. After performing a content analysis, Turner's research concluded that the teachers' theories of instruction and classroom practices were markedly different from prominent theories on culturally relevant teaching. Emerging from these stories was that underlying cultural relevance was the commitment of teachers to establish what Powell (1999) advocates as a classroom culture of compassion and care. Despite the racial differences between the teachers in that study and their students, a sense of connection, thus a degree of cultural relevance had been achieved. The findings of Turner's study provide some understanding of cultural relevance beyond race. Other research relates cultural relevance to increased levels of comprehension and performance. Ladson-Billings (1998), for example, asserts that an underlying element of meaningful curricula for reluctant learners is what she calls cultural relevance. In her study of successful learning experiences of African American learners, she proposes that cultural relevance helps to raise academic achievement levels, initiates and forwards cultural competence, and fosters a sense of sociopolitical awareness. This means of conceptualizing through relational and communal, social and analytical activities is said to enhance comprehension (Seixas, 1993).

Within a culturally relevant framework, the implementation of constructivist instruction might be used as a basis for teaching. Windschilt (2002) described how within the system of social constructivism, "knowledge is shaped by micro- and macro- cultural influences and evolves through increasing participation within different communities of practice" (p. 139). In this case, learning opportunities are directed primarily on the context of knowledge acquisition, rather than concepts. These opportunities provide what is introduced by Vygotsky as a "zone of 
proximal development" and are characterized by collaborative activities: learner participation with knowledgeable others and constructive tasks that involve problem-solving (Kozulin, Gindis, Ageyez, \& Miller, 2003). Students, therefore, internalize what is gained through interaction toward independent learning and higher order intellectual activity. Unlike other theories, social constructivism considers learning and understanding as activities, both of which are socially and culturally inherent. In this case, the students' socio-cultural practices beyond the classroom are significant as a point of reference from which the students participate within the classroom context. With this understanding, the teacher is able to use insights from students' culture in order to expand their ability to reconstruct knowledge.

To infuse the element of cultural relevance into one's curriculum would reflect the teacher's consideration of major aspects of the learners' experiences represented in the teachers' curricular choices. This would include considerations of students' learning systems, modes of communication, value systems, and other aspects of culture and identity, which in some ways may counter the traditional canon. Students, whose mode of learning and frame of reference, in terms of their lived and historical experiences, may not conform to the normative standards defined by curriculum experts. Consequently, these students may be relegated to alternative and remedial programs, perhaps a result of pedagogical omissions made by teachers whose instructional methodologies are not culturally relevant.

Giroux (1998) argued the need for a relative curriculum, one centered in the culture and communities of the students, their lived and historical experiences, as well as the knowledge that shapes their everyday realities. This requires that teachers become more conscious as educators of their student audience. This awareness is also embedded in assessment of student knowledge, which encompasses rich interpretive methods involving an evaluation of the processes and 
products of learning. Among the evaluation methods are well-designed rubrics that provide students a basis for knowing teachers' expectations and what is valued in the learning process. This takes into account students' attempts to make meaning, even when these attempts show immature understanding (Windshilt, 2002).

McLaren and Guiterrez (1998) also argued for a transformed curriculum that promotes critical pedagogy empowering its participants in an active role toward expanded and inclusive school initiatives and the realization of social reform. Contrarily, a mono-cultural approach to teaching, unbeknownst to classroom teachers, may foster a sense of resentment and low student achievement. This may further limit the ability of the teacher to reach students who perhaps are best suited to learn via a different mode. Additionally, this approach authenticates the voices of the majority as an esteemed discourse while relegating other voices to a level of insignificance (Delpit, 1995).

\section{Goma curriculum: A Character Education Paradigm}

The present study examined teacher talks and self-reports of six teachers, who shared their classroom experiences following their engagement in professional development based on Goma curriculum. Goma curriculum, a character education framework, serves among the possible responses to the social and academic conflicts that arise in today's classrooms. The term Goma curriculum was first developed in the early 1990s. Initially, Goma, an acronym that stands for Goal, Objective, Method, and Attitude was conceived as a character that would help students negotiate personal conflicts that often impede their ability to make right choices. Moreover, Goma was designed to teach individuals how to employ community-building values of caring, sharing, loving, trust, honor, and respect in first resolving inner conflicts toward ultimately establishing harmoniously abiding relationships with others (ICB Productions, Inc., 2006). 
From the acronym Goma, a series of character building booklets evolved (ICB Productions, Inc., 2006).The booklets introduce students to Goma as a non-descript main character, who serves as a role model for the way students should conduct themselves. Toward establishing a sense of relevance, each booklet shows how Goma's life relates to the lives of the students. Through interactive activities, students creatively illustrate their responses to Goma's experiences, and are provided alternative choices for dealing with challenging situations. Said to teach principles of character development, Goma curriculum uses the elements of curriculum to provide students with enriching and empowering classroom experiences. Within this context, students develop what is referred to as The ABCD's of Character Development, which seeks to foster positive Attitudes, Behaviors, and modes of Communication that will ultimately enable students to exercise Discipline and sound decision-making in all aspects of their lives, thus the evolution of Goma as part of a 7-step process. Within the Goma framework, Attitude is akin to what Lickona described as good habits of the mind and heart, and Behavior is akin to what he refers as good habits of actions (Lickona, 1991).

Goma curriculum has since been extended as a comprehensive character framework that, in fact, makes use of teachers' knowledge, skills, and dispositions toward establishing a character culture within the classroom. Hence, the present study examined six teachers' recounts of both their teaching and learning experiences as they were engaged in Goma curriculum with their student learners. Goma curriculum offers three propositions, all of which can be used as a lever for enhancing classroom environments: (a) a classroom ethos of unity and inclusion, (b) operational values of respect, trust, and honor, first modeled by the teachers, and then adopted by the other members of the classroom community, and (c) Relevance-Environment-Movement also known as REM. Goma describes a process by which students can experience social and 
academic success initiated by resulting from affirming classroom spaces. Goma curriculum takes into account that the goals have already been pre-determined and summarized in state standards and benchmarks or grade-level expectations. Knowledge, skill, and disposition then represent objectives, methods, and attitude, respectively.

The three (knowledge, skills, and disposition) relate directly to teachers and what they, as teaching professionals, have to offer students toward achieving the goals. Goma curriculum then challenges the teacher to see him/herself as the character agent, who assumes responsibility as a front-line curriculum interpreter and worker to ensure students are provided character-based experiences toward the learner's resulting in empowerment to accomplish what they may have previously thought impossible. While developers of Goma curriculum do not discount the importance of students' masteries of state benchmarks, they propose a set of goals that focus on the development of students' character, particularly their self-esteem as learners, their view of themselves as educational helpers, and their personal acknowledgement as competent academic and social achievers. The reference to Goma curriculum as a character education paradigm would be appropriate in that it is under-girded by a unique philosophy that promotes relationship building and the resolution of interpersonal and intra-personal conflicts that emerge in the classroom. Such conflicts often hinder the possibility of students' success, whether academic, personal, or social. Goma curriculum uses meaningful and relevant interactive activities and strategies to continually prompt students to a renewed and empowered self, reflecting the most prominent classroom character - the teacher. Using Goma curriculum framework, the teacher would be viewed as Goma, the classroom mentor who serves as a model for the way students should conduct themselves, both socially and academically. Researchers argue that the teacher or staff member is the person responsible for demonstrating proper moral behavior (Benninga, 
Berkowitz, Kehn, \& Smith, 2006). Their research advocates that schools provide students with opportunities to engage in moral activity and implies that the students would only be able to perform such tasks after the teacher has modeled them. Within the Goma paradigm, the teacher skillfully facilitates a mutually respectful relationship between the students and the curriculum in order to help students in order to help students realize whatever social and academic outcomes are desired. Hence, mentoring is an important component of Goma curriculum.

Teachers must create a classroom environment where students believe they can learn, are motivated to learn, and where students are confident that their teachers consider them as an important part of the learning process (Dodd, 1985 as cited in Carver et al, 2000). Goma curriculum seeks to foster an ambiance of respect and appreciation within the classroom environment. Specific motivational standards (valuable, success, safe, involving, caring, and enabling) are used to propel students toward mastery of academic standards and benchmarks. These standards are also used to empower and enrich learners in meaningful ways (Rogers, Ludington, \& Graham, 1997). Additionally, they help counter oppressive narratives (hooks, 1994), which present an exclusive character that incites conflict. When this happens, teachers may be perpetuating a classroom culture wherein only a select few can participate and benefit (Delpit, 1995).

\section{Theoretical underpinnings of Goma: The Inclusive Community Building Ellison Model}

Hunt initially developed TEM (The Ellison Model) in 1994 to establish a theoretical framework for his then current research on inclusive community building (Hunt, Howard, \& Rice, 1998). However, toward a better understanding of aspects of pedagogy and classroom communities, further research provides implication for use in education settings both at secondary and post-secondary levels (Ellison, 2002; Rice, 2001). Through the lens of TEM, 
classrooms are viewed as communities, whose knowledge base is broadened when the multiple intelligences and social capital of group members are valued and incorporated. This notion on community building in a classroom context assumes the students as important stakeholders, not only as learners, but also as teachers, who help determine how and what elements are used to facilitate the community building process.

At least within American education, there are three major sources for determining appropriate curricular elements for student groups: society, student, and subject specialists. Furthermore, in traditional curricular frameworks, the society is the most dominant source for several reasons: (a) it is the "governing" body that defines student needs, and (b) the society legitimizes subjects to be taught (Tyler, 1949). In this approach to curriculum development, the power structure of the classroom would reflect a top-down approach to decision making, whereby the position of power would originate from the top and dwindle significantly as the position moves downward. This leaves the student as the least empowered and as a result, the least considered in the framework. The Ellison Model would share an opposing approach to traditional curriculum development and classroom pedagogy given its emphasis toward inclusion of all stakeholders.

Unlike traditional curricular frameworks, The Ellison Model seeks to create learning communities, whereby all stakeholders are valued, feel a sense of empowerment, and demonstrate a commitment to the goals of the community (Howard, 1997). Howard describes how within The Ellison Model framework, a mentor/mentee relationship is established and mutual learning is incorporated across groups toward the enhancement of teaching and learning experiences. Within this framework, students are at the center, not only toward implementing projects or ideas taught by the instructor/mentor, but rather in contributing substantive input. In 
this way, the student is not considered a blank slate upon which to transmit culture (Freire, 2002). The student is instead considered a curriculum co-decision-maker, whose input contributes to the process of curriculum development. Therefore, The Ellison Model as an approach to curriculum development would be characterized by (a) an assessment of student interests, needs, and learning styles, (b) values of respect, honor, and empowerment, which foster a sense of inclusive community, and (c) affordable opportunities to follow up on student connections. This approach to curriculum development presents a much different view of traditional school design, where the flow of power is top-down. Instead, in The Ellison Model, these critical connections would mean the disbursement of input, feedback, improvement, and empowerment down, across, and up power lines.

\section{The Ellison Model Techniques}

While there are six techniques which The Ellison Model uses to describe its philosophy and progression (Hunt as cited in Ellison, 2002), for the purpose of this research, only three are considered since they are the most relevant to teaching and learning (see Figure 5 on p. 40). These techniques are referred to as Content-Process-Product (CPP), Ineffectual-ShallowEffectual (ISE), and the most common, Diversity-Unity-Community (DUC). The CPP technique directs its focus toward the student and describes the expected growth of the student as TEM is implemented. The growth of the individual is described as an inward metamorphosis with the student experiencing what is called 'community' in the process of teaching and learning (Hunt, 2000a). Ineffectual-Shallow-Effectual (ISE) is more descriptive of the teacher, who shifts from a traditional paradigm of instruction toward critical pedagogy, and subsequently is able to effectuate positive changes in the social and academic development of his or her students. DUC is the final technique discussed in this study, which embraces the notion of exchange or sharing 
of roles between teachers and students. Since teachers and students, according to this Model, are both learners and dispensers of knowledge, both at the end of this cycle are expected to achieve community, the highest level of existence in an organization or group as implied by TEM.

\section{Content-Process-Product}

The first technique, Content-Process-Product relates to the social growth of the learner, who through interaction with group members or peers within a classroom setting, finds enhanced opportunities to experience success, whether personal, social, or academic. Content might simply be defined in terms of what the students bring to the table or the students' cultural capital, including their learning styles and knowledge. In traditional classrooms, when students' content does not mirror that of the mainstream, opportunities for success are often minimized. Without proper guidance, students are still expected to fit their personal wealth within the parameters established by the powers that be. Employing strategies that based on The Ellison Model, students work cooperatively, since wealth is multiplied by group additions with each individual building on the cumulative resources of the community. In this technique, students establish a natural mode of interdependence where sharing becomes a fundamental element for success (Rice, 2001b).

In most cases, students are not aware of the content they possess. Interestingly, it is most often through student interaction that student content is uncovered. Though not all content is positive, as in the case of student weaknesses or deficiencies, however, the relationships forged by cooperative learning significantly reduces student deficiencies via peer scaffolding. Furthermore, through peer association, students become cognizant of their personal weaknesses. Consequently, students are challenged to build on their own strengths and make commitments 


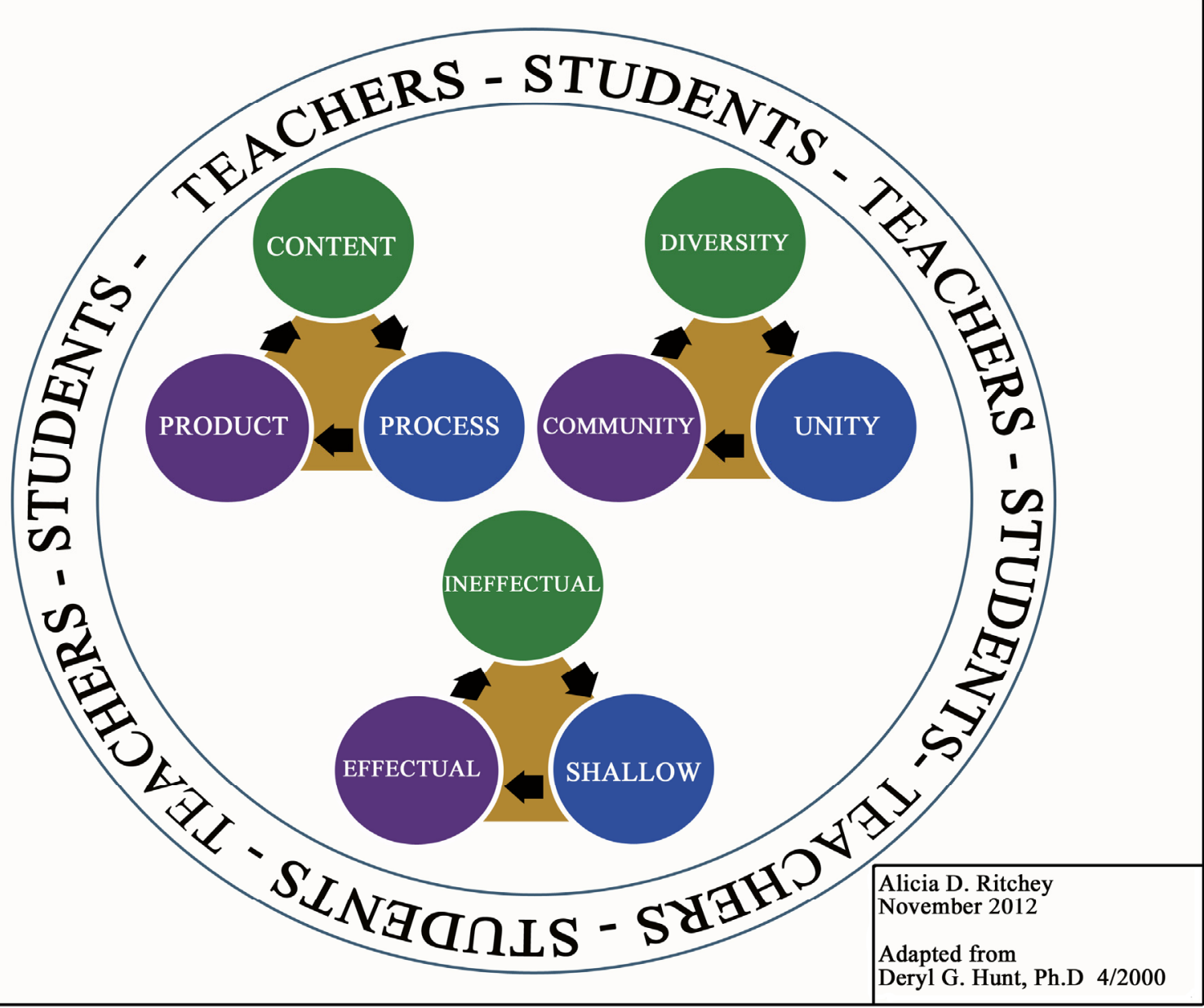

toward change. Like weaknesses, strengths may be academic, social or personal, which reflect both cognitive and affective domains. This affectivity or social phenomenon encompasses cultural capital, which of course varies from student to student, depending on his or her socialization. Unfortunately, it has typically been the cultural capital of the dominant culture, which has been valued.

Process can be defined as the opportunities the student has to critique systems. When students challenge certain systems or paradigms, this becomes a pedagogical moment to raise student consciousness in line with classroom democracy and critical thinking (Macedo, 1994). In 
culturally relevant environments, students are also provided opportunities to critique aspects of teaching and learning. His discussion on instrumentalist approach to literacy criticizes the minimal opportunities students are given to engage in such critical thinking exercises, suggesting that all students, even those in alternative education programs, must be engaged in active reading of both literary and social texts in order to make sense of their environment, assuming the environment to appear relevant to the learner. When the environment is relevant to the student, the student considers the environment as appropriate. As students are made to feel comfortable with learning, verbal skills and overall language development is heightened (Dunn, Beach, \& Kontons, 1994).

Finally, the product is thus, the ability of students to read and respond to the word and the world. In summary, product is the demonstration of the student to critique at the highest level of comprehension. This kind of critique is referred to by Spears-Bunton and Powell (2009) as "critical responses to the text" (p. 29). When students are taught to make critical responses, they are offered what the authors call "a literacy of promise" (p. 23). Teachers are able to measure the quality of the students' responses by academic performance. When academic performance is not what teachers positively expect, then teachers are able to reconsider the use of the classroom community and the text in their instruction. Rosenblatt argued that in order for teachers to assist students with making quality responses to the text, teachers must understand the life experiences of the students. "If his own experiences are limited, if his moral code is rigid and narrow or slack and undiscriminating, the quality of his response to literature will suffer" (Rosenblatt, 1995, p. 51). In some cases, the quality of student responses has to do with context, including the classroom culture or the way in which the learning is situated in any given lesson. This suggests that student responses or interpretations to texts can be strengthened when the teacher sets the 
information of the text in the life and personality of the learner. This would only seem possible when teachers have knowledge of their student learners.

\section{Ineffectual-Shallow-Effectual}

This technique of TEM relates primarily to the relationships forged within the classroom. At the Ineffectual level, conflicts are apparent. These vectors of relationship conflicts may exist between teacher and student, students and their peers, home culture and school culture, students and text, etc. At some point, these conflicts may subside to a degree of tolerance on behalf of each party where some aspect of resolution begins to surface; however, this level of conflict management is said to be shallow, thus the level of technique. The final stage of evolution within this technique is Effectual, wherein the parties grow toward mutual respect and appreciation of each other, and conflict resolution is manifested. While the resolution to conflict involves everyone, the process actually begins with teachers and their response to both the environment and the learner. The rate at which these relationships are forged has largely to do with the willingness of the teacher. Referred to as the social insider (Howard, 2004), the teacher is expected to (a) renounce old paradigms about teaching and learning and (b) embrace student diversity if the progression of the technique cycle is to commence.

Negative interactions with teachers predict interferences with peer relationships and often lead to peer- rejection and poor behavioral outcomes. These negative outcomes would likely contribute to further rejection of students by their teachers and their peers (Montague \& Rinaldi, 2001). In many instances, students become profiled for at-risk or alternative education programs. It may be argued that all other classroom relationships are founded upon the primary relationship between students and teachers. In demonstration of effectual methods of teaching, teachers would facilitate mutual relationships between students and themselves. This would allow 
students to establish alliances with other personalities and entities within the classroom, be it their peers and/or the curriculum, where they would likely be able to connect with other aspects of the classroom community text.

Relationship building in the classroom or the progression of the ISE technique can also be described in terms of Rosenblatt's discussion of approaches to literary instruction. In some cases, it may be said that the text and the reader are in conflict. This conflict may point to the absence of effectual facilitation on the part of the teacher. The personalities of both the teacher and student are represented as part of the text. This implies that students' involvement with the text enables them opportunities to better understand themselves and others wherein they experience the range of frustrations, excitement, struggles, accomplishments, etc. of classroom personalities. Effectual facilitation by the teacher would recognize these transactions between students and other classroom personalities. Additionally, teachers would aim toward conflict resolution and relationship building by allowing students to (a) share how they read the classroom world and their place in it, (b) discuss their interpretations of their classroom experiences, and (c) make subsequent responses based on their interpretations. The process of allowing students to critique and construct meaning of even social texts is critical since students are likely to apply the same frame of thought when reading literal texts (Freire \& Macedo, 1987). For example, if students read and interpret the experiences of the classroom as esteeming the ways of knowing and cultural capital of one group above another, they may expect to find similar patterns in literal texts. The effectual teacher, however, would have opportunities to clarify misconceptions that may arise in students' reading. Moreover, he or she may address student perceptions that may be harmful to the goal of inclusive community building. In this 
way, classroom relationships are built, comprehension increases, and students learn to react constructively to the text.

\section{Diversity-Unity-Community}

Diversity- unity-community is another technique of The Ellison Model (TEM). Within The Ellison Model framework, diversity is defined as a range of differences brought by individuals. In reality, these differences, sometimes manifestations of culture, can be seen as vectors of conflict, often posing the greatest instructional challenge for classroom teachers. In the classroom, this diversity encompasses both student and teacher differences, and represents constant variables such as ethnicity and gender. It may also be viewed in terms of the variations of what students bring to the classroom, such as cultural capital, as well as cognitive styles and knowledge. TEM suggests that diversity should be viewed as a platform to initiate dialogue in order to better understand and serve the needs, interests, and perspectives of all parties involved (Hunt, 2000a). For the educator, this would imply a consideration and assessment of the diversities, or variations of student perspectives before beginning to make curricular choices since these curricular choices should be based upon the interests and needs of the students (Tyler, 1948). With student assessment, teachers would have a basis to establish an appropriate curricular framework, one that evidences relevant curricular selections, the mitigation of classroom conflict, and efficient manipulation of curriculum elements including goals, objectives, purposes, content, materials, resources, activities, teaching strategies, evaluation, grouping, time, and space (Klein, 1991). TEM framework suggests that when teachers consider the multiple perspectives of the students, they, the students, are more likely to interpret the environment as relevant. In this way, students see themselves positively represented in every 
aspect of the classroom life. The classroom space is then read as a culturally conscious text, grounded in the multiple student perspectives that comprise the classroom community.

The technique, diversity- unity- community, presupposes that the society can hold as its ethos one of two meta-values: unity or division. Researchers have noted that within traditional models of education, the curriculum reflects an ontological perspective, whereby individuality, competence, and independence serve as an underlying ethos (Bell, 1994). TEM considers the concept of unity as its ontological perspective. Unity can be described as the facilitation and maximum attempt toward whole group or community success. For educators, unity would be conceptualized as the manipulation of curricular elements within the classroom. Unity would symbolize a connection between people, perspectives, and cultures in ways that would translate into an environment, where certain academic and social behaviors are prompted by the acknowledgement of diversity (e.g., race, class, and gender differences). The richness and varieties of knowledge are then used to ensure connections, which would promise classroom learning through a classroom character culture.

According to TEM, curriculum development begins with recognition of existing differences within the community. With student assessments, teachers should now have a sense of direction. The next objective is then to initiate the process of unifying student with shared opportunities for success. Within the classroom context, TEM would describe unity as the strategies used to balance the scales, level the playing field, and demonstrate an earnest attempt to offer participants opportunities to experience success. At the stage of unity, the intent of the facilitator is on public display and the meta-value is more clearly understood. Applied in the classroom, as an example of unity, Hunt's model would encourage unifying strategies such as the use of culturally conscious texts that (a) represent various student perspectives, (b) speak to the 
experiences of the students, and (c) address the students from an insider's view. These experiences create texts that reflect students' identities, their aspirations, struggles, and realities (Blake, 1998) with teachers' instructional delivery and classroom decor is as part of that text. Therefore, the text not only includes pieces of literature for student reading, but also everything the learner is able to read within the classroom community (Schubert, 1997). Consequently, the classroom or community text is a more appropriate way of conceptualizing the text.

When students are able to see stories of their own lives in the text, they are able to experience the kind of exchange necessary to begin building student-text relationships, and make critical reader-responses (Rosenblatt, 1978; Spears-Bunton \& Powell, 2009). Appropriate responses or interpretations to texts can be strengthened as teachers develop an awareness of the learners' background knowledge and set the information of the text in the lives of the students. This implies that teachers' curricular choices reflect a sense of the possible links between the classroom and the students' past experiences and present level of emotional maturity (Rosenblatt, 1995). Teachers would then be required to become more conscious as educators of their students' environments. Since teaching strategies are among the elements of a curricular framework, unity would warrant that teachers employ methods of instruction that match students' learning styles with the understanding that not all students will experience success in the same way or to the same degree. However, every student will be afforded the same opportunities to achieve success. Summarily, unity would be represented by strategies used within the classroom context to create a forum for success.

Other strategies, besides the use of culturally conscious text, may also manifest in the form of questioning, where the instructor may elicit first the most basic facts and grow into complexity as far as the students can reach. This requires conveying basic background 
knowledge and literary codes to ensure the necessary schema for advanced levels of critical thinking. In the questioning process, students' responses are elicited, which enable educators to know the depth of readers' engagements and connection. Allowances are made for peer group discussion as students struggle to listen to each other and the text. Such dialogic experiences provide students with a sense of agency and allow students to take from the verbalized contributions of their peers and build on their own understandings of the content.

At the final stage of the technique, known as community, members evidence an expanded vision unlike diversity, where individuals operate out of their own perspectives, and their individual perspectives became the basis for their analyses of themselves and the world around them. Now with the aid of a mentor, individuals are not only catapulted into a more inclusive vision of society, but are also equipped to manage conflict and bridge cultural gaps. In the classroom, community can be viewed as the highest level of existence, where both teachers and students can coexist as a cohort of successful learners. 


\section{CHAPTER III}

\section{RESEARCH DESIGN AND METHOD}

\section{Purpose of the Study}

The research problem addressed by the present study is related to classroom cultures initiated by particular instructional practices of classroom teachers. In some cases, such environments may pose social and academic classroom realities wherein dissonance exists between the culture of the learner and the common ideological culture of the traditional American classroom. This phenomenon seems to relate directly to teachers' management of the classroom space. The present study examined how within the classroom space, six teachers had particular experiences as they found themselves at one point or another along a character education pathway, Goma 7-Step pathway. Additionally, the study examined how these teachers employed particular instructional practices while attempting to compose a meaningful and purposeful classroom community text in which a classroom character culture would be fostered and sustained. Also described in this study is the use of qualitative research that allowed the six teachers to share their classroom experiences after they had undergone professional development in Goma curriculum, a culturally responsive pedagogy for character education. Moreover, the study described the use of secondary data within the qualitative domain, a growing research trend (Clemons, 2008; Corti, Witzel, \& Bishop; Van den Berg, 2005).

\section{Research Questions}

Toward that end, the present study examined the following questions:

1) What kinds of experiences were teachers having as they progressed along the character education pathway of Goma curriculum? 
2) What opportunities did teachers' instructional practices provide for creating a character culture in their classrooms?

\section{Research Design}

In order to explore teachers' classroom experiences that followed character education training in Goma curriculum, the present study used secondary qualitative data drawn from the research archives of DOR Foundation, a local non-profit organization which provides programs dedicated to character education, community building, and economic development within underserved communities.

The tradition of drawing from secondary data is more commonly used in quantitative research with large data sets. However, more and more, this tradition is gaining acceptance in qualitative research, as well (Clemons, 2008; Corti, Witzel, \& Bishop, 2005; Van den Berg, 2005). Clemons' research, examining Hip Hop as culturally responsive pedagogy, for example, found secondary data to be useful in that it allowed him entry into the lives of hip hop pioneers to which he would otherwise not have had access. Despite its growing acceptance among research scholars, there yet remains some skepticism regarding the use of secondary data within the qualitative domain. A primary concern among critics of the use of secondary data within the qualitative domain is whether data can be analyzed outside of an in-depth knowledge of both the research and social context from which the data were derived. To address this issue of context, Van den Berg (2005) offers a set of minimum guidelines in the form of six propositions for what information should be made available on behalf of secondary data analysis of qualitative data. Specific information includes (a) the interaction between interviewer and interviewee, (b) detailed transcriptions of the interviews, (c) background information of both the interviewer and interviewee, including age, gender, race, and social class, (d) the setting of the interview (i.e., 
time and place), (e) how interviewees were selected and how they were encouraged to participate in the research, and (f) a discussion of other important individuals whom the interviewee knows (i.e., other interviewees and administrators). The present study addresses each of the six propositions throughout the various sections of this chapter. While the transcribed interviews of the original study are not provided in the present study, the teacher talks can be obtained by contacting the appropriate agency noted on the interview protocol (see Appendix A).

The use of secondary data analysis is applicable to the existing study, in particular, because it helps to serve as a buffer against what biases the researcher, in this case, a teaching professional, may bring to the data collection process. The notion of researcher as instrument, a premise in qualitative methods, means that these biases would always have to be monitored. The researcher is never a pure scientist, in control of the research process, but rather is a subjective fieldworker, who brings with him or her lived and cultural experiences that manipulate the researcher's position in the process of the research (Kleinman \& Copp, 1993). Ignoring this reality may ultimately impact the researcher's analysis. The use of secondary data may temper some of these concerns. In the case of the present study, the researcher is able to step back and see into the narratives emerging from the data. From this perspective, the researcher attempts to determine what ways the six participating teachers see Goma curriculum as meaningful in the context of their classroom realities. In fact, the use of secondary data adds to the profundity of the present study in that this data can be used to expand the literature on character education methods and training for teachers as revealed by the stories of the teacher participants.

\section{Participants}

The participants, all African Americans, included a panel of six teachers who taught at various levels that ranged from elementary through high school across diverse content areas. The 
present study described the teachers according to the teaching posts they held at the time of the original study. Lequita, for example, was a general education elementary school teacher of third and fourth graders. According to transcripts, she is shown to be the most verbose among the teacher participants. Smooth, the only male teacher among the teacher participants, was a high school social studies teacher. Goma Diva and Lady A were both middle grades language arts teachers. Max was a middle school special education teacher, who worked primarily with special needs students teaching language arts, science, and math. Kim was an early career inclusion teacher, whose role was to ensure that her special needs students received modified instruction within regular classroom settings. Two of the teacher participants, Goma Diva and Max, worked at the middle school where the study was conducted, and both were familiar with the students in the program. The other teachers were from neighboring counties throughout southwest and middle Georgia. As part of the teachers' responsibilities in working with the youth Summer Institute, these teachers were required to participate in the teacher talks and self-reports used for this study. The teacher talks and self-reports were part of the program evaluation component of the Institute.

\section{Setting}

While the summer program is an initiative of the DOR Foundation, it is hosted by local organizations, which like the DOR Foundation share a character-based mission to help young people become empowered to their fullest potential within their respective communities. The host organizations are viewed as a valued stakeholder and they are allowed input into the curriculum by sharing what character traits are most relevant to the needs of each specific community. These character traits become emphasized within the curriculum to which teachers and students are exposed. Wilson (2000) refers to this curriculum development mode as a home- 
grown model for character education, and has shown that efforts to engage stakeholders in this way are productive in helping to sustain character education programs. Each year, the summer institute engages 100 - 160 middle and high school youth in Goma curriculum activities, emphasizing character-based lessons and certain community building values. Due to discrepancies in the capacity of each community to sponsor the program, there are differences in the number of student who participate in the summer Institute program. The summer program operates much like a traditional day school program (e.g., breakfast and lunch programs, transportation services, grade-level divisions, and expectations for classroom set-up).

Each student was enrolled in a character education class during the first three hours of the morning. In the afternoon, students are enrolled in an elective class, one of four selections of performing arts: drumming, drama, singing/rap/poetry, and dance. Each of the participating teachers, referred to as Goma educators, taught one of the character education classes for three hours of the morning. Their classes were separated by grade-levels and their lessons were prewritten; however, they still had the opportunity to make adjustments in the lessons based in the teachers' professional judgment. Each day, the character-based lessons had a focus that related to the Goma 7-Step pathway beginning with goal, objective, method, and progressed all the way through to discipline.

\section{Community Profile}

The particular community of interest, from whence the present study has drawn its research data, is located on the west side of a mid-sized town in South Georgia. Formerly a United States Congressional designation as one of only 10 rural empowerment zones in the United States, this community has a population of approximately 12,000 residents with a household median income of nearly $\$ 11,000$. Despite the town's designation as a rural 
empowerment zone as a highly distressed community, this community reflects socioeconomic and political structures that pose similar challenges of any economically disadvantaged and underserved urban community. What made this community ideal as a research site was its summer character education program that comprised an exhaustive teacher education program rare among many character education programs.

\section{School Profile}

Both the middle and the high school where the student participants attended are both heavily populated with African American students. In the case of the high school, $60 \%$ of the students are African American; however, close to 95\% of the instructional staff are White, with similar racial/ethnic proportions at the middle school. The setting for this Institute is at the local middle school. Perhaps the outcomes of the present study are impacted by the fact that all the teacher participants in the present study are African American and the overwhelming population of student participants is primarily African American, as well. However, the racial/ethnic student teacher ratio as a contributing factor in initiating classroom culture was not a focal point of the present study. Therefore, the significance of race and ethnicity cannot be determined.

\section{Research Data in Program Evaluation}

As earlier referenced, DOR Foundation is a local charitable organization dedicated to creating, promoting, and supporting a diverse range of community-based activities aimed at improving the quality of life in three program areas: character education, community building, and economic development. Programs of DOR are designed to strengthen and provide opportunities of hope for youth and families in under-served communities. Each year the local agency, toward the end of tracking its program's progress engages in evaluation procedures. The resulting data are shown as part of the outcomes of DOR's program evaluation and are used to 
determine program areas of strength, weakness, and opportunities for improvement. Moreover, the data provide a basis to support the organization's mission to use character development as a lever to positively influence the way in which at-risk youth are educated. The department of DOR, charged with program evaluation, gathers data that include both qualitative and quantitative inquiry. These are done through the following: (a) teacher talks sessions, (b) teachers' self-reports, (c) student surveys, (d) observations of teachers and artists, and (e) focus group interviews of students.

\section{Teacher Education}

The report on what works in character education conducted by Character Education Partnership (1995), where 33 character education programs were identified as scientifically sound, found that all 33 programs engaged in professional development. It was determined that the professional development component contributed to the long-term effects on students both in middle and/or high school, and even into early adulthood years. Clearly character education training is essential for teachers, particularly those teachers of high-risk students, who are often said to be in most need for character development. Chase (1999) called for the building of a "moral" climate in schools with efforts that include the infusion of character education into both curricular and extra-curricular activities, as well as teacher pre-service and in-service education. Along the same lines, DOR subscribes to the notion that professional development on Goma curriculum must be a central focus of their efforts.

The lack of substantial professional development for teachers prior to program implementation has been a weakness in some character education programs (Wilson, 2007). Wilson's study examined a school-wide character education initiative that had evolved first through home-room/advisory time, and was eventually integrated across the curriculum into all 
subject areas. As expansive as the initiative was in touching every aspect of the school, professional development efforts were scant. The staff received their character education curriculum guide just after returning to school from summer break. The committee who helped with the development of the program spent a total 30 minutes explaining to the teachers about the program. The research conducted by Wilson points to the level of significance teacher training is often given in the process of carrying out character education goals as they are stated. Consequently, it becomes difficult to successfully implement character education initiatives.

DOR Foundation considers professional development as a central part of its character education programs. Therefore, individuals who work with DOR'S programs must complete 30 contact hours of professional development, and are certified as Goma educators. Such persons include in-service teachers, artists, and co-teachers, comprising a group of individuals, who work with youth in schools and community programs. The professional development series, with its character-building learner-centered focus, is designed to educate those who work with youth on the philosophy of the curriculum, as well as an extensive overview of Goma concepts. Participants work through numerous exercises that lead to an understanding of Goma curriculum, including instructional practices, and The Ellison Model theory. These individuals are expected to return to their respective schools and job sites to introduce and employ Goma curriculum. As part of the philosophy, teachers learn about being both learners and sharers of knowledge, and are encouraged to take on a dual consciousness of student and teacher. They are then expected to operate from this perspective in their classes with their students.

\section{Teacher Talks and Self-Reports: Data Collection}

Because the present study examined six teachers' classroom experiences that followed their teacher training in Goma curriculum, specific data provided insight to the research 
questions addressed in the present study. Hence, the research data for the present study were generated from transcripts derived from teacher talks and self-reports as data collection techniques. Teacher talks were conducted for 45 minutes after every morning session, which ended at 11:30am each day. Interviews were conducted in classrooms in the same building where the program took place. Classrooms had been identified and isolated just for teacher talks. Each day during the teacher talks, a teacher was alternately paired with another to create four pairs. Because the teachers had taught the same lesson, they were able to discuss their own Goma teaching and learning experiences as they sought to implement Goma curriculum. teacher talks were tape recorded and transcribed by an external transcription company. These transcriptions were submitted to the Office of Program Evaluation and reviewed for content. Unlike traditional interview protocol, where the researcher asks participants a set of interview questions, teacher talks were based on a set of questions that guided the teachers' discussion (See Appendix A). This qualitative method for data collection appeared to be useful in that it was unobtrusive. Additionally, it would seem that teacher talks as a discussion between two teachers would allow the teacher participants to feel less intimidated by the interrogations of a live interviewer.

\section{Data Analysis}

The present study used secondary data taken from the archives of the DOR Foundation. The particular data included transcripts of teacher talks and six self-reports completed by the teacher participants. Both the teacher talks and self- reports were analyzed independently to provide specific information that answers the research questions of the present study. A system of coding based on themes related to components of the Goma framework was employed in order to identify patterns that emerged from the data. After independent examination of teacher 
talks and six self- reports, both were then reviewed in comparison for evidence of parallel or contradicting themes.

Research Question\#1: What kinds of experiences were teacher participants having as they progressed along the character education continuum of Goma curriculum?

To address this research question, the researcher of the present study examined 10 transcripts taken across 5 days ( 2 transcripts per day) of teacher talks, an interview-style discussion between two teachers. The teacher talks provided detailed accounts of the teachers' classroom experiences subsequent to their training in Goma curriculum. The researcher created a three-column chart to code data using both a priori and emergent coding processes. A priori coding was meaningful in that it allowed for the use of the character posts of the 7-step pathway, including objective, method, attitude, behavior, communication, and discipline as the themes for initial coding of the data (Stemler, 2001). These themes were listed in column 1(see Figure 6 on p. 58). The themes are defined as follows: Objective is defined as teachers' knowledge of student learners. Method involves the use of relevant instructional skills or specific instructional strategies. Attitude relates to teachers' dispositions, including perceptions, expectations, and their sense of efficacy. Behavior represents teachers' interactions with students. $\underline{\text { Communication }}$ deals with the messages teachers' behaviors convey and /or how students interpret or understand teachers' behaviors, including their verbal or non-verbal responses toward students. Discipline represents a reflection of a sustained classroom environment of positive character. The actual responses from the transcripts of the teacher talks that related to each theme or 7-Step character post were extracted from the transcripts and were listed in column 2.

The researcher then re-examined the teacher talks for a second category of themes that were listed in column 3 (see Figure 6). These represented the specific kinds of experiences that 
were evident in each teacher's responses. These experiences were identified during a process of emergent coding done through a preliminary review of the data (Stemler, 2001). Prior to formal analysis of the data, the researcher sought to determine what themes might emerge as possible types of experiences teachers were having. Such themes as cognitive, emotional, instructional, and social were prominent in the teachers' responses, and these were the themes used as listed in column 3.

Figure 6: Three column-chart used for coding teacher responses

\begin{tabular}{|l|c|c|}
\hline $\begin{array}{c}\text { Character Post } \\
\text { (a priori coding) }\end{array}$ & $\begin{array}{c}\text { Teacher Responses from } \\
\text { teacher talks that related to a } \\
\text { specific Character Post }\end{array}$ & $\begin{array}{c}\text { Types of Experiences } \\
\text { (Emergent coding) } \\
\text { Cognitive/Emotional/Instructional/Social/or } \\
\text { Blended }\end{array}$ \\
\hline OBJECTIVE & & \\
\hline METHOD & & \\
\hline ATTITUDE & & \\
\hline & & \\
\hline BEHAVIOR & & \\
\hline & & \\
\hline COMMUNICATION & & \\
\hline & & \\
\hline DISCIPLINE & & \\
\hline
\end{tabular}

Research Question\#2: What opportunities did teachers' instructional practices provide for creating a character culture in their classrooms?

To address this research question, the researcher of the present study examined six teachers' self-reports, where the primary researcher examined how the teacher participants used the Goma values in their teaching. The present study, however, drew from the teachers' responses found on six self-reports and coded their responses into the following categories: (a) social interaction, (b) emotional appeal; (c) instructional delivery; and (d) cognitive enhancement. For the purpose of the present study, social interaction relates to ways in which 
teachers used Goma principles to manage social interaction or classroom relationships. In examining the data for emotional appeal, the researcher noted instances where teachers made an emotional plea to re-direct students toward positive character. Another theme, instructional delivery, involved: (a) explicit and implicit instructional strategies, (b) management of classroom décor', (c) arrangement of classroom space, and (d) time. Finally, the researcher coded for evidence of cognitive enhancement, instances where teachers used curricular resources and subject area content to make associations to character-based principles. The researcher used (a) social interaction, (b) emotional appeal, (c) instructional delivery, and (d) cognitive enhancement in keeping with the codes used for the teacher talks, which were: social, emotional, instructional, and cognitive. This allowed the researcher to note evidence of alignment between what teachers reported in teacher talks and teachers' self-reports. 


\section{CHAPTER IV}

\section{DESCRIPTION OF FINDINGS}

The secondary data that were examined in this study included (a) ten transcripts taken across five days of teacher talks from six teachers (two transcripts per day) and (b) six teachers' self-reports. The Institute participants were eight Goma Educators, including six full-time content area teachers, one paraprofessional, and one pre-service teacher. Given the discrepancies in experiential classroom points of reference between in-service teachers and the pre-service teacher, as well as the para-professional, one might logically expect vast differences regarding their responses and the interpretations of their experiences. Therefore, in order to maintain valid analysis of the data, the transcripts and self-reports that included the paraprofessional and preservice teacher were not included in the data sets.

Question 1: What kinds of experiences were teachers having as they progressed along the character education continuum of Goma curriculum?

To answer this question, the researcher examined the ten transcripts mentioned earlier. The transcripts were from five days of teacher talks among six teacher participants, who adopted pseudonyms for the purpose of the original study. These pseudonyms are also used in the present study. Each teacher alternated a shared teacher talk session with a different teacher each day. The teacher talks were 30 to 45 minute sessions where teachers interviewed each other in pairs (See Appendix A). This discussion style format was set up to allow the participating teachers to feel comfortable in sharing their classroom experiences, and be unencumbered by the power dynamic that is sometimes created in traditional interview style. The present study included an analysis of teacher participants' classroom experiences that were reported in the transcripts. Using the teachers' reported experiences, it was determined at what character post the teachers were 
positioned along the Goma 7-step pathway (Goal, Objective, Method, Attitude, Behavior, Communication, or Discipline). Next, the researcher created a three-column chart to include the character posts, teachers' reported experiences, and the type experience that was reflected in the teachers' comments (See Figure 7 on p. 62). Teacher participants' character-based responses were drawn from the transcripts and captured in the second column. The responses were organized according to their related character posts. For example, the first character post was Objective. The framework of the 7-Step pathway begins with G or Goal, and therefore, it would seem that the analysis would begin at the Goal character post. In Goma curriculum, however, the "Goal" of a classroom character culture is pre-determined prior to the arrival of the teacher. The expectation of the teacher is to carry out practices toward achieving the established goal. These instructional practices are launched at the Objective character post. The analysis of the teacher talks began at Objective, as well.

After reviewing the teacher talk transcripts, the researcher extracted all the responses that indicated an Objective experience; these responses were written in column two. The subsequent character posts were done the same way, extracting those responses from the teacher talks transcripts that reflected that particular character post. After organizing the responses according to their related character post column, the researcher used a third column to note the teachers' responses as a description of one of the following categories: (a) Social, (b) Emotional, (c), Instructional, and (d) Cognitive, which represented the kinds of experiences the participants had in their classrooms.

The chart was separated not only by character post, but also by experience types within each post. For example, some responses showed Objective with cognitive experiences while others may have shown Objective with social experiences, and so on. Because not all teacher 
responses that were found within a certain character post reflected the same type experience, the researcher examined the chart within and across the various character posts and discussed the emergent themes within each section.

In the next section of this chapter, a robust discussion ensues and provides an analysis of what was reported by the transcripts of teacher talks as they were categorized on the researchergenerated chart. The succeeding themes drawn from the analysis are used for (a) painting a picture of the kinds of texts that emerge within the classroom and (b) developing an understanding of how Goma curriculum as a character education framework might have tremendous impact on teachers and a resulting impact on their classroom environment. The analysis of participating teachers' experiences, as indicated by their responses, is described comprehensively based on: (a) unique characteristics found at each post (e.g., type experiences, frequency of experiences, related themes and (b) similarities and differences among the teachers' responses within and across themes. Discussions of how The Ellison Model as a theoretical framework is used to explain what is being observed within the participating teachers'

Figure 7: Sample Coding

\begin{tabular}{|c|l|l|}
\hline Character Post & \multicolumn{1}{|c|}{ Character Based Experienced } & Type of experience: \\
\hline OBJECTIVE & $\begin{array}{l}\text { (Goma Diva) And one student- she was going through there } \\
\text { and she's always been, since we started, very quiet and } \\
\text { reserved...didn't say too much in class. I had to almost force } \\
\text { her to talk to me. }\end{array}$ & Cognitive \\
\hline & $\begin{array}{l}\text { (Max) They're not as verbal as I would like them to be, and I } \\
\text { don't know why because I told them you're free to talk, you } \\
\text { can communicate, you can hook up with a partner in class, } \\
\text { and you can work with a partner, you don't just have to sit }\end{array}$ & Cognitive \\
\hline & $\begin{array}{l}\text { (Kim) And the students feel that way too. They feel like they } \\
\text { can express themselves. You know, in a \{inaudible\} way, they } \\
\text { feel like, okay, I'm with my friends I can chill and talk like I } \\
\text { want to. }\end{array}$ & Cognitive \\
\hline
\end{tabular}


responses is reserved for Chapter 5 as part of a comprehensive summary of the teachers' experiences.

\section{Character Post: Objective}

Goma curriculum framework defines Objective as teachers' knowledge of students (Goma Curriculum Handbook, 2007). With such emphasis on knowing subject area content as shown in the research (Carpenter, Fennema, Peterson, \& Carey, 1998; Croninger, Rice, Rathbun, \& Nishio, 2007; Hill, Rowan, \& Ball, 2005), a review of knowing the students would likely provide great insight, especially as it relates to ensuring a particular classroom culture, one in which the students can interpret as character-driven. The Ellison Model framework, namely the technique Diversity-Unity-Community, points to the necessity of knowing the students since they are the primary focus for which teaching and learning occurs. The most frequently noted experience among teachers at the Objective character post was cognitive, with instructional occurring just slightly less frequent. Hardly any of the teachers' responses evidenced signs of a purely emotional or purely social experience when at the Objective character post. However, some responses evidenced signs of a blended experience, in which case, multiple experiences were simultaneously noted (see Appendix C).

\section{Character Post: Objective-Teachers' Cognitive Experiences}

Teachers' at the Objective character post appeared to have experiences that were primarily cognitive. These cognitive experiences described teachers' raised awareness, points of understanding, and new discoveries they had, mostly about their students. Teachers' responses within this category revealed a number of interesting themes, including: 
- Knowing student differences,

- Knowing why students behave in particular ways, and

- Knowing how to read students' physical, emotional, and academic behaviors.

Knowing student differences. One teacher, Lequita, for example, described several cognitive experiences while at the Objective character post. These experiences indicated her gaining knowledge of her students at various levels. In one instance, she described an awareness of knowing how certain curricular strategies uniquely impacted diverse student populations. She mused: "I realized it wasn't working-it worked for the boys, but it didn't work for the girls." In another instance, she reported, "I found like with my special child, when he gets bored, I gotta immediately be ready to solve the problem. Otherwise he's going around the room disrupting everybody else." Knowing what worked for the various sub-groups in her class would then allow her to differentiate instruction to meet the needs of both groups: boys and girls, as well as students with special needs. On a similar note, Lequita described knowledge of students' emotional needs. She expressed as it as: "Just also allowing them to be expressive of themselves. When I say that...for example, I have my lovely child that's in my class with me that's always seeking attention. And I realize that." Each of the three responses indicated a level of cognition, where Lequita developed greater knowledge of her students along lines of difference, specifically differences in students' needs. These differences may relate to students' interests, their ways of knowing, and/or differences in their attention spans. In this case, a single text may likely have different interpretations by the diverse groups of readers; or each group may be reading a different text altogether. In other words, the boys, for example, could be reading one text and the girls another. It seems clear that when teachers lack an awareness of the diverse needs of their students, such as those shown in Lequita's responses, this could negatively impact 
teachers' ability to: (a) differentiate instruction, (b) provide maximum opportunities for diverse student groups to achieve mastery of benchmarks and classroom goals, and (c) present a core text that expresses a clear pathway to success for all students.

Kim's response represented another instance of a cognitive experience at the Objective character post. She stated, "There was another student who I honestly think he may have some type of disability because instead of asking for something, he will point to it." In Kim's case, she reported having knowledge of a particular student based on a difference that suggested a possible exceptionality. Another teacher, Goma Diva, though still along the lines of knowing students, spoke less about knowing students' academic potential. Instead she spoke of her students' learning modalities. She commented: "Because I may be an auditory learner and you're a visual leaner...all that can play a role in it also." Here, Goma Diva expressed an awareness of a positive relationship between students' learning styles and academic success. Her recognition of this relationship may play a critical role in the creation of opportunities for student success.

Max was convinced that it doesn't take long before a teacher is able to know their students, specifically their academic limitations. She stated, "You know when you're in that class with that class for 180 days, you know what that child is capable and is not capable of doing just from simple observation.” Interestingly, Max's general comments about observing students offer a number of considerations that can be made for those teachers seeking to learn more about their students. First, teachers are able to make observations of students that include both social and academic behaviors. Further, formal assessment, as a form of observation, is not the only means by which teachers are able to learn about the academic abilities of their student learners. Importantly, both formal and authentic assessment may allow teachers to get to know students in ways beyond their academic performance. 
Lequita, Kim, Goma Diva, and Max all shared unique experiences that described how they learned about their students due to a specific difference found among their respective student groups. What they share as a similarity, however, is the fact that having knowledge of their students would expectedly position them all to make curricular choices on behalf of even the most challenged students, thereby increasing opportunities for success for all their students, and ultimately enhancing the classroom culture.

In one teacher talk session, Kim's comment related directly to Goma curriculum as an aid for understanding students, namely the conflicts that may be embedded in the cultural capital some students may bring. She stated:

So with Goma curriculum, it has taught me that I know kids that are gonna be faced with problems everyday over the course of their lives, it teaches me how to understand their problems, and just focus on the solution more than the problem.

Kim pointed to Goma curriculum as a tool of empowerment to help teachers move beyond emphasizing problems to focusing on solutions. This is profound because the myriad of considerations for student differences often represent wide vectors of conflict, which, unbeknownst to the teacher, could potentially foster a character of exclusion where only select students are successful. In this case, an even greater problem is created, with a total classroom climate characterized by division, a text of "dis-community" (Ellison, 2001). If, in fact, Goma curriculum is designed to facilitate a conflict resolution process, it would expectedly include the empowerment of teachers to know their student learners as a point of origin before meaningful instruction can begin.

Knowing why students behave in particular ways. Teachers at the Objective character post were shown to have had cognitive experiences evidenced other themes in their responses. 
This included teachers' knowledge of why students behave in particular ways. Teachers' comments surrounded discoveries related to student attitudes such as the influence of home life, peer acceptance, and negative prior experience. The experiences they reasoned provided an explanatory note regarding classroom behaviors. Lequita commented extensively about what she learned of her students' attitudes. On one occasion, she responded,

They bring that attitude into the classroom; they are used to being an adult and I even know this, I marked twice during our conversation today that they referred to themselves as adults. But they think they are and it took me back to a conversation that I had yesterday about cell phones. 'If I buy my own cell phone my mom has no business reading what is in my text messages.' Nobody is really supervising these children so the mom they come into contact with or the father figure they are coming into contact with is us.

What Lequita described may be the reality of many students who often have to navigate between divergent physical spaces of home and school, and perhaps the developmental spaces of adult and child as well. In this instance, Lequita learned that this particular student was, in fact, leading the life of an adult, and possibly had adult responsibilities. In general, it may be that many students have similar responsibilities as adults. At school, however, these same students are expected to behave as non-adult learners. This could make classroom management challenging for some teachers, who, for example, may seek to modify student behaviors as one would a child developmentally and in every-day experience. The student, on the other hand, could conceive the teacher as being disrespectful of his or her independence as an adult. In this case, the teacher may need to alter classroom management to a style more suitable for adult students trying to learn in a child's chair. Students' perceptions of themselves as adult learners might also require 
teachers to adjust their instructional strategies, as well, since teachers would obviously employ different teaching strategies for adult learners than for younger students. Lequita seemed to recognize how some students may have to wear what W.E. DuBois (1908) called a "double consciousness" having to be one person at home and another at school. Lacking an understanding of students in this way could cause rifts in student learning, as well as the social environment of the classroom.

Conversely, knowledge of students' attitudes and possible contributors to these attitudes is likely to allow teachers to plan, teach, assess, and manage the classroom space in ways that will tend toward maximizing positive relationship building opportunities between students, teachers, and the curriculum. With positive relationships, teachers can expect a much more desirable text than one in which teachers ignore, or are not aware of student attitudes. Knowing student learners, in particular their attitudes, coupled with appropriate pedagogical responses, would seemingly diminish classroom divides. It would seem that this would also contribute to the progression of a more inclusive classroom environment.

Goma Diva, on the other hand, found that some students behave in particular ways because they want to be accepted by their peers. She reported, "So most of it is more peer acceptance. He actually understood the concept but he is still a work in progress. That's what it is. He said he didn't want his friends to dislike him." Goma Diva's comment offered useful insight to classroom teachers. Knowing how peer acceptance affects some students may allow teachers to reach those students who may be reluctant to share or even make certain unpopular social and academic responses. Smooth reported that he recognized that some students share negative histories that may under-gird many students' responses to themselves, their peers, and 
their teachers. Smooth described how one of his students had been labeled prior to coming to his classroom, and according to Smooth, the student was blatant in his ill-regard for teachers. Smooth reported:

And he knows he's been labeled because this is the same child who said to me yesterday, 'I don't like teachers, I don't like none of these teachers. Well he actually said crackers, but we had to deal with that too. 'I don't like none of them up here,' he said 'I don't know any teacher that has been good to me.' It's hard for him because he has been licked into - he's been labeled, he really has. That has an effect on children too. I don't think anybody related to him, has actually taken the time.

The student in Smooth's comment described a history that did not involve Smooth. Yet, what was a part of the student's past had now become a present reality, not only for Smooth, but for the other students, as well. That is, the experience of this student had created a dynamic that, unaddressed, could have a negative impact on the classroom environment. As Smooth stated, "we have to deal with that too," which suggests that he acknowledged a capacity to assist the student through some of his frustrations and disregard for teachers. In so doing, the community of successful learners is enlarged.

Knowing how to read students' physical, emotional, and academic behaviors.

Teachers not only evidenced cognitive experiences that pointed to why students might behave in particular ways, but teachers' responses included an acquisition of knowledge of student behaviors as indicators that speak to their feelings about something they are experiencing, in some cases, right there in the classroom. In other words, student behaviors may be a direct response to the classroom text they may be reading at that very moment. Teachers who, in turn, are skilled at reading student behaviors may be surprised to find what messages underlie their 
students' behaviors. The underlying messages of student behaviors might encourage teachers to become proficient at reading student behaviors that may sometimes manifest themselves on physical, emotional, and academic levels. Max, for example, described how student behaviors may be a reflection of teachers' instructional quality. Max reported, "They do evaluate us informally. I think we just tend to overlook that fact saying that this child is sleepy, or this child wants to go to sleep...when it may be us really. It could be." In her statement, Max referred to a child being sleepy as an insinuation of the teacher's instructional quality, or at least the student's interest in the lessons. Lady A concurred with the sentiments of Max and stated, "I think they non-verbally evaluate us all the time, like with their gestures, slumping over, putting their head down. Sometimes they'll just plain out say, 'This is boring."' Both teachers agreed that the sleeping/sleepy or un-attending behavior of students could possibly be sending messages to teachers about how engaging or interesting the teaching is to students. According to Max, teachers often ignore messages such as these. Interestingly, teachers may seek to modify the student behaviors without modifying the instructional practices that engender such behaviors.

Lequita found that sometimes student behaviors are motivated by something that is impacting the students emotionally. Therefore, emotional behaviors are also tell-tell signs that teachers should be able to read. She stated:

My kids came into my classroom this morning in grief. And they were mad because of the talk that had occurred this morning in the cafeteria, which I knew the students would probably- some of them would be a little be a little frustrated - but they came in really angry, quite a few of my kids did. And as a teacher and as a GOMA instructor, it's important to pay attention to the moods of your children.

It may be that the emotional state of the students Lequita described affected their readiness to 
engage in an academic lesson. Lequita argued that perhaps teachers should pay attention to their students' frame of mind before lessons can begin. Otherwise, the issues may escalate into major problems that might spill further into the class period. In this case, students' involvement in the class activities and the overall classroom environment may be in jeopardy.

Lady A shared how she learned much about her students by observing their academic behaviors or responses. She reported: "This gave me time to go around and discuss with them about themselves, find out who they were, where they came from, by just looking at the things that they were deciding to put in their 'Me' book." In an exercise where students got to share aspects of their personal lives, Lady A viewed this not just as an academic exercise for her students, but she also capitalized on an opportunity to learn more about her students.

Just as Lady A did, Smooth recognized that students' academic responses and behaviors can provide important information about themselves. In one setting, he described how students responded to an academic exercise that obviously involved reading and writing. $\mathrm{He}$ stated:

They weren't feeling it simply because they were tired already so the last thing they want to do is read through a poem and talk about [or] discuss; and they did not want to write either. They didn't want to write in their reflections book.

In this instance, Smooth would have had to make some impromptu decisions in order to pique the interest of his student learners. This may have required him to modify the lesson to some degree. If Smooth is unable to read the responses of his students, and make the necessary adjustments in the lesson, he may be responsible for composing or at least presenting a narrative that counters the classroom text of which he intends. Further, Smooth may then find himself in an undesirable position where students might blatantly resist instruction, and may even 
completely withdraw their membership from the learning community. Should this happen, the community of achievement could be placed at risk.

\section{Character Post: Objective - Teachers' Instructional Experiences}

Some of the teachers' responses at the Objective character post evidenced instructional experiences. Teachers at the Objective character post who had instructional experiences made responses that indicated experiences with instruction that contributed to their knowledge of the students. While the teachers' responses that evidenced objective-instructional experiences occurred notably less than those indicating cognitive experiences at the same post, these instructional experiences gave rise to some important themes, including:

- Knowing how to present subject area content, and

- Cues for knowing when to make instructional adjustments.

Knowing how to present subject area content. Goma Diva, for example, talked about how that sometimes subject matter content presents a harsh reality for the students. She stated: "The main thing is basically about do you know your subject, and can you tell someone else that subject and different things like that where it doesn't focus on the child's feelings and values." In this instance of her instructional experience, she acknowledged the importance of presenting the subject matter in a manner that is not condescending or hurtful to the feelings of the students. Again, this would require that teachers have some knowledge of the lived historical and cultural experiences of their student learners. To what extent teachers understand the interplay between instruction and knowledge of the students might be determined by teachers' preparations as classroom educators. On this topic, Goma Diva commented:

I think the information I know about teaching comes from getting my degree in education. My childhood experience as a student in the classroom - sometimes we tend 
to mimic what we've seen. As far as the content or the strategies that I learned going through the teacher education, I think it's much different from what I've learned in the Teacher Education Academy. Going through the education department, they mainly teach about content. Know your content, and they give you some strategies for how to teach this content.

Goma Diva's commentary may be viewed as an indictment against some teacher education programs, where content knowledge and subsequent instructional strategies are emphasized, without a preceding knowledge of student learners or without evident use of this knowledge in teachers' instructional practices. This perhaps should raise questions about whether teachers are having instructional experiences without ever engaging students in meaningful learning experiences. The relationship (between teachers' instructional experiences or practices and knowing their student learners) may impact other classroom relationships, as well. If, in fact, the two are disconnected, this could potentially have an adverse effect on the classroom environment, where the teacher, by way of instructional practices may be initiating academic and social divides.

Cues for knowing when to make instructional adjustments. Both Lady A and Lequita shared their thoughts on instructional experiences in relation to knowing their students. Their comments pointed to cues that may reveal instances when teachers may perhaps need to make an adjustment in their instruction. Lady A reported:

They [the students] might not know it. They don't know what they're saying, or what they're doing, but I think that's something that we can pick up on, and take that as a cue to know that we need to do something different; change it up, or when we're not reaching the masses, or what have you. 
Lady A's comment points to how teachers, in the midst of instruction, may find that adjustments have to be made, sometimes by modifying a strategy or by clarifying information presented already. Knowing the student learners and being able to read their cues would seemingly help to ensure that the community of successful learners continues to flourish. Along the same lines, Lequita described her own instructional experience where she recognized one of her student's needs. She stated:

But it can be challenging and you gotta be quick. Some things I had to think about it and process it. If I approach him this way, this is what may happen because it's a different type of child I'm dealing with. He's not like the rest of them.

Lequita's account provided descriptions of challenges that sometimes go along with being in the midst of instruction and at the same time, the specific needs of the students may arise, unexpectedly. In which case, it helps to be quick, thoughtful, and mindful of how to modify instruction in keeping with the students being served.

\section{Character Post: Objective-Teachers' Multiple Experiences}

In some cases, teachers who were at the character post of objective seemed to have multiple experiences simultaneously. For example, some teachers expressed cognitive experiences as well as social. One such instance was Lady A, who recognized the importance of knowing her students on an individual basis. Hence, she would establish connections through verbal praise for students who may have needed that kind of reinforcement.

But kids at the age, you kind of have to know the individual kid. They don't want all eyes on them. I actually did praise the young lady today, but I just did it individually. I didn't bring attention to her. 
Max also recognized:

Then, with that sometimes too, there are some kids that are just so hungry for that attention; for you to just keep praising them and keep praising them. You're right; at this age, you kind of have to know your students. If you don't know your students, then you can find yourself in a very awkward position when you're dealing with that praise; individually, when to do it in a group, how much am I giving, or do I need to pull back some? That's true with these middle schoolers because they're transitioning. They still want to be babies, but they want to be grown too. They just don't know; we don't know on what day, Oh, you want to be a baby today, or, you want to be a grown [up] today? What day is for you, you know?

The combination of Cognitive and Social experiences at the Objective post might position teachers to use what they know of students to determine the most suitable means of engagement with students.

Another teacher's response reflected a direct and perhaps interdependent relationship between cognitive and social. Kim reported, "Now that I know them, I can relate it to each student better." In other words, once she learned her students, she was able to witness improvement in her ability to make teacher-student connections. This tells us a lot about the importance of learning students and subsequent decision making. The ability to make other connections (i.e., student-student; student-to-curriculum) might well rest on teachers' knowledge of the student. From this we are able to see teachers in their role as conflict resolvers, a key element of character. 
Lequita also described a cognitive experience, where she learned about her students through student-teacher engagement while in the process of social interaction with the students. She reported:

They were sharing with me things like they drink alcohol, I said, 'First off, where do you get alcohol?' They were telling me about parties in the neighborhood, and what they do at these parties. These are middle school to high school aged children. That right there tells me there is parent neglect. They are not getting the right attention.

Lequita's response offers an understanding that distant relationships between students and teachers may minimize teachers' opportunities to know their students both inside and outside the classroom. It would seem that social interaction and cognitive are inter-related, or at least, they collaborate as a single opportunity for teachers to gain knowledge about their student learners.

In summary, the Objective character post examined teachers' responses that dealt with the notion of teachers getting to know their students. Perhaps, this might segue into teachers presenting instructional strategies based on what they've learned. The next section addresses the Method character post, where teachers reported actual experiences during their instructional delivery. Teachers' responses at the Objective character post describe how instructional methodology can be viewed within a character-centered framework.

\section{Character Post: Method}

Following Objective is the Method post. Within Goma curriculum framework, Method involves the use of relevant instructional skills or specific instructional strategies (Goma Curriculum Handbook, 2007). Some may challenge whether the notion of Method as a general concept has significance as part of a character building paradigm. However, when 'relevance' is factored into the concept of Method, then Method takes on new meaning. Underlying Goma 
curriculum framework is the idea that the integration of 'relevance' within instruction creates a particular kind of pedagogy of Method that shows a willingness on the part of the teacher to meet students where they are. This would involve meeting students within the familiar space of their cultural capital and activating their ways of knowing, and their ways of understanding. In essence, attaining relevance requires that teachers have, metaphorically speaking, visited the homes and the lived realities of their students. In practice, teachers' instructional strategies would then extend to students as a bridge to connect them to the concepts of the curriculum. Goma curriculum views the teacher's willingness to extend him or herself in this way as a gesture of character, suggesting that when the teacher is not reluctant to meet the students on the students' turf, the teacher demonstrates that she places value on the student as worthwhile. For this reason, Goma curriculum presupposes that teachers are able to achieve success at Method through a demonstration of Objective. In other words, when teachers know their student learners, they are better positioned to tailor instruction to meet the diverse needs of their students.

\section{Character Post: Method-Teachers' Instructional Experiences}

With the very nature of Method relating to relevant instruction, when viewed within Goma curriculum paradigm, it stands to reason that teachers who landed at the character post of Method describe Instructional experiences as the most predominant experience. Additionally, it also lends understanding for why relevance resonates as a major theme in teacher talks. Teachers' responses within this category revealed themes involving topics surrounding relevance, including:

- Strategies for ensuring relevance (i.e., role-playing, group discussions, movement, and the use of real-life experiences), and

- Instructional Patterning. 
Strategies for ensuring relevance. Smooth offered an example of integrating relevance in his instruction. He described how relevance allows teachers to extend their teaching to new levels of instruction. He reported:

I think it would help the teachers to take a different approach away from traditional teaching, meaning that - and one of the other educators brought up an excellent point in regards to you to have to make it relevant to the student, not just relevant to the student, you have to put it in perspective in regards to what are you dealing with. So I took it to another level and brought something that's relevant to them, same type of- not same scenario, but the same morals and concept.

His comments suggested that relevance may fill gaps that traditional teaching may not address. Furthermore, he explained how he was able to still draw the concepts out of the prescribed curriculum yet in ways that students could relate.

Some teachers' responses addressed the importance of making sure that relevance was a key feature of their planning. Kim, for example, communicated, "I specifically used that time to go over all the readings in attitude and behavior books to make side notes for the discussion that I could bring up in class and make sure it's relevant." It would appear that Kim recognized that ensuring relevance is an instructional skill that must be cultivated and certainly factored into the planning process. Her comment also suggested that not all teachers have the same level of teaching aptitude. Further, not all see themselves as proficient as others in the area of relevant pedagogy. Max is one who expressed challenges with teaching in a way that students could relate. She stated, "I can see myself improving upon having more movement in class; making it more relevant to the child, you know, thinking about the environment of the class." By Max's own testimony, she needed improvement in this aspect of teaching. 
Other teachers' experiences showed that there are multiple strategies for ensuring relevance. One such strategy is through role-playing. Lequita used role-playing variously in her teaching. She stated, "The highlight was when we did the skit that we did for our group. We did a skit surrounding behavior; today's topic was behavior. They had to think of a sitcom that everybody pretty much had seen." The students' enactment of the sitcom alone did not ensure relevance; however, when she used a familiar sitcom as part of her lesson, the presence of relevance in her teaching was more pronounced.

In another instance, she used role-playing, only this time prefacing the role-play with a discussion about the concept, whereby the role-play could be used to further drive home the point of the lesson. Lequita commented:

And so instead of opening it up the way that I had intended to open, which was using the article of character. I was gonna have a couple of students to act out the section of the article of character that we were talking about. We actually had to go into a talk about communication. What is it that she was trying to communicate to you? And why is it that she had to communicate those things to you?"

Lequita's use of role-play, even in this case, was still used for the purpose of ensuring relevance. However, in this instance, role-play was not used to initiate relevance, but to support it where role-play came after the discussion. In other words, relevance was captured in the discussion. From this, we see how role-playing, following discussions, could be used to underscore what was presented through class discussions, giving students another opportunity to interact with the information to deepen their comprehension of the concepts at hand.

Interestingly, Lequita's use of role-play as an instructional strategy for ensuring relevance was not limited to teaching academic concepts. She reported: 
I mean, I even had to demonstrate with one of my students where one of the teachers spoke to him - it was actually Mark. I had him to sit, and we re-enacted what happened in the cafeteria that morning, and I said to him, 'What were you communicating by sitting in your seat like this?' And that led back into what we were supposed to have been learning at that time.

Even when teaching appropriate social behavior, as a behavior modification technique, she used role-playing as a tactic of relevance to convey points to her students in ways they could understand. In this case, the strategy of role-playing appears to be an effective instructional tool whether to lead-in, to complement other resources (i.e., familiar sitcoms), to underscore relevance for helping ensure retention, or as Lequita has described, to redirect behavior.

Lady A also used role-play, but unlike Lequita, who engaged the students as part of a skit, Lady A was the sole character. She reported: "Then I asked them based on the way I entered the classroom, what kind of attitude do you gather I have based on my non-verbal communications with you." What made this role-play activity relevant was the use of an experience to which students could relate, and also the fact that she allowed the students to create the meaning of the role-play.

Besides role-playing, other instructional strategies were used to ensure relevance. Several teachers, for example, reported experiences of group discussions to help achieve relevance. The use of group discussions seemed to allow teachers to situate whatever concepts are being taught into the interest of the students. Kim reported, "So as just a group we just discussed how GOMA can play an important part of a problem." Kim's engagement of the students in discussions allowed students to see relationships between Goma concepts and problems, where GOMA is presented as a vehicle for conflict resolution. In this case, the teacher used group discussion as an 
opportunity to walk students through a critical thinking process. Goma Diva allowed her students to share in discussion as a means to create a sense of community among her students. She commented: "If I'm asking them to open up to me and to create that atmosphere in the classroom where they feel comfortable to talk and discuss, then I discuss this and I tell them things that have happened to me." Whether asking students questions about what they like concerning some aspect of classroom instruction, or as a means to help activate their thoughts on pertinent issues, the relevant methodology used by the Goma teachers seemed to be useful in providing students with the learning tools for understanding the concepts the teachers presented.

Some teachers seemed to pursue relevance through discussions coupled with other engaging activities. Max stated:

So we actually had an open discussion and that was the first thing that we did this morning to evaluate how we were doing and how the camp was doing, any changes. And we wrote some of the responses down on the board. In addition to teachers being able to assess student comprehension, as well as correct miscues, writing student responses as part of the discussion activity seemed to be a clever means for ensuring relevance. When students' answers to discussion questions are published, they typically take greater ownership of responses (Elbow, 1998). Moreover, it seems likely that students will be more inclined to make further contributions to class discussions. Teachers may then use the students' responses to create a word wall to refer to the points of the discussion at a later time.

As shown in the earlier accounts of other teachers, who alluded to using classroom discussions simultaneously with other kinds of student activities — some activities more so than others - allow students multiple opportunities to interact with the information being taught. In these cases, the notion of relevance is realized and expanded beyond the lived social experiences 
of the students to include the learning styles or academic interests of the students as well.

Lequita, for example, offered an account of how she approached relevance by generating student interaction that involved adding a simple twist of a common activity, the Venn diagram. She arranged students in circles and the students, themselves, became the graphic organizer. She shared:

That's interesting you said that because one of the activities that I did. We're trying to make it more interactive because usually when children see Venn diagrams, the circles that interlock, because we use them so much in the classroom, they get, 'Uh. Oh, God, getting ready to do this again. It's work.' So I have them to get in a circle and I use the little - I went back and bought the hairy ball. It was $\$ 10.00$ for real. But I went back and I bought the hairy ball and it was just the mere fact of us throwing the ball back and forth to each other. It got them to begin to open up and share things with me. So I'd throw the ball to somebody and I basically asked them how do people perceive you and you're gonna start by saying "People see me as... and I threw the ball.

Sometimes traditional strategies may appear hum-drum for students and interaction can be used as an effective tool to pique student interest, thereby enacting relevance as did Lequita. Another example is Smooth, who used a combination of discussion, dancing, and writing to engage students with whatever concepts he was teaching.

They started talking about dancing, so I'm like, "Hey let me show you how to do the Cupid Shuffle." So I got everybody involved. We did the Cupid Shuffle, you know, about five minutes, didn't take too much out of the curriculum. When I need something done on the board, I engaged them. Instead of me writing it on the board, you come up. You write it. 
Smooth's experience seemed to represent the topic of relating to students' lives as a norm for teacher discussions. The notion of relevance is presented specifically, in terms of the lived realities or social experiences of the students. Goma Diva, Max, and Lady A consistently offered examples, where they used real-life examples as an instructional strategy to ensure relevance. Goma Diva reported:

To reach the classroom goals-in order for them to really understand the values that Goma curriculum is offering, I think I provided them with real life experiences. Things that they have heard of or things that have either happened to them, you know, and they're able to take that and use it in the real world.

In this example, Goma Diva used real-life experiences not only to help students understand the Goma values for the purpose of the lesson, but also to enable them to see the relevance of the values for later use in their lives. This approach seemed to add value to the teachers' use of relevance. It not only connected students to the curriculum in the moment of instruction, but it also helped students see the relationships between the curriculum and their future lives. Unlike Goma Diva, Max spoke of relevance as part of a deliberate attempt to help students understand the concept she was presenting at the time. She stated:

And I just tried to incorporate GOMA, my experiences, and their experiences. I tried to also relate today's activity to life in general at home when they're about in the communities. So I tried to make it relevant to them based on whatever they wrote on their nametags, but I was trying to give them examples about how they would react in certain situations.

In this example, Max used her personal experiences, as well as the experiences of the students. Based on Goma Diva's report, this was a different twist on how real life experiences can be 
integrated as part of the lesson. Again Goma Diva's use of real-life experiences seemed to be for a different purpose, namely, toward giving students skills and/or tools to be able to use in the future. The purpose for Max's use of real life examples seemed to have been the connection of students with an understanding of the concepts and/or lessons being taught, and did not seem to have the element of later application as part of her instructional purpose.

Lady A offered yet another presentation of teachers' use of real life situations. She commented:

Like I said before, I like to use real life situations. We were talking about communication. The students know that we communicate verbally. I walked out the door. I came back in, and I slammed the door shut. I didn't say anything. I walked over, slammed my hand down, put my hands on my hips, and then I asked them- because that's something they've experienced before.

While Goma Diva and Max appeared in a discussion format with the students, Lady A incorporated role-play into the lesson, using dramatizations of what she was sure the students had experienced.

Instructional Patterning. Instructional patterning was another theme among the comments of teachers whose responses evidenced an Instructional experience of the Method character post. Teachers described certain patterns that they used during their lessons. Kim, for example, reported how she made it a habit of pausing during readings and related the readings to the students' lives. She commented, "I would stop in the middle of the stories and I would ask them through their life experiences, you know, have you ever gone through this situation" Max, on the other hand, seemed to find a pattern that she was comfortable with presenting the lesson. She stated: 
a little discussion, a lot of engagement, a little discussion, so I'll probably follow the same pattern that I did today with them on tomorrow's discussion.

On the other hand, Lequita's description of her instructional pattern was more of a methodical nature. She reported, "I like to try and explain things step by step and watch things all unfold in front of my eyes."

Some teachers' responses pointed to recap as an instructional pattern in their teaching. Lady A reported, "After we had a three hour morning session, I went back to the Goma values, and the Goma attitudes, and I asked the students, you know, what were the values of Goma?" Goma Diva also mentioned how she recapped previous parts of the lesson, and stated:

We're constantly moving on to something else, but at the same time, we go back and we recap on what they have learned. If it becomes repetitive then, you know, it's going to, you know, stick when they hear it over and over again.

What is interesting in the accounts of the aforementioned teachers' responses was the consistency that appeared inherent in each account. If, in fact, this was the regular format in which the teachers presented their lessons, it seems likely that students might adapt more easily to the teachers' instructional style given the consistent format of the class activities. It is this kind of consistency that seems to allow students some predictability of activity and increasing familiarity with the classroom space.

\section{Character Post: Method-Teachers' Multiple Experiences}

In some cases, teachers' comments that evidenced positioning at the Method character post showed signs of multiple experiences. Most of these instances still carried primarily an Instructional experience. Both Smooth and Lequita both had moments during an instructional experience, where social interaction also played an important role. The following comments by 
Smooth demonstrated the interplay between instructional and social experience of which he experienced. He stated:

So I had a problem with standing my tree up. So I utilized her like an engineer. 'That's part of the job as an engineer. So if I can use you, I will greatly appreciate it if you show me how to do it.' So let her take the lead, and I'll follow her, and she was quick, like, "I don't know how it do. I may mess up." I'm like, "No. Whatever you do, that's what we're gonna do." And through her engineering, our tree stood up.

This account described an instance where his instructional skills were actually dependent on his social skills in order to teach the specific lesson. Lequita's experience was similar in presenting an exchange between instructional and social experiences.

According to the curriculum they were supposed to actually think about something that happened to them in their life, how did they respond to that conflict - they were supposed to write about it in their reflections book and then do the skit. I didn't do it that way. Instead, I started and went directly into the skit and then I had them take a few moments after the skit and we talked about...I asked the kids, “ Okay, judge what would be your sentence upon the defendant" because the defendant didn't win; he lost his case. What would be the judgment for him, how would you sentence him? I was curious to see what they would say.

In both descriptions, teachers coupled the presentation of a lesson with certain interactions with the students. It would appear that in these moments, teachers would be able to increase their opportunities to create an affirming environment both through their instructional practice, as well as social interaction with their students. 
In summary, the Method character post described teachers' responses that dealt solely with the teachers' instructional practices and skills. Found also in the teachers' responses were a number of strategies for ensuring relevance and uniformity in teachers' instruction (see Appendix C). At the next character post, Attitude, teachers reported experiences of all types, including cognitive, emotional, instructional, and social. Based on what their responses indicated, Attitude gives teachers opportunities to reflect on their dispositions toward students' potential, the teachers' sense of efficacy as character educators, and the curriculum.

\section{Character Post: Attitude}

Within Goma curriculum framework, Attitude is defined as teacher dispositions and efficacy, and also includes expectations and perceptions teachers have of their students (Goma Curriculum Handbook, 2007). Based on the transcripts of teacher talks, the overwhelming responses of participating teachers indicated that teachers were positioned at the Attitude character post most of the time. Themes derived from the responses at this character post showed indications of positive attitudes and changes in disposition towards their teaching, their students, themselves, and Goma curriculum, as well.

\section{Character Post: Attitude—Teachers' Instructional Experiences}

The most prominent experience at the Attitude character post was Instructional. Teachers who had instructional experiences described experiences that related their instructional practices in ways that impacted their perceptions of themselves, their students and the curriculum. Some important themes emerging from the transcripts, where teachers' responses indicated a landing at the Attitude character post, where instructional experiences were evident include:

- Attitudes toward teaching;

- Attitudes about flexibility as a feature of effective teaching; 
- Attitudes about opportunities for improvement in teaching; and

- Attitudes about Goma curriculum and its impact on teaching.

Attitudes toward teaching. Both Goma Diva and Smooth spoke of their attitudes toward teaching in general based on their classroom experience with Goma curriculum. To Goma Diva, teaching can be presented in such a way that students can enjoy the process of learning. She reported, "You can make it fun for them at the same time, you know and they're learning." Smooth described his philosophy of teaching and related it to the old adage about teaching a man to fish. He remarked, "I just believe that once - if you teach a man to- if a man's hungry and you buy him food, he'll go hungry again. But if you teach him how to fish, he'll never go hungry." This kind of thinking among teachers seems to require teachers to create a sense of independence in the minds of their student learners, wherein the application of academic concepts should translate into life-long skills. Even more profound is when these skills exceed students' understanding of a few content area concepts, but include a process of critical thinking that can be used across all disciplines. Goma Diva seemed to share similar sentiments. She also spoke of the notion of independent learning that is evident even in the absence of the teacher. She reported:

You know, but now once we give them those skills to be mediators, problem solvers, and a sub comes in there and can sit at my desk, put her heels up and say the class did everything they needed to do because they knew what to do.

In this case, Goma Diva presented specific critical thinking skills: mediation and problemsolving. These might be viewed as the fishing techniques to which Smooth was referring.

Attitudes about flexibility as a feature of effective teaching. Several teachers saw themselves as having to be flexible while teaching at the Institute. In the following comments, 
they described their attitude toward the importance of flexibility as a key ingredient for effective teaching. "Even though I had to switch some things because I felt like I was losing the student. They got what they needed out of it," reported Kim. For Kim, being able to make adjustments was an instructional life-saver. As a result, the students were able to understand what she was teaching. Max, on the other hand, described how the shifts may be required at the moment a teacher walks in his or her classroom. Max stated:

Whoo-whoo, you're gonna have the most beautiful lesson plans everyday. They could be published and sold for money, but when you walk through that door, and these kids are awaiting you, those lesson plans may go out the door when you walk through the door, so sometimes you have to learn how to adapt to that situation.

In other words, teachers must be able to adjust to whatever situation is presented in the moment. Smooth's position on this topic did not address teachers having to make total shifts as did Max. However, in his response, he did speak to instances that during instruction, some slight modification might be warranted. He commented, "I think the one way with planning is that, like I hit on earlier, that having a plan, but don't be afraid to move to the left or to the right just a little bit." In either case, whether modifications are slight or a complete shift from the planned lesson, teachers must be comfortable with making adjustments as necessary.

Attitudes about opportunities for improvement in teaching. Another theme emerged from the responses of those teachers at the character post of Attitude, who expressed having an instructional experience. This particular theme centered on attitudes teachers had about opportunities for improvement in their instructional practice. In some cases, it was a matter of teachers becoming a little more comfortable with some of the project-based activities. Max felt that this was one area in which she could improve. She stated, "But I think if I could just learn to 
be a little more relaxed in teaching and incorporate some of the hands, though I love hands- on." Along the lines of improvement, Kim described an instance where she wanted to recap the previous day's lesson. She commented, "What I didn't do this morning, and I wanted to do it, was, based on yesterday's teaching, I wanted to go back and recap on what we had done from the previous day, and I didn't do that." A recap of the lesson could conceivably improve student comprehension and performance. And the absence of a recap might create performance gaps between students, in which case, the teacher could be directly responsible for fostering divisions within the learning community. Interestingly, Lequita saw where she could improve her instructional practices by allowing students to evaluate her on a regular basis. She reported: I don't think I evaluated my teaching style with them today. I mean, I had a conversation with them last week about it and that's something that I'm gonna have to work on to make sure that I remember to, at some point in time have the kids critique or evaluate me. But at the same time I understand that the- that you could be evaluated just simply by walking around; see how the children are working on those projects. If they're able to sit down and work on those projects and they are calling on you and they're asking you for advice. "Can I use this? Can I do that?" that kind of gives you a clue that they're interested.

Lequita saw how teachers have multiple opportunities for determining the effectiveness of their teaching by allowing students to share in the evaluation process. This is a shift from the traditional form of teacher evaluation, which is normally conducted by a member of the teacher's administration team. Instead Lequita viewed students' active engagement as a measure of evaluation. Her response suggested that teachers are able to judge the quality of their teaching by a simple observation of how well the students are responding to their assignments and their 
understanding of the directions to complete their assignments. In other words, when students are focused on the assignments, or when students are asking questions of the teacher in relation to completing assignments, these might be indicators of the teacher's ability to present information in a clear and interesting way, in which the students are motivated to perform.

Attitudes about Goma curriculum and its impact on teaching. Some teachers'

responses indicated an instructional experience, for expressing their attitude toward the Goma curriculum and its impact on their instructional practices as classroom educators. Both Kim and Max expressed how Goma curriculum had impact on their becoming more composed in the classroom. Kim, for example commented:

This curriculum has taught me to be more relaxed and to make a connection. To me that was a big thing that Delia was stressing the most. Make the connection, students are able to relate a little more and I think it's a bigger percentage that they are able to retain it more because they can relate it to their everyday life. Before hand, I would have just tried to stick to the basic structure.

As a result of Goma curriculum, according to Kim's report, teachers are able to better connect with students. This might help students better comprehend and retain information since they are able to see relationships between the curriculum and their everyday lives. Max described how Goma curriculum aided in reducing the amount of stress she experienced in the classroom. She remarked, "GOMA has taught me to be a little more laid back, just to be relaxed instead of so always uptight." Learning to relax could have conceivable impact on Max's overall teaching performance, including her instructional delivery, as well as her management of the social environment of the classroom. Lequita compared her preparation as a regular educator to her preparation as a character educator through Goma curriculum. She stated, "I did not feel as well- 
prepared for actually getting into class as a [regular classroom] teacher. I felt prepared as far as being a Goma teacher and being able to express those Goma characteristics." The juxtaposing of Lequita's pre-service preparation and the preparation through Goma curriculum, based on Lequita's comment, provided an interesting comparison. According to Lequita, Goma curriculum carried certain value-centered characteristics that the teacher was expected to enact. It could very well be that these characteristics contributed to Lequita's feelings of preparedness for the classroom as a Goma educator.

Other reports described documents of Goma curriculum, particularly lesson plans, and their impact on instruction. Goma Diva, for instance, spoke specifically of the lesson plans of Goma curriculum, and viewed them as having a nice flow, where the activities transitioned smoothly from one to the next. She reported, "I believe that the lesson plan...I think that they are...they flow very well, and I like how one activity makes you go back and have to relate to the other activities." Her response showed a relationship between effective lesson planning and delivery, particularly how one activity is built upon the other.

\section{Character Post: Attitude_Teachers' Emotional Experiences}

Teachers at the Attitude character post also had emotional experiences, wherein they expressed feelings that impacted their perceptions of their students, themselves, their instructional practices, classroom relationships, and their responsibilities as character educators. Some themes found within the teachers' responses at this post, where emotional experiences were most evident included:

- Goma shapes teachers' hearts and

- The classroom as a space where teaching and learning can be fun. 
Goma shapes teacher's hearts. Lady A described her evolution to being a more kindhearted educator. She remarked, "I have already noticed a change in myself as a teacher by participating or by being in the Institute. I have become a more compassionate teacher." Similarly, Smooth detailed an instance of his first response to a student who did not come wearing his Institute tee shirt, the mandatory uniform for all students participating in the Institute. He stated,

But I didn't consider the fact that he didn't have the money to get it. So initially, I went- I was, like, 'you need to come ready.' But as this institute right here has enabled me to open my heart, like, you know what? Let's see what the problem is. He may not have that.

Smooth's remark pointed to the Institute as having inspired him to become a more caring and compassionate educator. In this instance, a compassionate educator stops to seek understanding of causes or conditions that may sometimes limit students' abilities to comply and in other cases, perform.

The classroom as a space where teaching and learning can be fun. Other teachers described their classroom time at the Institute as an upbeat and exciting teaching and learning experience for both teachers and students. Both Goma Diva and Max reported enjoying themselves. Goma Diva stated:

I think that before the academy I was a little more firm and really strict. I think that after going through this academy, I feel like I've loosened up a little bit because I'm showing more compassion and those values that are taking place in their lives. They're loose and they feel like they're having fun. I'm actually having fun at the same time. 
It was interesting to note that for Goma Diva, 'firm and strict' seemed to be at opposite ends of compassionate and fun-filled. One can conclude that Goma Diva's character-based description of her teaching was aligned with a fun-filled environment. On the other hand, Max alluded to herself as a more vibrant personality at the outset, and so the Institute gave her the chance to be herself. Like Goma Diva, Max reported having a wonderful time with the curriculum, and stated:

I'm having a good time. I don't know about anybody else, but I'm having a good time.

Because this is just so me, you know, the hands on, and the activities, and just being able to freely just kinda discuss things without a lot of restraints. That's just so totally me. For both Max and Goma Diva, Goma curriculum allowed teachers with opportunities to be immersed in an engaging environment rich with hands on, project-based, dialogic activity. These teacher participants created a classroom environment in which they could have fun while teaching.

\section{Character Post: Attitude-Teachers' Cognitive Experiences}

Teachers at the Attitude character post also reported cognitive experiences, where they described an awareness of their attitudes primarily toward themselves, the students, and the curriculum. Where a cognitive experience was evident, most of the teachers' attitudes related to their reflections of themselves as classroom educators. In most cases, they seemed to have looked introspectively at themselves in relation to their dispositions toward their students. Some emerging themes at the Attitude character post, where teachers reported having Cognitive experiences include:

- Character must be embraced before taught; and

- The Institute as an impetus for teachers' attitude change. 
Character must be embraced before taught. Max disclosed her awareness that she needed to address her personal attitude and embrace character values before teaching the values to her students. She commented:

I have to deal with myself first and then I have to try to instill those values that I have now internalized into the kids. Before I can instill them into them, I have to have ownership of those same types of values and characters.

Max's attitude reflected her thoughts toward the ideal that just as knowledge can be passed down character values are taught, as well. Max's reference to ownership is an interesting perspective. This suggested that unless one personally adopts the values as his or her own, he or she cannot teach the values effectively. By a similar admission, Lady A considered her own shortcoming, and reported: "I need to make a better habit of showing my students that I care." The acknowledgements made by these two teachers evidenced character education, specifically conflict resolution at least from The Ellison Model perspective. It would appear that teachers who make these kinds of admissions, assuming they work to continue along the 7-Step pathway, are likely to create a much different classroom environment that those who never engage in self reflections.

The Institute as an impetus for teachers' attitude changes. Other teachers discussed their attitudes and pointed directly to the Institute as the impetus for the changes they experienced. Goma Diva spoke extensively about the change in her attitude, and reported: I would say that my teaching prior to being involved with the Teacher Education Academy...I would describe it as not as thoughtful. I'm a whole lot more aware of my attitude in the classroom, my attitude toward the students, the way I respond to the students, the way I encourage the students. Sometimes not encouraging them is just like 
discouraging them. I'm a whole lot more aware and thoughtful and careful about the students and what I'm doing and how I'm affecting their learning in the classroom.

In Goma Diva's description, she compared her two experiences as a teacher, before and after the Institute. Lequita had a similar experience, where she described how the Goma learning experience at the Institute personally impacted her. She commented:

So in going through the education program, it reminded me...it made me go back and reflect especially having to go through the activities on attitude and behavior communication [and] discipline. It made you stop and realize 'what am I really like; how do the kids perceive me; how do other people perceive me; what kind of perceptions do I give off to others.' You start evaluating yourself. 'Am I really patient; am I really sharing my wisdom with the children, or am I forcing my ideas on them? Am I really accepting of their ways?' Utilizing what Goma is about me first and giving it back to them.

In their cognitive experiences, both teachers' comments spoke to their awareness of how they might be perceived by their students and their awareness of their responsibility as a reflective educator.

\section{Character Post: Attitude—Teachers' Social Experiences}

The second most prevalent experience among teachers at the Attitude character post was Social, where teachers described experiences that related to attitudes involving their interactions with students. A number of teachers commented on their social experiences when, in the process of their interactions with their students, particular attitudes came to light. These attitudes typically surrounded teacher-student relationships and opportunities teachers gave their students to feel comfortable interacting with them. Max, for example, gave a lengthy response regarding a conversation she had with her students on this matter. She remarked: 
I think I told my kids-in fact, I know I did last week, that I'm not perfect. I make mistakes. We're all human; I think kids need to hear that. But I'll tell you mine. I don't know all the answers. I tell them, 'Sometimes you may know the answer, and I may know the answer, and I may not know the answer. It depends on what day I come in. I may come in here bland, and slow to catch up, and I may just be that slow that I'm not grasping what's going on, or I'm just not with it that day.' I have to catch up with them on certain days. Some days I come in, and I'm just like, I'm on it, and I know the answer. I have the answers, but some days I won't. I think as teachers, we need to let our kids know sometimes we do get confused.

She spoke candidly about her attitude toward teachers' sharing their cognitive imperfections with their students. According to Max, teachers, in their interactions with students, should be honest about how they don't know everything there is to know about the subject matter. This may possibly minimize low perceptions students often have of themselves. As well, students may then be more inclined to openly participate in class activities, take academic risks, and stretch themselves in their academic creativity, without the fear of being ridiculed by their peers. Both Goma Diva and Lady A expressed attitudes about social interactions between themselves and their students. Goma Diva stated: "I "opened up" and allowed for them to talk and express themselves, allowed them to feel like their thoughts were respected." Lady A responded: "I give them opportunity to ask questions if they don't understand." Interestingly both teachers' comments signify an importance for providing students with opportunities to be heard. This points to a true sense of interaction between teachers and students, where the roles of speaker and listener are shared by teachers and students. 


\section{Character Post: Attitude_-Teachers' Blended Experiences}

At the Attitude character post, there were a number of instances where teachers' responses evidenced blended experiences, including emotional with social, cognitive with instructional, and emotional with instructional. In the case of Smooth, for example, he described an instance of social interaction with a particular student, where an emotional experience was also noted. According to Smooth's response, there was evidence of a change of attitude, where the student "opened [Smooth] up." In other words, the student encouraged Smooth to have a heart of caring and loving toward others. Lequita also described her blended experiences at cognitive and instructional levels. She explained how she realized she was beginning to become entrenched in the traditional mode of teaching, but how she had a change of attitude. As a result of the Institute, she was more thoughtful as a culturally responsive teacher integrating movement and relevance as central elements within her instructional practices. Interestingly, out of the three blended pairs, instructional and emotional were prominent in the experiences of the teachers. This pattern was also noted even when teachers' responses showed instructional and emotional markers that were independent of each other. Cognitive and social were also evident in teachers' responses, but with less frequency.

Summarily, the Attitude character post described responses that dealt with the participating teachers' personal growth as reflective classroom practitioners. Their narratives revealed the teachers' understandings of what it means to be character educators. Moreover, teachers' responses at the Attitude character post point to efforts toward improving their potential as effective teachers (see Appendix C). At the next character post, Behavior, teachers report social experiences born out of their interactions with their students. Based on what their 
responses indicated, teachers' social behaviors have the potential to be interpreted for messages of character such as trust, honor, respect, and conflict resolution.

\section{Character Post: Behavior}

Within Goma curriculum framework, Behavior represents teachers’ interactions with students (Goma Curriculum Handbook, 2007). How teachers engage with their student learners certainly has a tremendous impact on the social climate of the classroom. Ironically, the responses of the teachers at this post highlighted many of the values of Goma curriculum; the impact of Goma curriculum on teachers' instructional practices and classroom culture became more evident.

The comments of teachers who landed at the character post of Behavior evidenced primarily Social experiences. This is not uncommon since the post itself involves social interaction. Furthermore, there was neither instructional, nor cognitive, nor emotional experiences noted at this post, at least none existing in isolation. Some accounts of the teachers showed evidence of blended experiences. However, even in those cases, the dominant experience was still social with the other experiences playing a background role. For example, a teacher may have described a lesson he or she was teaching, and as part of the lesson, he or she may have had to interact with the students. In such a case, there would be clear evidence of an instructional experience, but the interaction between the teacher and students during the lesson may have greater significance as a focal point of the lesson. Several themes emerged from the examination of those teachers' responses that fell within the character post of Behavior, including:

- Respect;

- Honor; 
- Conflict resolution; and

- Trust.

Respect. At the character post of Behavior, teachers' behaviors evidenced a central theme of respect, showing various means by which respect can be demonstrated toward students. Within the Goma framework, respect is defined as the "teachers' integration of students' voices and communities into the classroom lessons in meaningful ways, as well as acknowledgement and value of their lived and historical cultural experiences" (Goma Curriculum Handbook, 2007). A summary of this definition would seemingly involve any instance where teachers outwardly acknowledged and demonstrated positive value toward their students. In essence, this would mean giving a presence to the students, and not treating their lived and historical experiences, their voices and the voices of their communities as if these were "elephants in the classroom"-issues that are present but never acknowledged.

Respect is also said to infer high regard for diversity (Nieto, 2002), an active appreciation for differences of students' cultures and their responses. Respect suggests actions and nuances in the classroom that positively acknowledged and infused student differences into the presentation of the curriculum. In addition, teachers should anticipate and accept variations in students' processes and academic outcomes (i.e., students' responses, their ways of knowing, and their learning styles).

To demonstrate respect, several teachers used verbal praise. Max, for instance, applauded students for their work, including their efforts. She commented:

I've just gotten into the habit of saying 'good job; way to go'; just saying, 'wow, look at this; this is great;' things like that to just show them 'this is awesome; this is some good 
work, and this is your just due.' That's what I do. I verbally praise them for their efforts in class.

Interestingly, Max's use of verbal praise stemmed from her attitude that this was the students' "just due." The precedence of attitude in relation to behavior was also evident in Smooth's comments, who demonstrated respect in a manner of speaking. He stated:

Speak to the students in a respectful manner, ma'am and sir. Also, I don't talk in a degrading way toward them just because they're a child and I'm an adult. I try to treat them, as much as possible, like we're all human beings, and just because you're a human being you deserve respect.

Both teachers seemed to progress toward "making the right turn" as the 7-Step Process dictates. According to the framework, individuals progress from Attitude to Behavior; Attitude precedes and influences Behavior. Neither teachers spoke explicitly of progressing from one point along the 7-Step pathway to the next. Still there was progression implicit in their comments. For example, Max's viewed students as worthy of praise, and her behavior was an outward reflection of her attitude. Similarly, Smooth described an attitude that viewed his students as deserving of respect just as adults are; therefore, he spoke in a respectful manner to his students.

Lady A shared a similar approach to Max in that she spoke of demonstrating respect by praising her students. However, with Lady A, she did not speak of praising students for completing academic exercises, but for showing efforts to build relationships with their peers. She commented:

So I make a habit of reiterating if a student does something in an attempt to understand another classmate or in an attempt to support or understand another classmate, I applaud them for that. I bring it to the forefront. 
It seems that the applause of students' social behaviors, as those described by Lady A, is not only an act of respect toward her students, but also serves to reinforce character building as students are encouraged to show respect from peer to peer. In this way, respect becomes a classroom cultural norm.

Kim displayed respect toward her students by immediately responding to them when they called her. She reported:

When my kids ask, "Come and see this; come and look at this; am I doing it right?" I make sure I always go. I don’t like to put them on hold, and say, “Okay, I'm coming." I try to get up that very moment that they call my name to tell me.

As Kim described how she acknowledges the call of the students, her behavior seemed to project the essence of respect, which would, in a nutshell, say to the students, "I see you." It would certainly speak volumes about how she values her students and how she ascribes worth to them and their social and academic products.

Honor. Honor was yet another theme that emerged from the responses of teachers indicating position at the Behavior character post, namely those having Social experiences. Within the Goma framework, honor is defined as:

the demonstration of teachers esteeming students as co-curriculum makers, who help to: a) create meaning, b) construct new knowledge, c) set curricular goals for learning, d) make decisions regarding content and instructional delivery, and e) evaluate teachers' ability to disseminate information in a manner that is comprehensible by students and relevant to their lives (Goma Curriculum Handbook, 2007).

In this way, teachers actually see their students as co-teachers, who have the capacity to learn and teach. Inherent in the definition of honor is the notion that to some degree, students are on 
par with teachers. They both are able to make substantive contributions to the meaning-making process of the curriculum. This does not mean that students are fully independent of their teacher. Rather, students are guided by the teacher into independent learning. In this context, teachers can release the reigns of accountability and responsibility for learning into the hands of the student learners, presuming there are no physiological and/or psychological barriers impeding this process. Several teachers engaged with students within the context of honor as defined by Goma curriculum. Smooth, for example reported:

I gave a personal experience and my story, and I genuinely...I looked at them in the eyes and told them, 'If I can do it, surely you can do it,' not just to say that and make myself look good or sound good because it's true; it's genuine.

Smooth, in this instance, described how he viewed his students, the learners, in comparison to himself, the teacher. What Smooth could do, his students could do, as well. Responses such as the one made by Smooth suggested an equal positioning between Smooth and his students in the sense that they all could achieve. This line of thinking can remove certain divides between teachers and their students, and may likely enhance the social environment of the classroom.

Kim provided another instance, where the value of honor was evident. She commented: That was the highlight for them, and then I asked them before lunch, 'how did you all like how things went today?' 'We really like it. Can you do that on Monday?' I was like 'I'll try my best to do that Monday.'

In consideration of her students' desire to continue a particular exercise, she allowed her students to set the pace for instruction. In this way, her students, by permission of Kim, the teacher, acted in the leadership role of teacher. This kind of interaction between teachers and students might look very different than the classroom where teachers are the sole decision makers. Such a 
scenario is contrary to the behaviors of teachers who might impose all decisions upon students allowing no input from their student learners.

Conflict resolution. Another major theme found within this category of experience related to conflict resolution occurred in some cases between one student and another. Lady A, for example, shared several instances of her approach to working with students who expressed differences. She reported:

And I tried to get them to see and at least come to an agreement of some action that they'll, what'd I say, perform, pursue, something that they'll do instead of running off at the mouth. I just tried to get them to come to an agreement. I had another situation with two young ladies, and they finally came to terms [and] came to the conclusion that what they were saying...they could see how what they were saying about each other could be offensive and that the other person's feelings could be hurt.

What Lady A experienced does not necessarily reflect an obvious process of conflict resolution techniques as a character educator. However, in the outcome of the students' "coming to terms," there was assumedly some time dedicated to help the students self-reflect, enhance their social capacity for relationship building, and at least manage their feelings.

Goma Diva's comment showed how she used "sharing" as a strategy for helping to create a conflict-free classroom. She reported, "I think that I promoted inclusiveness in my classroom because I allowed everyone an opportunity to share their feelings or whatever it is that they want to get out." Her objective for inclusiveness would seem to allow students to openly share their personal feelings about issues. In this way, conflicts can be addressed in an open format, and the entire class can participate in the resolution process. 
Several teachers mentioned conflicts their students had, not in the sense of two individuals at odds with each other. Instead they referred to conflict in terms of an internal disconnect: two states of being (the state of where students were in their behavior and where they should be). To help students resolve the conflict and modify student behaviors, teachers referred to the Goma principles and redirected students to a Goma consciousness. Kim reported:

And even in the lunchroom, some of the kids who wasn't applying the GOMA method in the lunchroom where they was, you know, "janking" a child or whatever, I just made sure that I reinforced, okay, that's not very GOMA-like.

In Kim's interaction with the students, she personified Goma as one who does not seek to belittle or "jank" another. In Goma Diva's account, she reported instances where her students seemed to have made an obvious connection with the Goma values. She stated:

Sometimes they get—may get off task, and then, you know, I may hear 'shut up'...and I'm like.... is that the Goma way? You know? And then they'll be like, 'oh, okay...I'm sorry.'

According to Goma Diva, students recognized the conflict, and had begun to make the transition toward positive change, as indicated by their apology. Assuming there was an apparent change in the students' behaviors, they would have made the manifest leap from a state of conflict to a state of resolution with no existing gulf between where they were and where they should be in their behavior. Lequita, although still using the Goma principles, described a slightly different approach to behavior modification among her students. She stated:

Now me, the cool teacher, we could figure out something together that you could do to keep you from doing the things you are doing right now because you are affecting us negatively not positively. Not as a Goma that I know that you are." 
In Lequita's social behavior with the students, she extended the approach used by Kim and Goma Diva. She broadened the reference of Goma to define the students as Goma. Her comment seemed to suggest that the student might relate to Goma not as someone they would seek to model; rather Goma would become the internal regulator who could help students make right choices even when no one was around. Further, the students might become models for their peers. In essence, the students themselves become Goma.

\section{Character Post: Behavior-Teachers' Multiple Experiences}

Trust. In the case of blended experiences at the Behavior character post, social was still a part of the composite experience. While respect and honor were prominent themes previously mentioned in the discussion of the teachers' responses at the Behavior character post, trust was the primary theme that arose out of some of the blended experiences. Within the Goma framework, trust involves teachers' demonstration of confidence in students' ability to make sound and logical judgments and to appropriately use information, manipulatives, and other resources (Goma Curriculum Handbook, 2007). This definition encompasses the use of information and physical manipulatives. Lequita, for example, took a very unique approach to demonstrating trust. This was shown during an instructional activity. As part of the instruction, she engaged the students in dialogue, and began a probing conversation with the students in order to help them critique some of their own values. She allowed them to manipulate the information and had confidence in their ability to handle the review of the values. She reported;

They tried to put in the fact that in the hood, though, they all say, "what's up cuz?" And they take that to mean that they are family. I said, 'family though? A family makes you feel like you're not safe? Does a family really make you feel like you're not safe? If you're in a real family where there are loving characteristics, caring characteristics, you 
feel nurtured, you're valued. Is that really a family or is it a false sense of family?' It opened up good dialogue and it turned out to be really cute. It was funny they had me in there laughing at them.

In this description, through social interaction with her students, Lequita was able to guide her students through the information. In other words, she did not leave them to manage the information without first walking them through it. This seemed to allow the opportunity to assess the degree to which the information and/or physical manipulative could be released to the student. It would appear that social interaction between teachers and their students is another means by which teachers may assess student comprehension.

The element of trust seemed most evident when Lequita laid out the values through questioning, without ever stating what might be appropriate responses to the question. She gave the students certain data and 'trusted' their ability to manipulate, analyze, and make judgments about the data. Teachers' trust of their students, as part of an instructional/social dynamic may not only allow teachers opportunities to assess their students, but may also provide teachers with occasions to assess the quality of their own instruction. Moreover teachers can reflect on how well they present information, assuming a direct relationship between the means by which information is presented by the teacher and the resulting responses by students. Further examination of Lequita's response suggests that social interactions between teachers and students give rise to scenarios that seemingly represent new challenges, problems, and or conflicts when students can use prior knowledge to arrive at new conclusions. Mayer (2002) defines this process as teaching for meaningful learning, allowing students to extend their knowledge base through new problem-solving opportunities. In so doing, the student can become aware that a problem-solving process will inevitably bring new discoveries to light. Simply 
stated, when teachers trust their students, as part of their social and instructional behaviors, they will likely provide their students with meaningful learning experiences that allow the learners to critique information and expand their capacity for problem-solving. Within that framework of trust, social and instructional behaviors, students could, of course, learn to use these problemsolving skills to resolve personal conflicts as they may arise.

In summary, the Behavior character post described responses that dealt with teachers' management of the social relationships found in the classroom. Their responses described opportunities teachers have to model character and affirm students' potential as instructional leaders, problem solvers, and role models (see Appendix C). At the next character post, Communication, teachers continued to describe their social interactions with students, including how they managed students' relationships with their peers. Their responses indicate a direct correlation between teachers' social behaviors toward students and subsequent student behaviors.

\section{Character Post: Communication}

Based on Goma curriculum, Communication is a character post that deals with the messages teachers' social and instructional behaviors convey, and /or how students interpret their perceived messages found in teachers' behaviors, including verbal or non-verbal responses (Goma Curriculum Handbook, 2007). At the character post of Communication, teachers described what interpretations they perceived their students made of the teachers' classroom behaviors. Teachers making this kind of judgment need to be cognizant of what interpretations students made. In actuality, teachers could only assume students' interpretations; they were never stated by the students. The most frequently noted experience at this post is cognitive, followed by social. At this post, neither instructional nor emotional experiences were evident in isolation. 


\section{Character Post: Communication-Teachers' Cognitive Experiences}

At the Communication character post, teachers described what they perceived students thought of their teachers' behaviors toward the students. These experiences were said to be cognitive in that they represent the participating teachers' mental notations of how their behaviors could be perceived by the students. Lady A, for instance, described what she saw as students' interpretations of what high expectations she held of them. Lady A perceived that students would be prompted to "do the right thing." She reported:

I see that the students are... when they see I'm not going to let up or allow them to continue doing things the old way, I think that slowly, but surely, I see some of them remembering, "Oh, I need not say that, " or " Maybe I need to do it this way."

In this instance, Lady A was aware that her instructional behavior, namely her insistence upon students to perform academically, communicated to her students her high expectation for their academic and social responses from her students.

Lequita also spoke on this issue using a different scenario. Her commentary addressed the impact of students' interpretation of teachers' behaviors. To make her point, she spoke specifically about reasons some students make inappropriate classroom responses. Her comments suggest that she believes students may misbehave because they sometimes interpret teachers' behaviors as devaluing of students. Lequita stated:

That's why you'll see certain kids in these classes. They'll pop off at any moment. And you don't expect it and you're like, "Where did that come from?" But it's from all of that built up anger for feeling like, “She don't value me. She don't really value-she don't really care about me." 
The scenarios described by both Lequita and by Lady A support the possible existence of an ebb and flow relationship between teachers' behaviors and students' behaviors, which may be mediated by students' perceptions of teachers' behaviors.

\section{Character Post: Communication-Teachers' Social Experiences}

The second most frequently noted experience of teachers at the Communication character post is social. A social experience at the Communication character post would involve interpretations that students make of teachers' behaviors, namely the teachers' management of social interactions that occur within the classroom space (Goma Curriculum Handbook, 2007). As an example, Smooth described his desire to create a civil classroom environment, one where feel safe and protected. Smooth stated:

I want the child who's being janked [belittled] to know that 'Mr. Smooth has my back. He's not gonna allow anyone in class to bring any harm to me. He's not gonna allow other people in class to talk about other kids.' The other kids will hear and see that as well, and they know that 'he's not gonna allow that to happen.' I hope I'm building their trust through that.

This scenario does not reveal specific interactions between Smooth and his students, but it does reveal that he understood that his students could read how he managed social interactions and relationships in the classroom. What may result are student behaviors that respond to what the teacher's behavior was intended to communicate.

\section{Character Post: Communication-Teachers' Multiple Experiences}

On a number of occasions, Max's comments pointed to having a blended experience while at the Communication post. In the midst of her teaching a lesson, a student wanted her attention. She gave attention to the student's request. She reported: "'Will you see mine?"' I do 
that so they'll know, 'Okay, she's taking value in what I'm doing. She's actually trying to honor me." Here, Max indicated several points of understanding: (a) students do read their teachers' behaviors, (b) it was important that she acknowledged the student, and (c) there were specific values that could be understood by Max's response to her students. In particular, the student could possibly read that Max saw the student as worthy of her time.

In another instance, Max described her intentions to communicate respect toward her students. In this particular instance, she became a learner alongside her students. She stated: To demonstrate that I respect you with my kids, I try to do the same thing that they are doing, or that they are working on. I try not to isolate myself and just walk around and monitor their work. I try to do the same activity that they're working on, so they can see that, 'Okay. She's doing this with us, and not that she's just got me doing some work.' I'm also getting down in the trenches and doing the work with them. I hope to them that it's demonstrating that once again, 'she doesn't supersede who I am as a person. She can do the same activities that I can do.' I hope that goes over to them.

While Max's comments did not allow us to see the actual responses of her students, she seemed to be quite aware of how her instructional and social practices are clear indicators of her attitude toward them.

In review of the Communication character post, teachers reported an awareness of how their students' behaviors are often a reflection of the messages embedded in their own behaviors toward students (see Appendix C). At the next character post, Discipline, teachers described instances of what appeared to be a state of classroom utopia evident in the moral and performance character of the students. 


\section{Character Post: Discipline}

The final character post of the Goma 7-Step pathway is Discipline. Goma curriculum regards Discipline as a reflection of a sustained classroom environment of positive character (Goma Curriculum Handbook, 2007). An examination of the teacher talks revealed few responses that evidenced teachers positioned at the Discipline character post. In fact, teachers were shown to be at the Discipline character post less frequently than at any other post. The dominant experience at the discipline post was social. Other experiences, such as instructional and cognitive were infrequently noted with no evidence of emotional experiences, not even in blended form. Even where the experiences were blended, social was a part of the blend.

Throughout the teachers' comments found in the teacher talks, it was shown that the overall culture of the classroom was largely dependent on teachers' management of the classroom space, including the relationships. For example, Lequita spoke of how teachers are able to create and sustain a particular climate. She commented, “They're very smart kids. And they're capable of coming up with all kinds of things. It's just being able to set that environment where they feel comfortable to be able to do that." While Lequita's comment does not state it directly, but "to set" the environment, teachers can interact with students in ways that affirm them as social and academic achievers. Smooth also spoke of the classroom environment, alluding to ways teachers' dispositions can impact the circumstances of the classroom space.

The style of me and the kids being a little more laid-back, a little more relaxed instead of it being traditional teaching. I think that's one of the things that's going to help my kids better and plus, I've been so calm since last Wednesday. It's almost like a peace about going in the classroom and teaching or whatever. 
The social interaction between Smooth and his students, "more laid-back," as he described, led by his calm disposition, sparked an outcome of peace that seemed to permeate the classroom space. Max reported: "I tried to make the environment friendly for the kids by showing, sharing and caring, loving, trust, honor and respect." It is obvious that Max attempted to create a friendly classroom environment using character-based values espoused by Goma curriculum.

As stated, some teachers at the Discipline character post had blended experiences. Still in each case, a social experience was a part of the mix. For example, Goma Diva described a blend of social and instructional experiences in the setting of the classroom in what some may consider a state of utopia. She reported:

I mean they had a lot of energy, and I didn't have to beg students to give me answers, and they were just-I mean it was just coming. I had to tell them to slow down. Wait a minute. Let me process this first and then we'll come to you-we'll get to you.

Goma Diva's comment suggests that she had obviously employed certain instructional practices that included wholesome social interaction. In so doing, she created an environment, where students felt comfortable and eager to engage in the lesson. In such an environment, students may be more likely to take academic risks, have richer fuller learning experiences, and develop a sustained sense of active participation in the process of their own performance and learning. Over time, with this kind of consistent nurturing, Goma Diva could probably expect that this inclination toward performance and engagement might well become a prominent theme of the classroom text with the students assisting in the composition process.

Taken together, the teachers' responses shown at the seven character posts described six instructors' journey through a process toward becoming a character educator. Each character post of the Goma 7-Step pathway appeared to have engendered certain experiences where 
teachers were impacted either cognitively, emotionally, instructional, and/or socially.

Presumably, these experiences would be reflected in teachers' instructional practices as a clear intent toward composing a particular classroom text - one in which students could interpret the classroom as a safe affirming space, where there are opportunities for all students to have stellar value-centered learning experiences on a consistent basis. In the next section of this chapter, discussions surround specific teaching strategies of the participating teachers. The strategies are examined for what opportunities they provide for helping to compose the kind of classroom text that would initiate a culture of positive character.

Research Question\#2: What opportunities do teachers' instructional practices provide for creating a character culture in their classrooms?

To address this research question, the present study examined six teachers' self-reports. The primary research used the reports to determine how teachers used the Goma values in their teaching. The present study, however, drew from the teachers' responses found on the six selfreports. Their responses of instructional practices were coded into the following categories: (a) social interaction, (b) emotional appeal, (c) instructional delivery, and (d) cognitive enhancement. These categories were in keeping with the codes used for the teacher talks, which are: social, emotional, instructional, and cognitive. The coding allowed the researcher to examine whether certain instructional practices are able to fit with Goma curriculum toward helping to establish a classroom character culture. Further, teachers' self-reports allowed the researcher to examine whether there was some evidence of a progression from manifestations in the teacher talks transcripts to those of the teachers' self-reports. This process provides a snapshot of what teachers may themselves be experiencing and what practices they may adopt and demonstrate as a result of their experiences. 


\section{Social Interaction}

For the purpose of the present study, social interaction relates to ways in which teachers use Goma principles to manage social interaction or classroom relationships. This was found to be a major category for describing certain instructional behaviors. Teachers' self-reports revealed that teachers were able to use social interaction to initiate an environment where students are regarded as empowered stakeholders within the classroom space. Some emergent themes derived from this category included:

- Use of open dialogue and discussion;

- Student as evaluators; and

- Incorporation of students' ideas.

Use of open dialogue and discussion. One such way teachers encouraged social interaction was through the use of open dialogue and discussion. As indicated in the teachers' self-reports, several teachers engaged students in discussion activities. In fact, one teacher used discussion as part of the daily teacher/learning ritual, and reported, "We had daily discussions about relevant issues." Another teacher used discussion to spark thought and reasoning that could very well serve as part of a problem-solving process, and shared, "Students discussed the neighborhoods that they live in and how they can be improved." A third teacher used discussion along different lines, allowing this to serve as a precursor to addressing sensitive issues. She stated, "We had a discussion on fears and one fear was 'homosexuals.' I showed students a clip of a murdered homosexual teenager whose murderers were released." In this case, the teacher used other curricular resources to embellish the discussion and/or to provide facts otherwise not a part of students' knowledge base. In other cases, teachers engaged students in open dialogue for reasons besides knowledge building. Sometimes discussions were used to create a certain 
classroom climate. A teacher's report acknowledged, "Students and I shared personal experiences to enhance the level of trust within the community." It was clear that this teachers' use of social interaction, namely discussions, was to ensure that relationships within the classroom community could flourish. In either case, the teachers' comments confirmed that there are myriads of uses for classroom discussions; and these can be instrumental in creating certain climates that welcome the sharing of students' ideas, give opportunities for teachers to evaluate students' understanding of concepts, and expand the knowledge base of the classroom community in a natural environment.

Student as evaluators. Engaging students as evaluators was one of the themes evident during some of the activities that fit within the category of social interaction. Evaluations are typically used as a means for assessment, and generated top down where teachers are the evaluators and the performance of students is measured. These Goma teachers, as evidenced by the teachers' self-reports, used evaluation from students. In these classrooms, as a bottom-up approach, students could evaluate the teacher's sense of classroom democracy, instructional methodology, and other aspects of teaching. One teacher reported, "I asked students how I was doing; how class was going; and how the program was going." Student evaluation and teachers' instructional delivery seemed to be powerful tools in extending students' thinking, and just as importantly, appeared to communicate a sense of regard for students' opinions. This kind of student engagement situates the learner at a level four within the depth of knowledge framework, level four being the highest demonstration of comprehension and performance (http://dese.mo.gov/divimprove/sia/msip/DOK_Chart). At a basic level, students were also able to compare and contrast what they "liked and disliked." One teacher indicated that "Some days I would just ask the students what they liked and disliked about the day's curriculum." Beyond an 
evaluation of the program, and the teacher's methodology, students now had the opportunity to critique the specific resources and activities used to teach the lessons. What teachers were obviously seeking by allowing their students to evaluate them was student input. In all cases, it would appear that student input did not necessarily mean the evaluation of the teacher's instructional methodology, but it did connote students' meaningful contributions to the instructional process. This suggested teachers' regard for their students as capable of making sound judgments for the good of the learning community.

Again social interaction in this case was used purposefully to foster a certain environment, where empowerment reached the students as end users of the curriculum. Couched in this way, it becomes understood that allowing students to evaluate their teachers has great potential for provoking an empowering exchange between teachers and their student learners. Teachers can use student empowerment to diminish power lines of superiority and inferiority among members of the classroom community, including students and their teachers. As one teacher noted, "My students were empowered through our honest interactions in class which resulted in them wanting to assist me with the music, and make sure I had my tap shoes." Here, the outcome of student empowerment was a mutually respectful teacher-student relationship.

Some students may be somewhat reluctant to accept a position of empowerment. Teacher reports showed signs of how one teacher attempted to address this issue. "I try to stay on the same physical level with my students, [whether] sitting or standing)." In what appears to be insignificant, through "on-par" physical positioning, this teacher showed an effort to help students overcome perceptions of power lines that might impede students' readiness to interact with teachers on non-hierarchal levels, whether through general input and/or in evaluating their teachers. Another teacher used the tactic of teacher invisibility, allowing students to regard each 
other as a learning resource and, in some cases, as a teacher proxy. "I wouldn't allow students to run ideas by me. I would have them consult with one another," reported one teacher. Over time, and with appropriate scaffolding, students might expectedly develop a sense of independence as learners, and even become more aware of their own learning needs. This would then likely position students to effectively evaluate their teachers, or make other kinds of productive input toward the process of their learning.

Incorporation of students' ideas. A key element noted in teachers' self-reports was the incorporation of student ideas in initiating social interactions within the classroom space. A number of teachers' responses spoke to how teachers incorporated students' ideas. One teacher reported, "Students shared their descriptions of their neighborhoods, and we were able to embrace our differences and our common ground." Another teacher stated, "Students were given the opportunity to share how they wanted to read information in the A, B, C, D booklets. We honored their request and ideas about developing the class projects." Her practice allowed students to know that their shared ideas would be incorporated within the lessons. Otherwise, they might have interpreted their input as insignificant, and have withdrawn from making contributions during class discussions. Both teachers' responses showed evidence of having addressed this issue of the intentional inclusion of student ideas into instructional lessons

\section{Emotional Appeal: A Call to Character}

In examining the data for emotional appeal, the researcher noted instances where teachers made an emotional plea to re-direct students toward positive character behaviors. In such instances, teachers called students to rise to the occasion to demonstrate character. It was obvious that in making such an appeal teachers did not have to wait for inappropriate student behavior. Teachers could use emotional appeal as a tool of persuasion in response to student 
behavior, as a curative measure. While emotional appeal may be used as a behavior modification strategy to redirect students from negative behaviors, participating teachers in the present study used this strategy as a preventive measure before negative behaviors were manifest. Some emergent themes derived from this category included:

\section{- Affirmations}

- Sharing/encouraging \& motivating

Affirmations. Affirmation emerged as a theme during instances when teachers made an emotional appeal to their students. One teacher commented, "I asked the students to bring an object from home or a talent to class. The next day students shared and each child was affirmed." A notable attribute of this activity was that the teacher not only affirmed the students, but also seemed to give value to the home community of the student learners. This may perhaps be an effective means of helping students view their homes as learning centers, as well as bridging the gap between home and school space. Another teacher's comments showed affirmation as a constant tool for the teacher's assessment of students' work, even affirming students for their efforts. The teacher reported: "I motivated their efforts by actually having them perform in front of an audience in the classroom, constantly reminding them how well they were doing and how proud of them I am." The regular use of affirmations may help teachers build a student's confidence to share ideas, and participate as an active member of the learning community. A third teacher stated: "I constantly applauded them when they cooperated and when they helped me." This teacher's comment, though simplistic in nature, perhaps represents the sentiments of those teachers who believe that affirmations as an act of verbal praise can positively impact students, whether the praise is for scholarly research or for a mere act of kindness, in the case of this teacher. 
Sharing/encouraging \& motivating. Teachers also used sharing/encouraging and motivating as opportunities for making an emotional plea. The strategy of the emotional plea seemed to be an attempt to encourage students to rethink their choices. In this case, what teachers might consider as frontloading or activating prior knowledge became opportunities for writing a character-based text. One teacher reported:

"They openly shared that they really wanted to be in other classes in which they feel they would excel. I also made known that this was something new that would add to whatever area of art they showed interest in."

It appeared that allowing students to share in an open forum is ideal for helping them develop appreciation for diverse perspectives. This development fits well within The Ellison Model's view of multicultural appreciation, where individuals are encouraged to see commonalities even when the ideas that are presented may differ from one's own.

In other instances, teachers reported encouraging and motivating their students as part of their use of emotional appeal, suggesting an earnest attempt on teachers' parts to inspire and empower students toward active learning. For example, one teacher stated: "Students are encouraged to participate at their highest level." Another commented, "I motivated their efforts by actually having them perform in front of an audience in the classroom." These examples illustrate the use of making an emotional plea through encouraging and motivating in order to prompt performance character. Additionally, they may indicate some relation to character education and academic performance. 


\section{Instructional Delivery}

Another category, referred to as instructional delivery, involved: (a) explicit and implicit instructional strategies, (b) management of classroom décor', (c) arrangement of classroom space, and (d) management of time. Some emergent themes derived rom this category included:

- Using student-generated rubrics - a basis for learning and performance;

- The expansion of classroom community knowledge;

- Extending knowledge through varied interactions with academic concepts; and

- The use of classroom space.

Using student-generated rubrics - a basis for learning and performance. Among the key themes emerging from of the instructional delivery category was teachers' use of studentgenerated rubrics for establishing levels of proficiency and evaluating students' mastery of certain concepts. Teachers seemed to give students multiple opportunities to show themselves as instructional leaders. Sample responses from teacher activities that evidence their integration of student-generated rubrics included:

G.O.M.A activities allowed students to set personal goals;

I allowed students to create the basis for their community project; and

Students were given the opportunity to share how they wanted to read information in the A, B, C, D booklets. We honored their request and ideas about developing the class projects.

While teachers' comments do not reflect the use of a traditional type rubric with a point or letter grade system, students were yet permitted to set standards for excellence in ways that measure achievement. 
The expansion of classroom community knowledge. Another theme that emerged as a strategy of instructional delivery was teachers' expansion of classroom community knowledge. While the activities related to this strategy seemed few in number, they were consistently inherent as part of teachers' instructional designs. For example, one teacher's comment spoke of the overall design of the lessons: "the activities were designed to integrate students' communities." This alluded to the instructional practice of this teacher. So despite the activity, a consistent feature in the teacher's instruction was the opportunity for students to recognize the faces of their communities in the lessons. This might include community voices, symbols, and personalities. Another teacher seemed to possess the art of inclusion, using the experiences and contributions of the students and somehow integrating them into the lessons of the day. The teacher commented: "I also made sure to never exclude anything or any experience a student shared." With this kind of instructional skill, teachers are able to recognize what may be awkward student responses and use these as opportunities to teach valuable lessons, whether life lessons or lessons related to the general content or the topic at hand. In both cases, the teachers' instructional delivery generated a platform for students to expand their knowledge through the shared lived and historical experiences of their peers and their communities.

Extending knowledge through varied interactions with academic concepts. Some teachers, whose responses fit within the instructional delivery domain, evidenced a common theme of allowing students to extend their knowledge using multiple formats in order to apply knowledge and demonstrate their understanding of the content. For some, they engaged students in discussions, where students had to develop their own discussion questions. One teacher reported: "Students contributed their own discussion questions." Another teacher used discussions and coupled the dialogue with the use of technology to underscore the facts 
presented in the discussion. Other comments from several teachers evidenced the use of authentic assessment measures, engaging students in a range of activities that allowed the students to apply knowledge in a variety of meaningful contexts. Some teachers reported the following:

Students created a short skit comparing bad and good character traits;

Throughout the process students were asked to develop their final performance; Students developed community project;

Students used their own talents in classroom activities (i.e., dancing, acting, singing, etc.); and

Students were able to choose 3 dye colors, a tie-dye design and to decorate a t-shirt. In contrast, one teacher engaged students in an activity that used a traditional writing exercise to teach the lesson. In this instance, students were expected to use the letter writing format to send a formal communiqué to address a specific issue. The teacher stated: "Students wrote a letter to Debra Lee, Executive of BET Network to contact them about sending mixed messages." As independent activities, these would appear to have no relationship to a character education framework, but when viewed as a collective, they can be understood as unifiers for reinforcing to ensure student understanding. This broad range of instructional activities fit within a body of academic activities that can be said to meet the needs of diverse populations of students, including the most reluctant learners. These activities might enable diverse learners with opportunities to experience success within a single classroom, and likely enhance students' overall performance character.

The use of classroom space. A final theme captured within the instructional delivery category was the use of classroom space. Several of the teachers' responses demonstrated an 
attempt to use the classroom space to create a sense of community. Comments such as "We moved all the desks to form a circle of unity;" "[We] positioned desks to foster a unified community;" and "We moved all the desks to form a circle in order to represent unity" spoke of positioning the classroom to unify students so that each had equal access to the social and academic advantages that were perhaps situated in the center of the community. One teacher stated: "I displayed ideas on wall and allowed students to verbally share ideas. I even posted a class constitution and recited it daily." In this case, the teacher's management of the classroom space included the teachers' use of classroom walls to reiterate the precepts of the lessons. The use of space in classroom settings indicate an understanding that "texts" may vary in presentation to include other forms beyond print (e.g., oral and social text).

\section{Cognitive Enhancement}

A final category for which the researcher coded for evidence was cognitive enhancement. The researcher looked for instances where teachers used curricular resources and subject area content to make associations to character-based principles. In one instance, the teacher used the content of a production. The teacher reported, "We discussed the role of individuals in a community. We then compared roles in a production to a community." In this case, the teacher showed the students the significance of team building, and how roles in a production are much like those in community building. Another teacher seemed to have been teaching a lesson that involved music and colors. The teacher stated, "Students listened to a song "Yellow" by India Arie and discussed how colors represent certain character styles or circumstances." This teacher using a song about colors showed students how colors can be related to character traits. One other teacher used history and social studies content, and shared: "I showed students short clips of Emmett Till and they were able to compare his situation to their life. (There are different 
cultures and different ways to act in different places. Racism still exists.).” This teacher connected historical content to life lessons that relate to the social character of our society, and for some, personal character. Based on the responses of these teachers, what they have shown is that regardless of the content area, the use of cognitive enhancement provides teachers opportunities for showing symbiotic relationships between the elements of content and character.

\section{Summary}

This chapter was divided into two sections. Each section addressed the two research questions that guided this study. In the first section, there were descriptions of experiences reported by six participating teachers in their teacher talks, interview-style discussions shared by two teachers per teacher talk session. The teacher talks related to their classroom experiences after professional development in Goma curriculum. The teachers' responses were used as indicators to determine at what character post they were positioned along the Goma 7-Step pathway, as well as the types of experiences the teachers had. A summary of the analysis related to the findings of the teachers' experiences are found in Appendix C.

The next section provides a description of findings presented from the analysis of teachers' instructional practices. The categories of the teachers' instructional practices (instructional delivery, social interaction, emotional appeal, and cognitive enhancement) were discussed within a character-based context, specifically the potential of each to help initiate a classroom character culture. The next chapter provides a discussion of the findings of the study and the implications of those findings for classroom educators. Finally, the chapter concludes with recommendations for further research. 


\section{CHAPTER V}

\section{FINDINGS AND CONCLUSIONS}

The content of our character - the elements that hold us erect and responsible—is seen through our daily walk and talk and in our grateful attitudes. Praisesong for the vision, passion, and faith of our kinsmen and women who have brought us together. Like Sankofa, the Adinkra bird who looks backward and flies forward, we have found wisdom in our ancestry to right our communities, applaud our teachers, and rejoice in the possibilities of our children. Praisesong to GOMA. (L. Spears-Bunton, personal communication, May 2012)

The present study offers hope to classroom educators seeking to create classroom environments that affirm and empower all students. Found within this study are the stories of six teachers, who described their teaching and learning experiences as they adopted and infused Goma character-based principles in all dimensions of their daily instructional practices. Their narratives provide opportunities for rethinking the role of teachers in helping to shape the character of students, as well as the possibilities they have to "right our communities," according to Spears-Bunton. This chapter presents a broad overview of their experiences and what can be learned from the study overall.

The chapter is separated into four distinct parts. The first part of the chapter includes a summary of findings related to each research question. In addressing research question \#1, teachers' experiences are summarized as they progressed along the character posts of the 7-Step character education pathway of Goma curriculum. Through the lens of Goma character education curriculum, the character posts are discussed in conjunction with the experiences reported by the teachers. When addressing research question $\# 2$, this section presents a summary of the 
participating teachers' instructional practices and how these supported a classroom character culture either through social interaction, instructional delivery, cognitive enhancement and/or emotional appeal.

The second part of the chapter presents conclusions about (a) the impact of Goma curriculum on teachers' instructional practices, (b) instructional practices as opportunities for shaping classroom character culture, and (c) the text. The chapter concludes with implications for classroom educators, and finally, recommendations for further research are presented.

\section{Summary and Discussion of Findings}

This section provides a summary and discussion of general findings that addressed each research question independently, namely: (a) What kinds of experiences were teachers having as they progressed along the character education pathway of Goma curriculum? (b) What opportunities did teachers' instructional practices provide for creating a character culture in their classrooms?

\section{Research Question \#1}

In summary, the major findings of question \#1 of this study are discussed below.

Finding \#1. The participating teachers of the present study had a variety of experiences as they progressed along the 7-Step pathway of Goma curriculum. Their experiences included: (a) cognitive, (b) emotional, (c) instructional, and (d) social. Each character station along the 7Step Pathway seemed to engender a specific type experience among the six teachers. Each post is summarized below with a discussion of the experiences that were evident in the teacher talks.

Objective. Based on the responses, teachers who landed at the Objective character post had primarily Cognitive experiences that were followed in frequency by instructional experiences. Emotional and Social experiences were infrequently noted. Derived from both 
categories of experiences, cognitive and instructional, were a number of themes surrounding pockets of information that can be revealed about students. For example, teachers who had cognitive experiences at this post shared responses that carried themes regarding (a) knowing student differences, (b) why students behave in particular ways, and (c) knowing how to read students' emotional, physical, and academic behaviors. On the other hand, teachers who had instructional experiences shared responses that pointed to themes on topics of knowing how to present subject area content, as well as knowing when to make instructional adjustments based on student cues. Teachers' comments that pointed to cognitive experiences offered key pieces of knowledge that teachers can use to more effectively respond to student needs, thereby supporting a healthy character-filled learning environment.

Taken together, these themes provide a narrative about what vast knowledge teachers could, and perhaps should have about their student learners. Interestingly, the themes do shed light on how teachers' knowledge of their students is important for creating a classroom culture that is driven by positive character intentions. The teachers' comments showed that knowing student learners, in particular, having an awareness of student differences, their needs, and their unique ways of communicating their needs and interest, does in fact support a character framework. Nieto (2002) argued that students bring vast knowledge and experiences into the classroom, a reality that is sometimes disregarded by teachers. With the vast differences students bring to a single classroom, equally, teachers are presented vast opportunities to demonstrate a character focus based on what they do with the knowledge they have of their students. Whether this knowledge is used as a basis for further learning or altogether ignored is a choice that is rooted in discussions surrounding character, in that it speaks to teachers' value of student knowledge. It may be possible that without knowledge of individual student backgrounds and 
diverse characteristics, teachers could be challenged in their ability to initiate classroom character culture since a character culture acknowledges student differences and uses these differences, in essence, as a bridge to help write a relevant classroom text.

The emphasis of knowing students as an important part of the teaching process means that students are featured prominently, not only in terms of their distinct ability levels and unique learning styles, but also as classroom policy makers because they are provided opportunities to assist with curriculum planning. Clearly, in this schema, the student is not regarded as a blank slate upon which teachers can begin to write (Freire, 2002). Instead they are treated as valued stakeholders in the teaching and learning process.

Method. Based on the responses of the participating teachers, those who landed at the Method character post indicated Instructional experiences as the only experience noted. Neither Social, nor Cognitive, nor Emotional experiences were evident in teachers' responses. In the instructional experiences of teachers at the Method character post, two major themes emerged from the teachers' responses: relevance and the evidence of instructional patterns.

Relevance resonated throughout most of the teachers' responses. Goma curriculum views relevance as a key feature found in teachers' instructional strategies that enabled students to make connections between the curriculum and their own lives. (Goma Curriculum Handbook, 2007). As it appeared in the teachers' responses, students' lives became the bulls-eye for which the instruction was targeted or at least situated. Generally speaking, teachers could refer back to the Objective character post, and take what they had learned of their students to present concepts that related to student lives. Participating teachers described how they were able to couch their instruction within the lived realities of the students. In this way, students could reach the academic goals of the classroom, with the least amount of resistance. The teachers indicated the 
use of specific strategies for ensuring relevance, including: role-playing, group discussions, movement, and real-life experiences. Secondly, the teachers' responses showed a theme of instructional patterning, where there was some predictability in the way the class was organized, more specifically, how the teachers presented the lessons. Seemingly, students would adapt more easily to classroom environments where teachers' instructional style and presentations of the lessons were consistent, thereby, allowing students some predictability of the activities and increased familiarity with the classroom space. In the case of both themes, based on teachers' responses in the transcripts, Method was shown as an instructional bridge, where relevance and consistency seemed to unite as the dominant character within teachers' responses_-a character that would appear to help minimize the conflicts or gaps that might exist between students and the curriculum.

Attitude. Overall, the character post most evident in teachers' responses shown from the transcripts of teacher talks was Attitude. An interesting observation is that the teachers' responses that reflected a presence at the Attitude character post showed experiences of all types: instructional, emotional, cognitive, social, as well as blended experiences (see Appendix C). This is a unique characteristic of the teachers' responses since no other post indicated this pattern. When teachers were found at the character posts of Objective, Method, Behavior, Communication, and Discipline, there were instances where there was no evidence of certain experience types. Based on the responses, teachers who landed at the Attitude character post had Instructional experiences followed by Emotional, Cognitive, and Social, respectively. During their Instructional experiences, teachers showed changes in their attitudes toward: (a) teaching, in general, (b) notions of flexibility as a feature of effective teaching, (c) opportunities for improvement in teaching, and (d) the impact of Goma curriculum on teaching. Interestingly, 
some teachers' Emotional experiences appeared to be sparked primarily by the application of the Goma values during their social interactions with their students, where they described heartfelt attitude changes toward their students. Others described their experiences with teaching in the Institute as a fun activity. During their Cognitive experiences, some teachers reported discoveries surrounding the idea that character must be embraced before it can be taught. As well, their responses indicated an acknowledgement of the Institute as impetus for the changes in their attitudes. The purely Social experience seemed nominal; however, it would expectedly bear great significance within a character education framework. During this experience, teachers described their attitudes regarding their own transparency during interactions with students. Another interesting observation was that the Attitude character post seemed to represent a point of climax. The teachers' responses between Objective and Attitude continued to escalate and after the Attitude character posts, the responses that reflected Behavior, Communication, and Discipline decreased. Attitude, as the apparent nexus of the framework, seemingly represented instances where the teachers, at various points, made the "right turn" down the vertical plane of the 7-Step pathway. It seemed that at this point, teachers began to integrate the art of teaching into the science of teaching as shown in the responses indicating teachers' social interactions with students and the teachers' management of student relations with their peers.

Behavior. Based on the responses of the participating teachers, those who landed at the Behavior character post indicated Social experiences, with no evidence of Instructional, Cognitive, nor Emotional experiences. As shown in the previous chapter, the involvement of social interactions between teachers and students, as well as the teachers' management of other classroom relationships are inherent in the definition of the character post itself. It seemed logical that Social experiences would be strongly noted among the teachers' responses. Themes 
of respect, trust, honor, and conflict resolution saturated the teachers' experiences while at the Behavior post. These themes also represent the core values of Goma curriculum, as well as The Ellison Model (Ellison, 2002). This is an interesting observation that the values of the curriculum would be most conspicuous at the Behavior character post when at other times, the values seemed to be present as part of a hidden curriculum. At Behavior, teachers appeared to begin doing the "art of teaching," whereas at Method, teachers appeared to be doing the "science or theory of teaching." In this way, the Behavior character post might be described at the point at which theory meets practice, or where science meets art.

At the Behavior post, students would seemingly read with greater fluency the teachers' behaviors. This was expected since at the horizontal plane of the Seven-Step pathway, involving Goal, Objective, Method, and to some degree Attitude, Goma curriculum seems to present character along theoretical lines. The application of the theory seemed to really take shape in ways that could be more comprehensible by the students. For example, students may not have had understanding of what teachers knew about them, as in the Objective character post, but they could recognize the ways in which the teachers interacted with them, as in Behavior character post. Goma curriculum argues that all along the pathway, the curricular choices made at every post are meant to be reflective of character values (Goma Curriculum Handbook, 2007); however, the role of the teacher's behavior in student interactions are more likely to be distinguishable by the students as the sole deliberate choice of the teacher.

The responses and experiences of the teachers suggested that Behavior shares a parallel relationship with Method in that they both could be drawn from the Objective post to provide information about the student learners. For example, at the Objective character post, teachers could develop knowledge of their students, and at the Method character post, teachers could then 
use what they learned of their students to build instructional bridges. Similarly, at the Behavior character post, teachers could use what they had learned of their students from the Objective post to build social bridges. Therefore, Behavior showed some degree of similarity to the Method character post, in that they both represented a segue from simply knowing the students to using what was known as a foundation for building bridges to help the students achieve the classroom goals. These bridges could conceivably connect students to the center of the classroom community, thereby increasing their opportunities for social and academic success. The difference between Behavior and Method was in what character was presented and/or emphasized at each post. Shown earlier, Method provided instructional bridges through relevance and consistency toward minimizing conflict between the student and curriculum. Behavior, however, provided social bridges where trust, honor, and respect serve as the collective character for resolving conflict on social levels.

Communication. Based on the responses of participating teachers, those who landed at the Communication character post had primarily cognitive experiences with some evidence of social experiences. Neither instructional nor emotional experiences were evident in teachers' responses. During their cognitive experiences, the following themes emerged from teachers' responses: (a) reasons for which students "do the right thing” and (b) what happens when students interpret teachers' behavior as devaluing of students' own lives. During teachers' social experiences, their responses were centered on what happens when students sense that the classroom is a safe and protected space.

From the overall responses of the teachers, who landed at the Communication character post, it appeared that there may have been a linear relationship between the behaviors and succeeding communication between teachers and students that may look as follows: 
that were interpreted by students as either affirming or devaluing. As a result of these interpretations, students responded in ways that were regarded by their teachers as either appropriate or inappropriate. This suggested (a) that students learn from their teachers and (b) that students give teachers what receive from their teachers, either through explicit or implicit instruction. If students learn from their teachers, they learn how to perform, how to respond, and how to behave.

Discipline. Based on the responses, teachers who landed at the Discipline character post had primarily social experiences. Their responses indicated no other type of experience. Even when blended experiences were shown, the hybrid experience involved social component. During their social experiences, teachers' responses reflected the central theme of teachers' management of classroom space \& social relations as a major contributor of social climate.

Discipline was the character post with the least number of responses from the teachers. This may be due to the interview protocol of the primary research, which did not address how teachers proposed to sustain the character culture. On an interesting note, however, discipline and behavior showed the same pattern of experience, and that being social. Further research might confirm that there is a relationship between teachers' behaviors and the overall outcome of the classroom culture. What is remarkable about this observation is that Behavior follows Attitude. Perhaps the nature of the environment that is sustained depends on the quality of Behaviors that are born out of a certain Attitude, whether inclusive or exclusive; and the subsequent interpretations students make of teachers behaviors.

Finding \#2. The research of this study could not determine a completely linear progression along the pathway, but there was evidence of teachers' personal progression in 
terms of (a) how teachers understood Goma curriculum concepts, as well as (b) their understanding of potential relationships between teachers' instructional and social practices and the development of students' character, and (c) how this might be reflected in students' academic and social responses to the curriculum (classroom text). It appeared that the pathway itself provided opportunities for teachers to (a) get to know their students, (b) monitor their own attitudes toward their students' potential, the curriculum, and their efficacy as educators, namely character educators, and (c) engage their students in relevant and value-centered instructional and social practices. The responses of the participating teachers evidenced a clear alignment along the objective, method, and attitude (OMAB) of the Goma 7-Step pathway to teachers' knowledge, skills, and dispositions. While the Goma 7-step pathway defines Methodology in a way that is akin to skills (Goma Curriculum Handbook, 2007), teachers' experiences, based on the responses, showed that Behavior is also a part of that Skills network. In other words, skills were not limited to how well a teacher delivers instruction, but also included how well they managed classroom relationships.

Finding \#3. In examining teachers' responses, it was evident that at the Method character post, the text was more curricular in nature. Conversely, at the Behavior character post, the text appeared to be more social in nature. It seems that the actual composition of the text takes place at these two character posts. However, the teachers' responses indicated that all the character posts of the 7-Step pathway carry unique, yet interdependent experiences, all of which contribute to the quality of the classroom text and classroom culture (see Figure 8 on p. 136).

Finding \#4. Teachers were shown to have had cognitive, instructional, emotional, and social experiences that were most evident when they reported changes in their attitudes toward their students, themselves, and their instructional practices. (see Appendix C). 
Figure 8: Goma curriculum: composing a classroom text

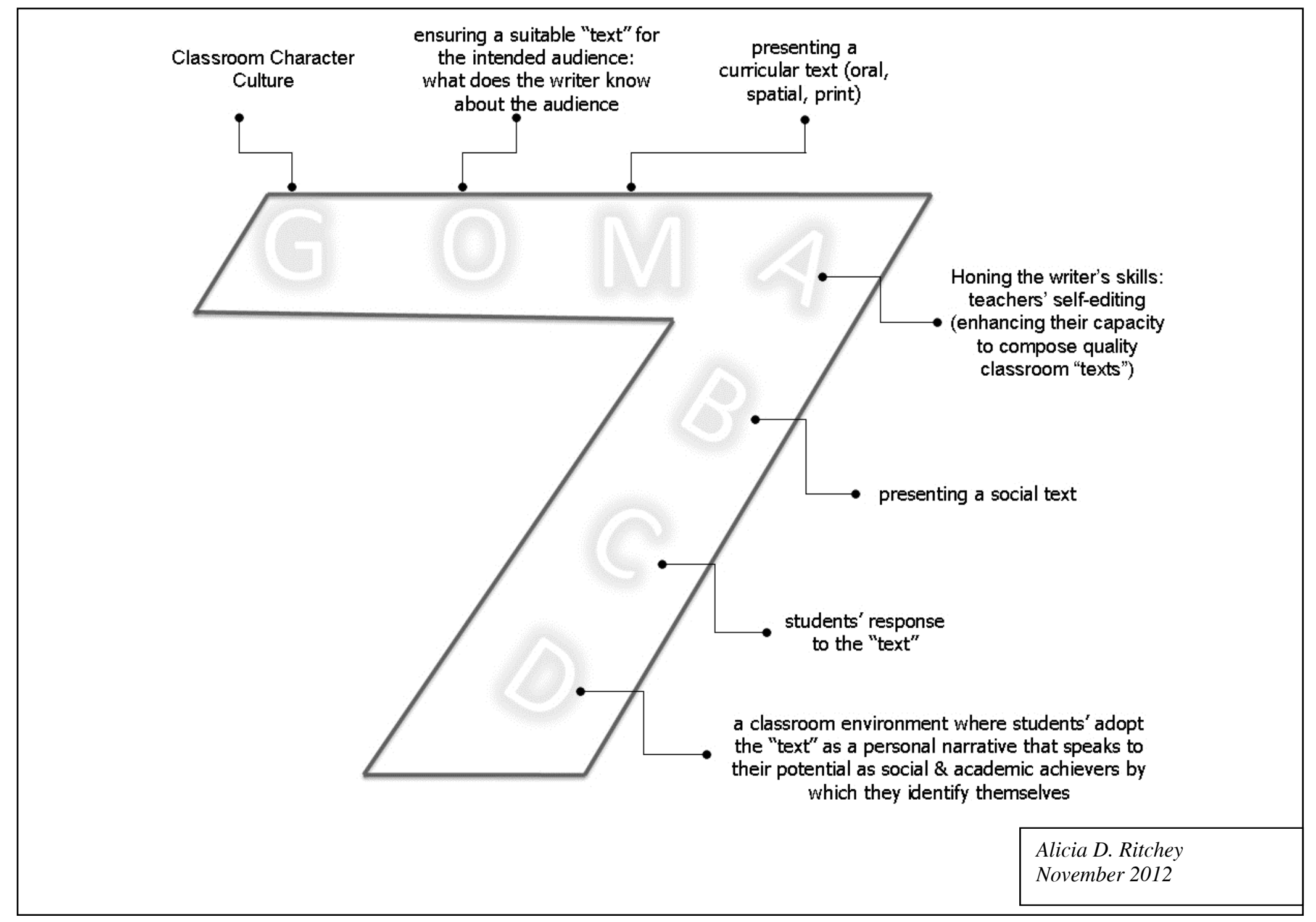




\section{Research Question \#2}

In summary, the major findings of Question \#2 are outlined below.

Finding \#1. A "classroom character culture" could not be absolutely determined since classroom culture involves students' responses to the text and the present study did not involve the examination of students' responses. However, a classroom character culture might be logically assumed based on (a) the character focus of the participating teachers' instructional practices, and (b) the integration of Goma values in their instructional practices. Examination of the participating teachers' responses, does allow us to (a) watch the unveiling of the text, (b) observe what values teachers used to write the script, and (c) conclude how students might respond to a text of this nature. If classroom culture is shaped by the constant exchange between the text and the students' subsequent interpretations and responses to it, it is possible that students' social and academic responses to the text will follow the same nature as the text they read. Therefore, if character values are used to create the text, and students interpret the text as a narrative that is uplifting, relevant, and empowering, students are likely to make character-based responses to the text. It stands to reason that the subsequent classroom culture will be charactercentered, as well.

Finding \#2. Teachers showed numerous ways to present text, as there were different forms of text evident in their instructional practices (e.g., print, oral, social, and spatial). Further, the reports of the six participating teachers showed that teachers employed cognitive enhancement, emotional appeal, instructional delivery, and social interaction as part of their instructional practices. It appeared that embedded within these teachers' instructional practices were a myriad of opportunities by which teachers facilitated the process of creating a classroom character culture. Researchers (Benninga, Berkowitz, Kehn, \& Smith, 2006) argue that character 
education is not presented merely through explicit character education initiatives, but should also be infused throughout the curriculum. Teachers' self-reports showed that the six teachers' instructional practices, as part of the curriculum, provided character-building opportunities for their students. This gave the teachers the chance to model values they wanted their students to emulate. The responses of the participating teachers showed how they executed Goma curriculum through certain instructional strategies. That is, demonstrate practices that represented opportunities which any educator could use to initiate the process of beginning to build a positive and effective a classroom culture

Social interaction. Weissbourd (2003) posits that the development of students' character is greatly impacted by what relationship experiences unfold as they interact with their teachers assuming their teachers express mature ethical capacities. A number of participating teachers' instructional practices fell within the category of social interaction, including: (a) the use of open dialogue and discussion, and (b) regard for students as instructional evaluators. In those instances where teacher reports' evidenced activities involving the use of open dialogue and discussion, teachers appeared to be deliberate in creating a dialogic classroom that allowed students to develop comfort and competence expressing thought in an open forum. Spears-Bunton and Powell (2009) emphasize dialogue as a distinct feature of a "literacy of promise" and argue that through dialogue, students' responses become the focal point of teaching. In this way, teachers express clear intentions to give students the same regard as themselves and the curriculum. Moreover, teachers' instructions seemed then help establish the classroom as character space with the evidence of respect, not only between the teacher and the students, but between students and their peers as student ideas are presented in an open forum. 
Based on teachers' self-reports, the other instructional practice that seemed part of teachers' social interactions with their students occurred when teachers allowed their students to serve as evaluators of instructional quality and the content of the lesson. Social interaction, in this case, contained elements of honor and respect which were present as intrinsic values of the teachers' instructional practices seeing that incorporated students' ideas.

Emotional appeal. Teachers whose strategies fit within the category of emotional appeal evidenced use of strategies that included: (a) affirmations, (b) sharing, and (c) encouragement \& motivation. These strategies appeared to have significant impact as teachers modeled certain behaviors in effort to call students to rise to character. These attempts can encourage students to develop an authentic voice. Collectively, these strategies parallel what researchers refer to as "reinforcing effort and providing recognition" (Marzano, Pickering, and Pollock, 2001, p.49). In their extensive study of effective teaching strategies, researchers, Marzano, et. al. found "reinforcing effort and providing recognition" to be among one of nine classroom strategies that promote student achievement.

Cognitive enhancement. Lickona (1991) argued that values should be taught through the curriculum; however what he proposes may be limited to disciplines of social sciences and language arts. Cognitive enhancement as demonstrated by a Goma educator could work in any discipline or subject area. In other words, the relationships found in any subject area content would seemingly be able to serve as a metaphorical representation of social relationships; thus a teachable moment for teachers to reinforce character and values. Based on the teachers' selfreports, teachers were able to use types of social relationships to describe interactions among variables found within content areas. This suggested that whether describing how a plant relates to the sun in photosynthesis; whether describing the relationship between an organ in the human 
body and a particular internal environment; or whether describing the relationship between specific numbers in a sequence, teachers have vast opportunities to help students understand academic concepts as outcomes of relationships. Relationships may be complementary, volatile, cause and effect, continuous, parallel, and/or oppositional in nature. Teachers are able use these relationship types as categories for describing social relationships and teaching character-based principles, while deepening students' understanding of subject area content.

The responses found in the teachers' self-reports showed that teachers are able to use cognitive enhancement to show symbiotic relationships between the elements of the subject area content and character, regardless of the content area. When concepts are presented in this way, they get opportunities to identify similarities and differences between concepts that may be easy to understand and problems that may be difficult to solve (Marzano, et. al., 2001). These

opportunities could lead students to (a) experience interdisciplinary learning, making linkages to other information, (b) develop a knack for presenting information from multiple perspectives, and (c) increase their capacity for relationship building with others who view, understand, and interpret the world from a different perspective than themselves.

\section{Summary of the Impact of Goma Curriculum on Participating Teachers}

A noteworthy observation of Goma curriculum 7-Step pathway is that once teachers had experienced the Attitude character post, they were not always confined to the pathway in the consecutive order of its outline (GOMABCD). This might have happened because Attitude is described within Goma curriculum paradigm as the pivotal point that swings between method and behavior. This would allow teachers to be able to use certain modes of social interaction (Behavior) in order to inspire, move, or orient students toward formal instruction (Method) in cases where the text is more curricular in nature. 
The overwhelming responses of participating teachers indicated that Goma curriculum had a profound impact on the classroom educators in ways that impacted their ability to teach character. In other words, teachers were able to make curricular choices that reflected values of positive character. These values were reflected in their planning, instructional delivery, assessment and management of the social environment. Viewed in this light, definitions of teaching would also encompass a reflective conflict resolution process that makes use of certain character-based values, including trust, honor, and respect.

The process of teaching would begin with knowledge of the student as the point of instructional origin. This would look differently from the instructional model that views knowledge of the content as the basis from which instruction begins. Classrooms guided by this kind of instructional delivery might be viewed as an efferent text, in which case, the students are silent readers (Rosenblatt, 1995). As well, teachers who use an efferent model of teaching as an approach for constructing a classroom text would have certain expectations of the succeeding responses students should make toward the text. Connor and Willis (2009) argue for particular modes of teaching that enable a 'critically framed reader response' so that students reading and responses to the text would enhance students' sense of agency and social justice. This kind of instruction, toward the creation of an aesthetic text (unlike that of an efferent text), would likely involve teachers' knowledge of the cultural, academic, historical realities that would shape their students' ultimate responses to the text.

One may argue that simply knowing the academic differences of students may suffice for composing a character-based environment. Differentiated instruction, for example, primarily deals with academic differences of the students. Still teachers must take into account social, cultural, and personal dynamics that may influence academic performance (Nieto, 2002). 
Therefore, it is encumbered upon teachers to develop a comprehensive working knowledge of their students whether in terms of their learning style differences, or the cultural perspectives that may inform their academic and/or social responses to the classroom community text

\section{Summary of Instructional Practices as Opportunities for Shaping Classroom Character Culture}

The instructional practices of the participating teachers found in the present study demonstrate possibilities for teachers to create a certain environment within the classroom space. As it appears, these practices would foster a certain classroom environment since they reported having allowed their students to become active participants in the values and norms of that environment. In other words, the teachers granted their students access to rights of practice through membership into a community that was based on the values practiced by the teachers themselves (Lewis, 2001). Through such instructional and social practices, it is likely that the teachers helped their student learners achieve greater participation with other participants in the classroom space. Teacher participants in the present study have demonstrated that these practices represent a network of strategies that can be used to promote character education in ways that do not require any additional work on the part of the teacher. What may be required, however, is that teachers recognize and utilize what bountiful opportunities their instructional practices provide for character building. This may also entail adjustments in the way teachers think about their classroom practices. In turn, students may read and interpret the teacher's delivery and management of the curriculum and classroom relationships are likely to be presented in ways that students' read and interpret as a guide for how they should behave and respond.

Instead of viewing character education, more specifically the creation of classroom character culture, as an increase in work load, teachers should perhaps consider the fact that such 
an environment may reduce the work load since the kind of culture, at least the one proposed by Goma curriculum, regards students as instructional leaders - as individuals who are encouraged to become active learners, and who take ownership in the teaching and learning process.

\section{Summary of the Text}

What can be understood from both the teacher talks and the teachers' self-reports is that within the classroom space, teachers have a variety of ways to present a text since there were different forms of text evident in their instructional and social practices (e.g., printed, oral, social, and spatial).Within Goma curriculum, the classroom goal centers on efforts to establish a classroom character culture-one that represents an inclusive community where performance and moral character are evident as a way of life for all its members (Goma Curriculum Handbook, 2007). In such classrooms, teachers' instructional and social practices would be guided by values of trust, honor, and respect. Behaviors of character would be perpetuated by a consistent narrative that affirms participants of the classroom community as social and academic achievers.

As the six participating teachers moved about the Goma 7-Step pathway, they described a collective of experiences, attitudes toward their experiences, and varied instructional and social practices. These elements became the basis for the kind of text they could expect to compose for their students, as well as the succeeding culture of their classroom. It was obvious that the classroom became a world in which participating teachers were able to manage artifacts, personalities, events, and contexts (Powell, 2001). Attempts to compose an affirming text necessitated that teachers situate the lessons in the realities of the students' lives, wherein students could see themselves represented throughout the curricular choices of the teacher (Rosenblatt, 1998). Giroux posits (as cited in Powell, 2009) that this text would be best described 
as "pedagogical resources to rewrite the possibilities for new narratives, identities, and cultural spaces" (p. 185).

The responses of the participating teachers support the Goma 7-Step pathway as a plausible framework to assist teachers' efforts to initiate a classroom character culture. Such a culture would reflect an inclusive community where performance and moral character are evident as a way of life for both teachers and students. The effort toward establishing the classroom as an inclusive community is supported by teachers' instructional and social practices. Here we can interject Powell's expanded notion of text, where the individual, in this case, the student, is able to carve out meaning from his/her experiences in the classroom. The messages embedded in these experiences would then facilitate interpretations by the student learners (Spears-Bunton, Powell, Blake, Ritchey-Brown, \& Salahuddin, 2004). Additionally, students would create their personal identities, as well as develop understandings about how the world should be viewed, and their place in it (Freire \& Macedo, 1987; Powell, 1999). This being said, it is likely that when teachers' instructional and social practices are guided by values presented in The Ellison Model, a narrative or a particular text is composed —one that affirms the members of the classroom community as social and academic achievers. The responses of the participating teachers, suggest that the text is not static, but fluid. Moreover, the text is multifaceted with components that may include print, oral, social, and spatial dynamics.

One could argue that OMAB of the Goma 7-step pathway may be catalysts for the nature of the classroom text and the process by which the text is created. As the text is being composed, students are simultaneously interacting with it. This transaction involves how students view the text in relation to their own lives, and how they interpret what value the text ascribes to their potential as contributing members of the classroom community. Teachers can expect a character 
culture when the text affirms the potential of the student learners, and is presented in a relevant manner where students can see themselves represented throughout.

Whether the teacher presents the classroom text within the aesthetic or efferent domain, students are likely to engage in the process of interpretations. The Ellison Model presents two approaches to community building: Inclusive community building and Dis-community building (Howard, 1997). Both communities are built and sustained by activities, which are guided by certain values. Within The Ellison Model framework, classroom communities would be characterized as inclusive or exclusive. The classroom, as an exclusive text would expectedly create conflict ridden classrooms since they, like efferent texts, ignore the lived realities of the students. In the context of the classroom, the practice of exclusion would counter the efforts of Goma curriculum to develop understandings of student learners as a basis to develop meaningful lessons and begin the process of resolving classroom conflicts. Conversely, the classroom as an inclusive community would provide a text wherein the students can see themselves in all aspects of the teachers' practices. Expectedly, this would facilitate a classroom culture where positive character predominates in the moral and academic character of both teacher and students.

\section{Implications for Classroom Teachers}

\section{Teacher Attitudes}

Nieto (2002), in her discussion of students' cultural capital, asserts that teachers' attitude towards cultural capital owned by certain students have direct impact on students; followed by teachers' attitudes are certain behaviors. Goma Educators, namely the participating teachers in the present study often spoke of their need to improve their attitude toward themselves and their students. Teacher attitudes may be a major contributor in student's social and academic outcomes. Undoubtedly teachers must recognize the need for making adjustments in their 
attitudes. Otherwise, their students might be facing social and academic disadvantages. Hunt (2008) insists when he leads development programs for education administrators that 'Attitude,' supported by "caring, sharing, loving behaviors, as well as affirming communication, yield discipline or sustainability of a desired outcome." Hunt also argues that the desired outcome is achieved through nurture over time. Congruent with Hunt's various theories, within the context of the classroom, the participating teachers in this study evidenced that they carried particular attitudes or perspectives of themselves and their students. Those attitudes were shown to drive the way they behaved toward the learners. Hunt's theory about community building refers to these behaviors as being of a "caring, sharing, loving" nature. The Goma framework speaks more of specific behaviors as being respect, trust, and honor. It is important that teachers communicate these messages to their student learners - messages that affirm student potential as social and academic achievers, no matter what the behaviors are named. Participating teachers in the present study confirmed an on-going dialogue between the behaviors of themselves and their students. In this way, when the behaviors of the teacher and the resulting responses from the students are not complementary, the teacher is able to reassess, make adjustments, and apply additional relevant strategies or behaviors to motivate the learner toward more advanced and appropriate responses. The additional strategies could involve nurturing the learner, through social interaction, cognitive enhancement, emotional delivery, and/or instructional delivery. And with a persisting affirming and inclusive attitude held by teachers, the students, over time, would likely be able to move from a point of disconnect to becoming a part of a sustained community of successful learners, comprising both the teacher and other students. This being said, teachers, perhaps, should expand their notions of who they are as educators. This would involve redefining teachers as character educators who also teach specific disciplines or subject area content. This 
would move teachers beyond a narrow view of themselves as subject area experts, where character education is maintained as a separate discipline outside of their teaching domain. Teacher Education and Professional Development for In-service and Pre-service Teachers

Participating teachers in this study made references to having learned instructional methodology as part of a methods curriculum in their teacher education programs. Their responses indicated, however, that what they had learned in their methods classes was in no way presented as part of a character-building exercise. Unlike the traditional methods courses, Goma framework introduced teachers to Methods as a bridge to resolve academic conflicts that students may have with the curriculum. The lack of substantial professional development for teachers prior to program implementation is seen as a weakness in some character education programs (Wilson, 2007). Ironically, researchers argue that the teacher or staff member is the person responsible for demonstrating proper moral behavior (Benninga, Berkowitz, Kehn, \& Smith, 2006). If teachers are responsible for modeling appropriate behaviors for their students, then it would seem reasonable that teacher education programs and professional development initiatives would infuse a character-driven component within its framework. This component could involve an emphasis on teaching both pre-service and in-service teachers the importance of modeling acceptable character through instructional and social practice.

Some scholars define character as "the image of an original perpetrator(s), whose philosophy is guided by a meta-value in its purest form" (D. G. Hunt, personal communication, June 26, 2009). While the original intent of the perpetrator may become diluted over time, nonetheless, vestiges of the character may still be evident and carried out depending on how the society adapts and/or responds to the influence of the character. This may also depend on how well the character is able to legitimate itself within changing societies. Goma curriculum regards 
character as the expression of inclusion, the overarching intent or meta-value of its framework (Goma Curriculum Handbook, 2007). The life of the character would expectedly be sustained by teachers' knowledge, skills, and dispositions toward certain students, which are perpetuated in all aspects of teaching, including planning, pedagogy, assessment, and classroom management. Underlying this study is the idea that the development of student's character is to some degree influenced by his or her experiences with the curriculum, and those who deliver it. This has weighty implications about the need for teachers to become aware of what values under-gird their instructional and social practices and the curriculum they present to students (Jackson, Boostrum, \& Hansen, 1993). They must consciously examine what methods they use to present the curriculum, so as not to pass on certain limitations to their students. Toward this end, teacher education and continuing education programs could emphasize and extend ideas of what it means to model character. Modeling character must include an emphasis on the execution of curricular practices that are positioned toward an inclusive classroom culture — one that promotes relationship building opportunities between classroom personalities, including students, teachers, and the curriculum.

\section{Recommendations for Further Research}

The present study examined the kinds of experiences which six teachers had as they progressed along a character education pathway, known as Goma curriculum 7-Step pathway. Moreover, the study examined opportunities that the participating teachers' instructional practices provided for creating a character culture in their classrooms. Additional research might offer a fuller broader perspective of the classroom culture when examined through student narratives. Therefore, the following recommendations are made to extend the research further: 
Add students' perspectives by perhaps interviewing who were taught by the pool of participants. Teachers' responses at the Communication character post were limited in that teachers could only make assumptions about what messages the teachers' behaviors conveyed to their students. To include students' perspectives, answers to this question may have been analyzed from multiple perspectives, thereby providing an enlarged view of Goma curriculum paradigm.

Further research could also investigate the prolonged effect of Goma curriculum on teachers' instructional practices. Because the setting of the study was character specific, where the Institute had the sole purpose of character education, results of the study may have expectedly revealed a favorable view of Goma curriculum and its impact on educators. Another study may then investigate to what extent Goma curriculum is still being used to drive the teachers' instruction, and whether Goma curriculum is a complementary framework given the realities of teachers in regular school settings.

Teacher participants in the present study were all African Americans who taught a population of student who were largely African Americans, as well. Further research could examine the impact of Goma curriculum of non-African American teachers on the same students. Perhaps this might generate possibilities for generalizations similar to the findings of the present study, including the impact of Goma curriculum. 


\section{References}

Artilles, A., \& S. Trent. (1994). Over-representation of minority students in special education: A continuing debate. The Journal of Special Education, 27, 410-437.

Bandura, A. (1997). Self-efficacy: The exercise of control. New York, NY: Freeman.

Barkley, J. M. (2006). Reading Education: Is self efficacy important? Reading Improvement, 43(4), 194-210.

Bell, Y. R. (1994). A culturally sensitive analysis of Black learning styles. The Journal of Black Psychology, 10, 47-61.

Benninga, J. S., Berkowitz, M. W., Kehn, P., \& Smith, K. (2006). Character and academics; What good schools do. Phi Delta Kappa International, 87(6), 448-452.

Berkowitz, M. W., \& Bier, M. C. (2005). What works in character education: A research-driven guide for education. Washington, DC: Character Education Partner. www.character.org.

Blake, B. E. (1998). "Critical” response in an urban classroom: creating cultural texts to engage diverse readers. Theory into Practice, 37(3), 238-243.

Brophy, J., \& Good, T. (1974). Teacher-student relationships: causes and consequences. New York, NY: Holt, Rinehart \& Winston.

Carpenter, T., Fennema, E., Peterson, P., \& Carey, D. (1998). Teachers' pedagogical content knowledge of students' problem solving in elementary arithmetic. Journal for Research in Mathematics Education, 19(5), 385-401.

Carver, E., Price, K., \& Wilken, D. (2000). Increasing student ability to transfer knowledge through the use of multiple intelligences (Master of Arts Action Research Project). Retrieved from ERIC (ED44798)

Chase, B. (1999). "Is Character Education the Answer?" Education World. www.education-world.com/a_admin/admin097.shtml

Cirino, P., Durdadola, P., Foorman, B., \& Carlson, C. (2007). Teacher characteristics, classroom instruction, and student literacy and language outcomes in bilingual kindergartens. The Elementary School Journal, (107)4, 341-364. doi:10.1086/516668

Clemons, K. (2008). Hip Hop as a Cultural Genre of the African American Musical Tradition: A Critical Race Theory Analysis of Hip Hop Pioneers' Experience. (Doctoral dissertation). Retrieved from http://dc.lib.unc.edu/cdm/ref/collection/etd/id/1931 
Coleman, J. S. (1966). Equality of Educational Opportunity. (COLEMAN) Study (EEOS). Ann Arbor, MI: Inter-university Consortium for Political and Social Research [distributor]2007-4-27. doi:10.3886/ICPSR06389v3

Connor, J., \& Willis, A. I. (2009). Educational, controversial, provocative, and personal. In L. A Spears-Bunton \& R. Powell (Eds.), Toward a Literacy of Promise (pp. 81-104). New York, NY: Routledge.

Corti, L., Witzel, A., \& Bishop, L. (2005). On the Potentials and Problems of Secondary Analysis. An Introduction to the FQS Special Issue on Secondary Analysis of Qualitative Data [13 paragraphs]. Forum Qualitative Sozialforschung/Forum: Qualititative Social Research, 6(1), Art. 49, http://nbnresolving.de/urn:nbn:de:0114-fqs0501495

Croninger, R., Rice, J., Rathbun, A. \& Nishio, M. (2007). Teacher qualifications and early learning: Effects of certification, degree, and experience on first-grade students.

Davidson, M., Lickona, T., \& Khmelkov, V. (2007). Smart and good schools: a paradigm shift for character education. Education Week, 27(12), 31, 40.

Delpit, L. (1995). Other people's children: Cultural conflict in the classroom. New York, NY: The New Press.

DuBois, W. E. (1903). The souls of black folks. New York, NY: Bantom Books.

Dunn, L., Beach, S., \& Kontos, S. (1994). Quality of the literacy environment day care and children's development. Journal of Research in Childhood Education, 9(1), 24-34.

Ellison, H. (2002). The Efficacy of The Ellison Model as a retention initiative for first semester freshmen. (Doctoral dissertation). Retrieved from http://digitalcommons.fiu.edu/dissertations/AAI3049781/

Freire, P. (2002). Pedagogy of the oppressed. New York, NY: Continuum International Publishing.

Freire, P., \& Macedo, D. (1987). Literacy: Reading the world and the world. Connecticut: Bergin \& Garvey.

Garcia, E. (2002). Student cultural diversity: Understanding and meeting the challenge (3rd ed.). New York, NY: Houghton Mifflin Company.

Gay, G. (1997). Educational equality for students of color. In J. A. Banks \& C. A. Banks (Eds.), Multicultural Education: Issues and Perspectives, (3rd ed., 195-228). Boston: Allyn \& Bacon. 
Giroux, H. (1998). Education in unsettling time: Public intellectuals and the promise of cultural studies. In Dennis Carlson \& Michael Apple (Eds.), Power/knowledge/pedagogy (pp. 41$60)$.

Goma curriculum handbook: A character education guide for teachers. (2007). Unpublished manuscript.

Good, T. L. (1981). Research on teaching: What we know and what we need to know. Austin, TX: University of Texas at Austin, Research and Development Center for Teacher Education.

Griffin, G. (1998). Teacher education and curriculum decision making: the issue of teacher professionalism. In M. F. Klein (Ed.), The politics of curriculum decision-making (pp. 121-148). Albany, NY: State University of New York Press.

Henson, R. (2002). From adolescent angst adulthood: Substantive implications and measurement dilemmas in the development of teacher efficacy research. Educational Psychologist, $37(3), 137-150$.

Hill, H., Rowan, B., \& Loewenberg-Ball, D. (2005). Effects of teachers' mathematical knowledge for teaching on student achievement. American Educational Research Journal, 42(2), 371-406.

hooks, b. (1994). Teaching to transgress: Education as the practice of freedom. New York, NY: Routledge.

Howard, L. C. (1997). Learning communities, connections and inclusive communities: A learning community building model. Preparing Black Students for the Millennium: The role of Faculty, Staff, Administrators and Students [Newsletter]. Miami: Florida International University, Bay Vista Campus, Office of Multicultural Programs and Services.

Howard, L. (2004, September). How to build and sustain inclusive communities. Symposium conducted at the meeting of ICB Productions, Miami-Dade Office of Community Relations and Florida Memorial College.

Hoyt, D. (2012). Living Two Lives: The ability of low income females to break the glass ceiling of education. Doctoral dissertation. Unpublished paper, Washington State University, Pullman, WA.

Hunt, D. G. (2000a). Community moments and teachable seconds. Miami, FL: ICB Productions, Inc.

Hunt, D. G. (2000b). Community moments and teachable seconds. The executive speaks series. (Training Manual). Miami, FL: ICB Productions, Inc. 
Hunt, D. G. (2003, February). Building Sustainable Community Relationships. Symposium at the meeting of Nova Southeastern University. Davie, FL.

Hunt, D. (2008). Report at 5th International Globalization, Diversity, \& Education Conference. Washington State University. Spokane, WA.

Hunt, D. G., Howard, L., \& Rice, M. (Eds.) (1998) From Diversity to Unity. Conference proceedings on developing inclusive community. October 27-31. Manuscript unpublished. Florida International University. Miami, FL.

ICB Productions (2006). ABCD character education booklets. Miami, FL: Author.

Jackson, P., Boostrum, R., \& Hansen, D. (1993). The moral life of schools. San Fransisco, CA: Jossey-Bass, Inc.

Jencks. C. S., Smith, M., Acland, H., Bane, M. J., Cohen, D., Gintins, H., Heyns, B., \& Michelson, S. (1972). Inequality: A reassessment of the effect of family and schooling in America. New York, NY: Basic Books.

John-Steiner, V., \& Mahn, H. (1996). Sociocultural approaches to learning and development: A Vygotskian framework. Educational Psychologist, 31(3/4), 191-206.

Johnson, L. \& Reiman, A. (2007). Beginning teacher disposition: Examining the moral/ethical domain. Science Direct Teacher and Teaching Education, 23, 678-687.

Kleinman, S., \& Copp. M. A. (1993). Emotions and fieldwork. California: Sage Publications.

Klein, M. F. (ed.) (1991). The politics of curriculum decision making. Albany, NY: State University of New York.

Knoblauch, D., \& Wollfolk-Hoy A. (2008). "Maybe I can reach those kids." The influence of contextual factors on student teachers' efficacy beliefs. Science Direct Teachers and Teacher Education, 24, 166-179.

Kozulin, A., Gindins, B., Ageyez, V., \& Miller, S. (2003). Vygotsky's educational theory and practice in cultural context. Cambridge: Cambridge University Press.

Ladson-Billing, G. (1994). The dreamkeepers: Successful teachers of African-American children. San Francisco, CA: Jossey-Bass, Inc.

Ladson- Billings, G. (1998). Who will survive America? Pedagogy as cultural preservation In Dennis Carlson \& Michael Apple (Eds.), Power/knowledge/pedagogy (pp. 289-304).

Lewis, C. (2001). Literary practices as social acts - power, status, and cultural norms in the classroom. New Jersey: Lawrence Erlbaum Associates. 
Lewis, W. C., \& Moore III, L., J. (2008). African American students in K-12 urban education settings. Urban Education, 43, 123-126.

Lickona, T. (1991). Educating for character: How schools can teach respect and responsibility. New York, NY: Bantam (pp. 67-69).

McLaren, P., \& Gutierrez, K. (1998). Global politics and local antagonisms: Research and practice dissent and possibility. In D. Carlson \& M. Apple (Ed.), Power/knowledge/pedagogy (pp. 305-333).

Macedo, D. (1994). Literacies of power: What Americans are not allowed to know. Boulder, CO: Westview Press.

Marzano, J. M., Pickering, D. J., \& Pollock, J. E. (2001). Classroom instruction that works: research-based strategies for increasing student achievement. Alexandria, VA: Association for Supervision and Curriculum Development.

Mayer, R. (2002). The promise of educational psychology. Upper Saddle River, NJ: Pearson Education, Inc.

Montague, M., \& Rinaldi, C. (2001). Classroom dynamics and children at risk: a follow-up. Learning Disability Quarterly, 24(2), 75-83.

Milson, A. J. (2000). Creating a curriculum for character development: A case study. Clearinghouse, 74(2), 89-93.

Milson, A. (2003). Teachers' sense of efficacy for the formation of students' character. Journal of Research in Character Education, 1(2), 89-106.

Milson, A., \& Mehlig, L. (2002). Elementary school teachers' sense of efficacy for character education. Journal of Educational Research, 96(1), 47-53.

Nieto, S. (2002). Language, culture, and teaching. Mahway, NJ: Lawrence Erlbaum Associates.

Noddings, N. (1997). Character education and community. In Alex Molnar (Ed.), The construction of children's character (Ninety-sixth Yearbook of the National Society for the Study of Education, pp. 1-16). Chicago, IL: University of Chicago Press.

Pajeres, F. (2002). Gender and perceived self-efficacy in self-regulated learning. Theory Into Practice, 41. (pp. 166-225).

Paneque, O., \& Barbetta P. (2006). A study of teacher efficacy of special education teachers of English language learners disabilities. Self-efficacy of teachers of ELLs with disabilities, 30(1) 171-193. 
Powell, R. (1999). Literacy as a moral imperative: Facing the challenges of a pluralistic society, (pp 57-77). New York, NY: Rowman \& Littlefield Publishers, Inc.

Powell, R. (2009). The promise of critical media literacy. In L. A. Spears-Bunton \& R. Powell (Eds.), Toward a literacy of promise (pp. 185-196). New York, NY: Routledge.

Puchner, L. D., \& Taylor, A. (2006). Lesson study, collaboration and teacher efficacy: Stories from two school-based math lesson study groups. Teaching and Teacher Education, 22, 922-934.

Purpel, D. (1997). The politics of character education. In Alex Molnar, (Ed.), The construction of children's character (Ninety-sixth Yearbook of the National Society for the Study of Education, pp 140-153). Chicago, IL: University of Chicago Press.

Raths, L. E., Harmin, M., \& Simon, S. B. (1966). Values and clarification, NASSP Bulletin, 50, pp. 226-501. doi:10.1177/019263656605031246

Reiman, A. J. (2004). Longitudinal studies of teacher education candidates' moral reasoning and related promising interventions. Journal of Research in Character Education, 2(2), 141150.

Rice, C. (2001a). A case of The Ellison Model's use of mentoring as an approach to community building. (Doctoral dissertation). Retrieved from http://digitalcommons.fiu.edu/etd/37/

Rice, C. (2001b). The Ellison Model: Building inclusive communities through mentoring. Miami, FL: ICB Productions, Inc.

Rogers, S., Ludington, J., \& Graham, S. (1997). Motivation \& learning: A teacher's guide to building excitement for learning and igniting the drive for quality. Michigan: Peak Learning System, Inc.

Rosenblatt, L. (1978). The reader, the text, the poem. Carbondale, IL: Southern Illinois Press.

Rosenblatt, L. (1995). Literature as exploration. 5th ed. New York, NY: Modern Language Association of America.

Schubert, W. H. (1986). Curriculum: perspective, paradigms, and possibility. New York, NY: Collier Macmillan Publishers.

Schubert, W. H. (1997). Curriculum - perspective, paradigm, and possibility. New Jersey: Prentice-Hall, Inc.

Shulman, V., \& Armitage, D. (2005). Project discovery: An urban middle school reform effort. Education and Urban Society, 37(4), 371-397. 
Sexias, P. (1993). The community of inquiry as a basis for knowledge and learning: The case of history. American Educational Research Journal, 30, 305-324.

Sitton, D. (1980). The child as informant: The teacher as ethnographer. Language Arts, 57, 540545.

Smith, J., \& Niemi, N. (2007). Exploring Teacher Perceptions of small boys in kindergarten. Journal of Educational Research, 100(6).

Spears-Bunton, L. A. (2009). Obscured white voice in the multicultural debate: race, space, and gender. In L. A. Spears-Bunton \& R. Powell (Eds.), Toward a literacy of promise (pp. 105-123). New York, NY: Routledge.

Spears-Bunton, L. A., \& Powell R. (Eds.). (2009). Along the road to social justice: a literacy of promise. Toward a literacy of promise (pp. 23-39). New York, NY: Routledge.

Spears-Bunton, L., Powell, R., Blake, I. K., Ritchey-Brown, A., \& Salahuddin, P. (November 2004). Critical Reading of Black Representations in Media Texts: Alternative Narratives in Popular Culture. Paper presented at the National Council for Teachers of English $94^{\text {th }}$ Annual Conference in Indianapolis, Indiana.

Stemler, S. (2001). An overview of content analysis. Practical Assessment, Research \& Evaluation, 7(17). Retrieved October 12, 2012 from http://PAREonline.net/getvn.asp?v=7\&n=17

Taylor, E. (2000). Critical race theory and interest convergence in the backlash against affirmative action: Washington State and Initiative 200. Teachers College Record, 102(3), 539-560.

Turner, J. (2003). To tell a new story: A narrative inquiry of the theory and practice of culturally relevant teaching (Doctoral dissertation). Available from ProQuest Dissertations and Theses database. (UMI No. 3100513)

Tyler, (1949). Basic principles of curriculum and instruction. Chicago, IL: The University of Chicago Press.

Van den Berg, H. (2005). Reanalyzing Qualitative Interviews from Different Angles: The Risk of Decontextualiztion and Other Problems of Sharing Qualitatie Data [48 paragraphs]. Forum Qualitiative Sozialforschunge/Forum: Qualitative Social Research, 6 (1), Art. 30, http://nbn-resolving.de/urn.neb

Weissbourd, R. (2003, March). Moral teacher, moral students. Educational Leadership, 6-7.

Weiner, L. (1993). Preparing teachers for urban schools: Lessons from thirty years of school reform. New York, NY: Teachers College Press. 
Windschitl, M. (2002). Framing constructivism in practice as the negation of dilemmas: An analysis of the conceptual, pedagogical, cultural, and political challenges facing teachers. Review of Educational Research, 72(2), 131-175. 
APPENDICES 
APPENDIX A: Interview Questions 
Teacher talks

Day \#1

1. How would you describe the effectiveness of your teaching today?

2. What might you do differently tomorrow?

3. Would you say you had any bumps along the road today? If so, how did you handle them?

4. In what ways did you include the knowledge, skills, and activities of your students' communities as part of the curriculum?

5. Give an example of how you demonstrated and promoted inclusiveness in your classroom?

6. Did you notice any children with limitations, or any reluctant learners? If so, what did you do to get them involved in the lessons?

7. What support did you provide for these students to reach their classroom goals?

8. How do you think Goma curriculum is impacting your teaching?

9. Beyond traditional methods of assessment that involve pen and paper, how do you think Goma curriculum will assist you with your evaluation of children in under-served communities? How will you know when they are learning the concepts you are teaching?

10. In general, what are your thoughts about the lesson plans in terms of the flow, logic, meaningfulness, and any other comments you may have concerning the lessons and how they impact you and your students.

(C) 2008. The Unity House Community Foundation. All Rights Reserved. Communications regarding this instrument should be addressed to Permissions, The Unity House Community Foundation; 307 South Dade Street; Madison, FL. 
Teacher talks

Day \#2

1. What would you say was a highlight of your teaching today? What were your students doing at this time?

2. What would you say was a highlight for your students today? What were you doing at this time?

3. How did you connect with your students?

4. Give an example of how you started one of your lessons in your class.

5. How did you use your students' background knowledge, skills, and experiences as part of your lessons?

6. In what ways do you think Goma curriculum is impacting your students' learning? What other ways has Goma curriculum influenced or impacted students?

7. How would you describe your own teaching prior to your involvement in the Teacher Education Academy?

8. Think about what you know about teaching. Where did you get this information? How is this information different from what you learned in the Teacher Education Academy?

(C) 2008. The Unity House Community Foundation. All Rights Reserved. Communications regarding this instrument should be addressed to Permissions, The Unity House Community Foundation; 307 South Dade Street; Madison, FL. 
Teacher talks

Day \#3

1. As you recall, in what ways did the Teacher Education Program do to emphasize respect, trust, and honor of all students?

2. What did you do in class to verbally demonstrate respect toward the students?

3. What did you do in class to non-verbally demonstrate respect toward the students?

4. What did you do in class to verbally demonstrate honor toward the students?

5. What did you do in class to behaviorally demonstrate honor toward the students?

6. What opportunities did you provide for students to evaluate your teaching?

7. What did you do in class to verbally demonstrate trust toward the students?

8. What did you do in class to non-verbally demonstrate trust toward the students?

(C) 2008. The Unity House Community Foundation. All Rights Reserved. Communications regarding this instrument should be addressed to Permissions, The Unity House Community Foundation; 307 South Dade Street; Madison, FL. 
Teacher talks

Day \#4

1. In your discussions with students today, were you faced with students who responded in ways that you didn't expect? How did you handle these kinds of student responses?

2. Compare the amount of listening and viewing time to the amount of actual engagement time that you allowed today. Which was greater, and why do you think this was this was the case?

3. How do you hope participating in the Institute will better serve your teaching and your students?

4. Do you think you teach differently in the Institute than you teach in regular school settings? Talk about these differences.

5. What do you see as similarities between the Institute and regular school settings? Can you give an example of these similarities?

6. Do you think the Institute's emphasis on character is different in regular school settings? Talk about these differences.

7. Based on your experiences with Goma, how will you create learning communities in your classroom?

(C) 2008. The Unity House Community Foundation. All Rights Reserved. Communications regarding this instrument should be addressed to Permissions, The Unity House Community Foundation; 307 South Dade Street; Madison, FL. 
Teacher talks

Day \#5

1. Think about students today, who were obviously engaged versus those who were appeared not to be engaged. What did you do to ensure that all students were engaged?

2. Do you expect that your participating in Institute will better serve you as a teacher in your respective profession? If so, please explain how so.

3. Do you expect that your participating in Institute will better serve your students? Can you give some examples of how so (or how not)?

4. Think of the four elements of hip-hop: DJ as problem-solver; $\mathrm{MC}$ as crowd pleaser; Break Dancer as body mover; and Graffiti Artist as Illustrator. Give an example of how you represented each one of these in your teaching over the course of the Institute.

5. What do you see as a major benefit of Goma curriculum?

6. In what ways do you anticipate that Goma curriculum will influence your planning and instruction?

7. As you consider your experiences with students throughout the Institute and all that you have observed about teaching and learning, how would you define Goma curriculum in terms of what it is (and) what it does for both the student and teacher.

(C) 2008. The Unity House Community Foundation. All Rights Reserved. Communications regarding this instrument should be addressed to Permissions, The Unity House Community Foundation; 307 South Dade Street; Madison, FL. 
APPENDIX B: Chart of Character Posts and Ranked Experiences 


\begin{tabular}{|c|c|c|c|c|c|c|}
\hline $\begin{array}{c}\text { 'GOMA' } \\
\text { CHARACTER } \\
\text { POST }\end{array}$ & $\begin{array}{c}1-- \\
\text { Primary } \\
\text { Experience: } \\
\text { the most } \\
\text { frequently } \\
\text { noted } \\
\text { experience }\end{array}$ & $\begin{array}{c}2-- \\
\text { Secondary } \\
\text { Experience: } \\
\text { noted slightly } \\
\text { less than } \\
\text { primary } \\
\text { experience }\end{array}$ & $\begin{array}{c}3- \\
\text { Tertiary } \\
\text { Experience: } \\
\text { noted less } \\
\text { frequently } \\
\text { than secondary } \\
\text { experience }\end{array}$ & $\begin{array}{c}4- \\
\text { Quaternary } \\
\text { Experience: } \\
\text { noted less } \\
\text { frequently than } \\
\text { tertiary } \\
\text { experience }\end{array}$ & $\begin{array}{c}5-- \\
\text { Infrequently } \\
\text { Noted } \\
\text { Experience: } \\
\text { hardly noted } \\
\text { experience }\end{array}$ & $\begin{array}{l}\text { No Experience } \\
\text { Reported }\end{array}$ \\
\hline OBJECTIVE & Cognitive & Instructional & & & $\begin{array}{c}\text { Emotional } \\
\text { Social }\end{array}$ & \\
\hline METHOD & Instructional & & Social & Cognitive & & Emotional \\
\hline ATTITUDE & Instructional & Emotional & Cognitive & Social & & \\
\hline BEHAVIOR & Social & & Instructional & & Cognitive & Emotional \\
\hline COMMUNICATION & Social & Cognitive & & & & $\begin{array}{c}\text { Instructional } \\
\text { Emotional }\end{array}$ \\
\hline DISCIPLINE & Social & & & Instructional & Cognitive & Emotional \\
\hline
\end{tabular}


APPENDIX C: Chart of Character Posts, Related Experiences \& Emergent Themes 


\begin{tabular}{|c|c|c|}
\hline Character Post & Type of Experience & Emergent themes \\
\hline \multicolumn{3}{|l|}{ OBJECTIVE } \\
\hline & COGNITIVE & $\begin{array}{l}\text { Knowing student differences, relating to: } \\
\text { academic limitations } \\
\text { learning modalities } \\
\text { diverse emotional needs }\end{array}$ \\
\hline & & $\begin{array}{l}\text { Knowing why students behave in particular ways, } \\
\text { including: } \\
\text { student attitudes } \\
\text { peer acceptance } \\
\text { negative prior experience }\end{array}$ \\
\hline & & $\begin{array}{l}\text { Knowing how to read students' emotional, physical, and } \\
\text { academic behaviors }\end{array}$ \\
\hline & INSTRUCTIONAL & Knowing how to present subject area content to students \\
\hline & & $\begin{array}{l}\text { Taking cues from students to know when to make an } \\
\text { instructional adjustment }\end{array}$ \\
\hline & SOCIAL & \\
\hline & EMOTIONAL & \\
\hline
\end{tabular}

\begin{tabular}{|c|c|c|}
\hline Character Post & Type of Experience & Emergent Themes \\
\hline \\
\hline \multicolumn{3}{|c|}{ COGNITIVE } \\
\hline & INSTRUCTIONAL & $\begin{array}{l}\text { Strategies for ensuring relevance, including: } \\
\text { role-playing } \\
\text { group discussions } \\
\text { movement } \\
\text { real-life experiences }\end{array}$ \\
\hline & & Instructional Patterning \\
\hline & SOCIAL & \\
\hline & EMOTIONAL & \\
\hline
\end{tabular}




\begin{tabular}{|c|c|c|}
\hline Character Post & Type of Experience & Emergent Themes \\
\hline \multicolumn{3}{|l|}{ ATTITUDE } \\
\hline & COGNITIVE & $\begin{array}{l}\text { Teachers' awareness that character must be embraced } \\
\text { before taught }\end{array}$ \\
\hline & & $\begin{array}{l}\text { Teachers' acknowledgement of Institute as impetus for } \\
\text { teachers' attitude change }\end{array}$ \\
\hline & INSTRUCTIONAL & Attitudes toward teaching \\
\hline & & $\begin{array}{l}\text { Attitudes about flexibility as a feature of effective } \\
\text { teaching }\end{array}$ \\
\hline & & $\begin{array}{l}\text { Attitudes about opportunities for improvement in } \\
\text { teaching }\end{array}$ \\
\hline & & $\begin{array}{l}\text { Attitudes about Goma curriculum and its impact on } \\
\text { teaching }\end{array}$ \\
\hline & SOCIAL & Teacher transparency \\
\hline & EMOTIONAL & Goma shapes teacher's hearts toward students \\
\hline & & Teachers having fun \\
\hline
\end{tabular}

\begin{tabular}{|c|c|c|}
\hline Character Post & Type of Experience & Emergent Themes \\
\hline \multicolumn{3}{|l|}{ BEHAVIOR } \\
\hline & COGNITIVE & \\
\hline & INSTRUCTIONAL & \\
\hline & SOCIAL & $\begin{array}{l}\text { Respect: } \\
\text { verbal praise- } \\
\text { immediate feedback } \\
\text { a manner speaking }\end{array}$ \\
\hline & & Trust \\
\hline & & $\begin{array}{l}\text { Honor } \\
\text { Teachers creating student leaders } \\
\text { Teachers allowing student to set pace for } \\
\quad \text { instruction }\end{array}$ \\
\hline & & $\begin{array}{l}\text { Conflict Resolution } \\
\text { Teachers' bringing students to terms of } \\
\text { agreement } \\
\text { Sharing } \\
\text { Teacher willingness to move forward - showing } \\
\text { student forgiveness } \\
\text { Using Goma to redirect student behavior }\end{array}$ \\
\hline & EMOTIONAL & \\
\hline
\end{tabular}




\begin{tabular}{|l|l|l|}
\hline Character Post & Type of Experience & Emergent Themes \\
\hline COMMUNICATION & \\
\hline \multirow{5}{*}{} & COGNITIVE & $\begin{array}{l}\text { For what reasons do students have to 'do the right } \\
\text { thing'? }\end{array}$ \\
\cline { 2 - 3 } & $\begin{array}{l}\text { When students interpret teachers' behavior as devaluing } \\
\text { of students }\end{array}$ \\
\cline { 2 - 3 } & INSTRUCTIONAL & \\
\hline & SOCIAL & $\begin{array}{l}\text { When students sense the classroom as a safe \& protected } \\
\text { space }\end{array}$ \\
\cline { 2 - 3 } & & \\
\cline { 2 - 3 } & EMOTIONAL & \\
\cline { 2 - 3 } &
\end{tabular}

\begin{tabular}{|l|l|l|}
\hline Character Post & Type of Experience & Emergent Themes \\
\hline DISCIPLINE & COGNITIVE & \\
\hline & & \\
\cline { 2 - 3 } & INSTRUCTIONAL & \\
\cline { 2 - 3 } & & \\
\cline { 2 - 3 } & SOCIAL & $\begin{array}{l}\text { Teachers management of classroom space \& social } \\
\text { relations, a determinant of social climate }\end{array}$ \\
\cline { 2 - 3 } & & \\
\cline { 2 - 3 } & EMOTIONAL & Classroom utopia \\
\cline { 2 - 3 } & & Impact of Goma on environment \\
\cline { 2 - 3 } & Minor themes & Negative encounters \\
\cline { 2 - 3 } & & \\
\cline { 2 - 3 } & &
\end{tabular}




\section{ALICIA D. RITCHEY}

Born, Miami, Florida

1990

Bachelor of Arts

Florida International University

Miami, Florida

1991-2011

English/language arts Teacher

Miami Dade County Public Schools

Miami, Florida

2000

Masters in Urban Education

Florida International University

Miami, Florida

2011

National Board Certification

Early Adolescence English/language arts

$2002-2012$

Doctorate of Education

Florida International University

Miami, Florida

\section{PUBLICATIONS AND PRESENTATIONS}

Clemons, K., Moore, K., Ritchey-Brown, A. (March 2008). Hip-Hop Pedagogy: A Culturally Responsive Approach for Teaching at Risk Youth. Poster session presented at the National Youth At-Risk Conference at Georgia Southern University.

Ritchey-Brown, A. (February 2008). On higher ground: building relationships beyond the code. Workshop presented at the State of Black Affairs Symposium at Broward Community College (Davie, Florida).

Rice, L., Ed D. and Ritchey-Brown, A. (April 2007). After diversity, then what? Workshop presented at the Student Diversity Conference hosted by Johnson \& Wales University at The Center for Performing Arts (Miami, Florida).

Ritchey-Brown, A. (November 2006). The Student, the Community, \& the Teacher: The Compleat Teacher. Seminar presented at the National Council for Teachers of English $96^{\text {th }}$ Annual Conference in Nashville, Tennessee. 
Spears-Bunton, L., Ed D. Ritchey-Brown, A. (November 2005). On Higher Ground: Culture, Literacy, Art, and Performance. Seminar presented at the National Council for Teachers of English - 95 ${ }^{\text {th }}$ Annual Conference in Pittsburgh, Pennsylvania.

Spears-Bunton, L, Ed D, Powell, Rebecca PhD, Ritchey-Brown, Alicia, and Salahuddin, Patricia, (November 2004). Critical Reading of Black Representations in Media Texts: Alternative Narratives in Popular Culture. Paper presented at the National Council for Teachers of English - $94^{\text {th }}$ Annual Conference in Indianapolis, Indiana.

Ritchey-Brown, A. (January 2004). Incorporating the Arts in Language Arts Instruction Nassau, Bahamas / Margaret McDonald Policy Management \& Administration Centre.

Ritchey-Brown, Alicia. (June 2003). Challenges Facing the New Millenium, Educational Perspectives. MMPMAC \& The Ministry of Education, Nassau, Bahamas.

Ritchey-Brown, Alicia. (December 2002). The Ellison Model: Assessing Curricular Choice. ICB Productions, Inc. Miami, Florida.

Ritchey-Brown, Alicia. November 2002. Conflict Resolution Lecture presented at Race \& Ethnicity Graduate Course at Nova Southeastern University Department of Conflict Analysis \& Resolution Ft. Lauderdale, Florida.

Ritchey-Brown, Alicia. November 2002. Best Practices for Student Success. North Dade Middle International Education Magnet. Miami, Florida.

Ritchey-Brown, Alicia. August 2002. Back to School Educational Workshop. Mt. Carmel Missionary Baptist Church Miami, Florida.

Ritchey-Brown, Alicia. December 2001. Understanding Culturally Different People. Paper presented at the Democracy, Justice, \& Trade in US/ Caribbean/ African Policy Symposium at Florida International University Miami, Florida. 